Método baseado em rotação e projeção otimizadas para construção de ensembles de modelos

Ednaldo José Ferreira 



\title{
Método baseado em rotação e projeção otimizadas para construção de ensembles de modelos
}

\author{
Ednaldo José Ferreira
}

Orientador: Prof. Dr. Alexandre Cláudio Botazzo Delbem

Tese apresentada ao Instituto de Ciências Matemáticas e de Computação - ICMC-USP, como parte dos requisitos para obtenção do título de Doutor em Ciências - Ciências de Computação e Matemática Computacional. VERSÃO REVISADA

USP - São Carlos

Junho de 2012 
Ficha catalográfica elaborada pela Biblioteca Prof. Achille Bassi e Seção Técnica de Informática, ICMC/USP, com os dados fornecidos pelo(a) autor(a)

\begin{tabular}{|c|c|}
\hline F383m & $\begin{array}{l}\text { Ferreira, Ednaldo José } \\
\quad \text { Método baseado em rotação e projeção otimizadas } \\
\text { para construção de ensembles de modelos / Ednaldo } \\
\text { José Ferreira; orientador Alexandre Cláudio Botazzo } \\
\text { Delbem. -- São Carlos, } 2012 \text {. } \\
\quad 114 \text { p. }\end{array}$ \\
\hline & $\begin{array}{l}\text { Tese (Doutorado - Programa de Pós-Graduação em } \\
\text { Ciências de Computação e Matemática Computacional) -- } \\
\text { Instituto de Ciências Matemáticas e de Computação, } \\
\text { Universidade de São Paulo, } 2012 \text {. }\end{array}$ \\
\hline & $\begin{array}{l}\text { 1. Métodos de Ensemble. 2. Aprendizado de } \\
\text { Ensemble. 3. Aprendizado de Máquina. I. Delbem, } \\
\text { Alexandre Cláudio Botazzo, orient. II. Título. }\end{array}$ \\
\hline
\end{tabular}


Dedicatória

A Deus pela luz e amparo em um caminho que, por intuição ou ciência, devo trilhar. Aos meus pais, meus exemplos de vida, justiça e perseverança.

Às minhas irmãs pelo carinho, atenção e ensinamentos.

À minha noiva pelo amor, carinho, paciência e companheirismo. 



\section{Agradecimentos}

Ao meu orientador, Prof. Dr. Alexandre Cláudio Botazzo Delbem, por me conduzir no caminho da ciência e por me ensinar que a construção do conhecimento é salpicada com ingredientes como entuasiasmo, amizade, tolerância e respeito mútuo. Não posso também me furtar em mencionar um momento crucial da pesquisa em que, após inúmeras tentativas, a proposta do projeto parecia insólita. Foi nesse momento de adversidade que o Prof. Alexandre interveio, não com a solução que eu esperava, mas com o ensinamento de uma abordagem estruturada para analisar o problema. Esse ensinamento permitiu entender e transpor a barreira, revigorando o entusiasmo. Ser-lhe-ei sempre grato por todas as lições que aprendi desde o mestrado.

Aos pesquisadores da Embrapa Instrumentação, Dra. Débora B. P. Milori, Dr. João M. Naime, Dr. Luiz H. C. Mattoso e Dr. Lúcio A. C. Jorge que sempre me apoiaram em toda e qualquer "empreitada" científica. Em especial, à minha conselheira acadêmica, a Dra. Débora Milori, pela amizade, apoio irrestrito, parceria nos trabalhos aplicados e pelas longas e enriquecedoras discussões científicas.

Ao pesquisador José Dalton C. Pessoa por ceder o no-break que viabilizou a execução dos experimentos de forma ininterrupta.

A todos os colegas da Embrapa e do ICMC que, de alguma forma, contribuíram para a realização deste trabalho.

À minha noiva Thalita M. Camikado pelo incentivo e por colaborar incansavelmente em todas as fases do doutorado. Das atividades de pré-processamento dos dados até a formatação final dos resultados, todas, de alguma forma, intercorreram com seu auxílio.

À Embrapa pela oportunidade de ascensão profissional, suporte financeiro e estrutural. 

"Eu sempre achei que a inteligência de uma pessoa é diretamente refletida pelo número de pontos de vista conflitantes que ela pode deter simultaneamente sobre o mesmo tema".

Abigail Adams 

O desenvolvimento de novas técnicas capazes de produzir modelos de predição com erros de generalização relativamente baixos é uma constante em aprendizado de máquina e áreas correlatas. Nesse sentido, a composição de um conjunto de modelos no denominado ensemble merece destaque por seu potencial teórico e empírico de minimizar o erro de generalização. Diversos métodos para construção de ensembles de modelos são encontrados na literatura. Dentre esses, o método baseado em rotação (RB) tem apresentado desempenho superior a outros clássicos. O método RB utiliza a técnica de extração de características da análise de componentes principais (PCA) como estratégia de rotação para provocar acurácia e diversidade entre os modelos componentes. Contudo, essa estratégia não assegura que a direção resultante será apropriada para a técnica de aprendizado supervisionado (SLT) escolhida. Adicionalmente, o método RB não é adequado com SLTs invariantes à rotação e não foi amplamente validado com outras estáveis. Esses aspectos tornam-no inadequado e/ou restrito a algumas SLTs. Nesta tese, é proposta uma nova abordagem de extração baseada na concatenação de rotação e projeção otimizadas em prol da SLT (denominada roto-projeção otimizada). A abordagem utiliza uma metaheurística para otimizar os parâmetros da transformação de roto-projeção e minimizar o erro da técnica diretora da otimização. Mais enfaticamente, propõe-se a roto-projeção otimizada como parte fundamental de um novo método de ensembles, denominado ensemble baseado em roto-projeção otimizada (ORPE). Os resultados obtidos mostram que a roto-projeção otimizada pode reduzir a dimensionalidade e a complexidade dos dados e do modelo, além de aumentar o desempenho da SLT utilizada posteriormente. O método ORPE superou, com relevância estatística, o RB e outros com SLTs estáveis e instáveis em bases de classificação e regressão de domínio público e privado. O ORPE mostrou-se irrestrito e altamente eficaz assumindo a primeira posição em todos os ranqueamentos de dominância realizados. 

The development of new techniques capable of inducing predictive models with low generalization errors has been a constant in machine learning and other related areas. In this context, the composition of an ensemble of models should be highlighted due to its theoretical and empirical potential to minimize the generalization error. Several methods for building ensembles are found in the literature. Among them, the rotation-based (RB) has become known for outperforming other traditional methods. RB method applies the principal components analysis (PCA) for feature extraction as a rotation strategy to provide diversity and accuracy among base models. However, this strategy does not ensure that the resulting direction is appropriate for the supervised learning technique (SLT). Moreover, the RB method is not suitable for rotation-invariant SLTs and also it has not been evaluated with stable ones, which makes RB inappropriate and/or restricted to the use with only some SLTs. This thesis proposes a new approach for feature extraction based on concatenation of rotation and projection optimized for the SLT (called optimized roto-projection). The approach uses a metaheuristic to optimize the parameters from the roto-projection transformation, minimizing the error of the director technique of the optimization process. More emphatically, it is proposed the optimized roto-projection as a fundamental part of a new ensemble method, called optimized roto-projection ensemble (ORPE). The results show that the optimized roto-projection can reduce the dimensionality and the complexities of the data and model. Moreover, optimized roto-projection can increase the performance of the SLT subsequently applied. The ORPE outperformed, with statistical significance, RB and others using stable and unstable SLTs for classification and regression with databases from public and private domains. The ORPE method was unrestricted and highly effective holding the first position in every dominance rankings. 



\section{Lista de Figuras}

2.1 Razões fundamentais da superioridade de ensembles. . . . . . . . . . . 12

3.1 Efeito da rotação em ML. . . . . . . . . . . . . . . . . . . 27

3.2 Propriedade da roto-projeção no espaço e subespaço de projeção. . . . 30

3.3 Dados artificiais para modelagem de classificação. . . . . . . . . . . 33

3.4 Dados artificiais para modelagem de regressão. . . . . . . . . . . . . . 34

3.5 Árvore induzida pelo C4.5 (J48) com os dados artificiais. . . . . . . . 35

3.6 Particionamento do espaço - C4.5 (J48) . . . . . . . . . . . . . 35

3.7 Dados de classificação rotacionados em prol do C4.5 (J48) . . . . . . 36

3.8 Particionamento produzido pelo C4.5 (J48) nos dados rotacionados. . 36

3.9 Árvore de decisão induzida dos dados rotacionados. . . . . . . . . . . 37

3.10 Dados de classificação rotacionados e projetados em prol do kNN. . . 38

3.11 Dados de regressão rotacionados e ilustração da projeção em prol do kNN. . . . . . . . . . . . . . . . . . . . . . 39

3.12 Predições do 3NN com e sem ORP. . . . . . . . . . . . . . . . . . . . 40

3.13 Regressão linear simples utilizando a variável independente $\mathrm{x}_{1}$. . . . . 41

3.14 Dados de regressão rotacionados em prol da regressão linear. . . . . 42

3.15 Regressão linear simples utilizando a variável $x_{2}$ após rotação. . . . . 42

3.16 Abordagem wrapper para seleção de atributos (KOHAVI; JOHN, 1997). 44

3.17 Abordagem para otimização da roto-projeção utilizando técnica diretora. 45

3.18 Imprecisão da direção de rotação ótima no processo de otimização. . . 52

4.1 Técnica ORPT. . . . . . . . . . . . . . . . . . . . . . 58

5.1 Taxa de densidade média T2 - ORPT $(\mathrm{kNN}) \ldots \ldots$. . . . . . 76

5.2 Taxa de redução de dimensionalidade - ORPT $(\mathrm{kNN}) . \ldots .77$

5.3 Taxa de densidade média T2 - ORPT(RBF) . . . . . . . . . 78 
5.4 Taxa de redução de dimensionalidade - ORPT(RBF). . . . . . . . . 79

5.5 Taxa de densidade média T2 - ORPT(J48). . . . . . . . . . . 81

5.6 Taxa de redução de dimensionalidade - ORPT(J48) . . . . . . . . . . 82

5.7 Taxa de densidade média T2 - ORPT(NB) . . . . . . . . . . . . 85

5.8 Taxa de redução de dimensionalidade - ORPT(NB) . . . . . . . . . 86 
4.1 Características das bases públicas de classificação. . . . . . . . . . 64

4.2 Características das bases públicas de regressão. . . . . . . . . . . . 65

5.1 REQM em regressão - ORPT(kNN). . . . . . . . . . . . . . . . . . . . . . . . . 75

5.2 REQM em regressão - ORPT(RBF). . . . . . . . . . . . . . . 77

5.3 Acurácia em classificação - ORPT(J48). . . . . . . . . . . . . . 80

5.4 Média dos tamanhos das árvores induzidas - ORPT(J48) . . . . . . . 83

5.5 Acurácia em classificação - ORPT(NB) . . . . . . . . . . . . . . . . 84

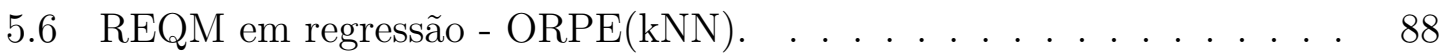

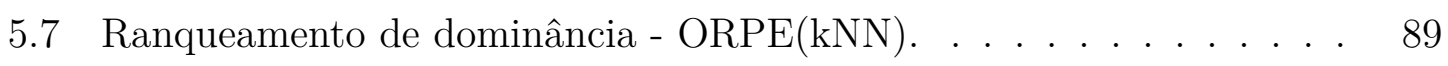

5.8 REQM em regressão - ORPE(RBF). . . . . . . . . . . . . . . 90

5.9 Ranqueamento de dominância - ORPE(RBF). . . . . . . . . . . . 91

5.10 Acurácia em classificação - ORPE(J48) . . . . . . . . . . . . . . . 92

5.11 Ranqueamento de dominância - ORPE(J48) . . . . . . . . . . . . 93

5.12 Acurácia em classificação - ORPE(NB) . . . . . . . . . . . . . . 94

5.13 Ranqueamento de dominância - ORPE(NB) . . . . . . . . . . . . . 95

5.14 Acurácia em classificação - ORPE(RBF) - complementar. . . . . . . . 96

5.15 Ranqueamento de dominância - ORPE(RBF) - complementar. . . . . 97 



\section{Lista de Siglas}

\begin{tabular}{|c|c|}
\hline ANN & Artificial Neural Network \\
\hline $\mathrm{CG}$ & Computação Gráfica \\
\hline $\mathrm{DM}$ & Data Mining \\
\hline EIA & Embrapa Instrumentação Agropecuária \\
\hline EM & Ensemble Method \\
\hline $\mathrm{kNN}$ & $k$-Nearest Neighbor \\
\hline LIBS & Laser Induced Breakdown Spectroscopy \\
\hline LIFI & Laser Induced Fluorescence Image \\
\hline $\mathrm{MC}$ & Modelo Componente \\
\hline MLP & MultiLayer Perceptron \\
\hline ML & Machine Learning \\
\hline NF & Número de Folhas \\
\hline ORP & Optimized Roto-Projection \\
\hline ORPE & Optimized Roto-Projection Ensemble \\
\hline ORPT & Optimized Roto-Projection Technique \\
\hline $\mathrm{PCA}$ & Principal Components Analysis \\
\hline QG & Qualidade Global \\
\hline
\end{tabular}


RB Rotation-Based

RBF Radial Basis Function

REQM Raíz do Erro Quadrático Médio

RF Rotation Forest

ROC Receiver Operating Characteristic

RPEM Random Projection Ensemble Method

RSM Random Subspace Method

RSM-IPCS Random Subspace Method - Instance and Principal Components Spaces

RSM-PCS Random Subspace Method-Principal Components Space

SA Simulated Annealing

SLT Supervised Learning Technique

SVM Support Vector Machine

TA Tamanho da Árvore

$\overline{\mathrm{TA}} \quad$ Tamanho médio das Árvores

$\overline{\text { TDT2 }} \quad$ Taxa média de Densidade T2

$\overline{T R D} \quad$ Taxa média de Redução de Dimensionalidade

A maior parte das siglas utilizadas não foi traduzida para língua portuguesa por serem amplamente difundidas na comunidade científica ou por serem termos freqüentemente utilizados nas produções científicas decorrentes desta tese. 


\section{Lista de Algoritmos}

2.1 : Método RSM-IPCS (FERREIRA et al., 2009). . . . . . . . . . . . 18

2.2 : Método RB (RF) (RODRIGUEZ; KUNCHEVA; ALONSO, 2006). . . . . 21

3.1 : Abordagem geométrica para PCA. . . . . . . . . . . 25

3.2 : Método ORPE. . . . . . . . . . . . . . . . 54

4.1 : Arrefecimento simulado-SA. . . . . . . . . . . . . . . . . 60

4.2 : Procedimento GeraSoluçãoVizinha $(\mathrm{S}, t) \ldots \ldots \ldots 61$ 

Resumo

Abstract ix

Lista de Figuras

Lista de Algoritmos xvii

1 Introdução $\quad \mathbf{1}$

1.1 Inserção e motivação da pesquisa . . . . . . . . . . . . . . . . . 4

1.2 Declaração da tese . . . . . . . . . . . . . . . . 5

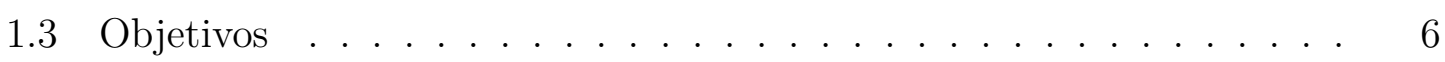

1.4 Síntese dos fundamentos . . . . . . . . . . . . . . . . . . 7

1.5 Organização do trabalho . . . . . . . . . . . . . . . . . . . . 8

2 Ensembles e métodos de construção 9

2.1 Ensemble de modelos . . . . . . . . . . . . . . . . . . . . . . . . . . . 10

2.2 Diversidade de predição . . . . . . . . . . . . . . . . . . . 13

2.3 Métodos de construção de ensembles . . . . . . . . . . . . . . . 15

2.3.1 Métodos clássicos e suas variantes . . . . . . . . . . . . 15

2.3.2 Método baseado em projeção aleatória . . . . . . . . . . . . 18

2.3.3 Método baseado em rotação . . . . . . . . . . . . . . . . . . . 19

2.4 Considerações finais . . . . . . . . . . . . . . . . . . . . . 22 
3 Fundamentos da proposta 23

3.1 Interpretação contextualizada da PCA . . . . . . . . . . . . . . . . 24

3.2 Abordagem matemático-geométrica . . . . . . . . . . . . . 25

3.3 Transformações geométricas . . . . . . . . . . . . . . . . . 26

3.3 .1 Rotação . . . . . . . . . . . . . . . . . . . 27

3.3.2 Rotação $n$-dimensional . . . . . . . . . . . . . . . . . . 27

3.3.3 Projeção ortogonal . . . . . . . . . . . . . . . . . . . . . . . 28

3.3.4 Projeção ortogonal $n$-dimensional . . . . . . . . . . . . . 29

3.3.5 Concatenação roto-projeção . . . . . . . . . . . . . . . . . . 29

3.4 Princípios da roto-projeção otimizada . . . . . . . . . . . . . . . . 30

3.4.1 Modelagem de classificação utilizando árvore de decisão . . . . 33

3.4.2 Modelagem de classificação utilizando o kNN . . . . . . . . . . 37

3.4.3 Modelagem de regressão utilizando o kNN . . . . . . . . . . . 38

3.4.4 Modelagem de predição utilizando regressão linear . . . . . . 40

3.4.5 Considerações sobre modelagem e roto-projeção otimizada . . 43

3.5 Técnica diretora e aspectos da otimização . . . . . . . . . . . . . . . . 43

3.5.1 Framework da otimização . . . . . . . . . . . . . . . . 44

3.5.2 Complexidade do modelo . . . . . . . . . . . . . . . . . . 47

3.5.3 Princípio da parcimônia . . . . . . . . . . . . . . . . . . . 49

3.5.4 Complexidade dos dados . . . . . . . . . . . . . . . . 49

3.6 Roto-projeção otimizada para ensembles . . . . . . . . . . . . . . . . 51

3.7 Considerações finais . . . . . . . . . . . . . . . . . . . . . . 54

4 Metodologias de desenvolvimento e validação 57

4.1 Metaheurísticas . . . . . . . . . . . . . . . 58

4.1.1 Arrefecimento simulado . . . . . . . . . . . . . . . 59

4.1.2 Arrefecimento simulado com vizinhança dinâmica . . . . . . . 60

4.2 Metodologia de implementação e validação . . . . . . . . . . . . . . . 62

4.2.1 Bases de dados públicas . . . . . . . . . . . . . . . 63

4.2.2 Bases de dados da Embrapa . . . . . . . . . . . . . . . . 63

4.2 .3 Pré-processamento . . . . . . . . . . . . . . . . 67

4.2.4 Experimentos e configurações . . . . . . . . . . . . . . 68

4.3 Considerações finais . . . . . . . . . . . . . . . . . . . . . . . . . 71

5 Resultados e discussões

5.1 Experimento roto-projeção . . . . . . . . . . . . . . . . . . 74

5.1.1 Análise do desempenho de ORPT(kNN) em regressão . . . 74

5.1.2 Análise do desempenho de ORPT(RBF) em regressão . . . . . 76

5.1.3 Análise do desempenho de ORPT(J48) em classificação . . . . 79

5.1.4 Análise do desempenho de $\operatorname{ORPT}(\mathrm{NB})$ em classificação . . . . 83 
5.2 Experimento ensembles . . . . . . . . . . . . . . . . 85

5.2.1 Análise do desempenho de $\mathrm{ORPE}(\mathrm{kNN})$ em regressão . . . 86

5.2.2 Análise do desempenho de ORPE(RBF) em regressão . . . . 87

5.2.3 Análise do desempenho de ORPE(J48) em classificação . . 89

5.2.4 Análise do desempenho de ORPE(NB) em classificação . . . . 91

5.3 Experimento complementar . . . . . . . . . . . . . . . . . 93

5.4 Considerações finais . . . . . . . . . . . . . . . . . . . 95

6 Conclusões e trabalhos futuros $\quad 99$

6.1 Propostas de melhorias computacionais . . . . . . . . . . . . . . . . . 101

6.2 Outros aspectos para análises futuras . . . . . . . . . . . . . . 102

$\begin{array}{ll}\text { Referências Bibliográficas } & 105\end{array}$ 

CAPÍTULO 1

Introdução

O desenvolvimento de novas técnicas que induzem automaticamente modelos de predição a partir de conjuntos de dados é foco de áreas e/ou subáreas correlatas como aprendizado de máquina $\left(\mathrm{ML}^{1}\right)$, redes neurais artificiais $\left(\mathrm{ANNs}^{2}\right)$, mineração de dados $\left(\mathrm{DM}^{3}\right)$, reconhecimento de padrões e estatística. Em ML, está vinculado ao segmento de aprendizado supervisionado que visa a construção de modelos capazes de prever uma variável alvo (variável dependente) a partir de outras variáveis explicativas (variáveis independentes) do problema em questão. A natureza do problema delineia dois tipos de tarefas de modelagem de predição (TAN; STEINBACH; KUMAR, 2005): classificação, quando a variável alvo é nominal; e regressão quando a variável alvo é contínua. O objetivo em ambas as tarefas é induzir modelos que minimizem os erros entre os valores previstos e reais da variável dependente.

A expectativa sobre um modelo de classificação (classificador) ou regressão é quase sempre, prioritariamente, relacionada à sua capacidade de apresentar alta acurácia ou baixo erro de predição em dados novos. A habilidade de desempenhar com acurácia sobre dados não utilizados na etapa de treinamento (fase de indução) determina a capacidade de generalização do modelo.

A literatura de ML dispõe de um considerável número de técnicas de aprendizado supervisionado $\left(\mathrm{SLTS}^{4}\right)$ de concepções variadas capazes de produzir modelos relativa-

\footnotetext{
${ }^{1}$ Machine Learning.

${ }^{2}$ Artificial Neural Networks.

${ }^{3}$ Data Mining.

${ }^{4}$ Supervised Learning Techniques.
} 
mente acurados. Dentre elas, destacam-se as baseadas em: ANNs (HAYKIN, 1999), árvores de decisão (QUINLAN, 1986), instâncias (AHA; KIBLER; ALBERT, 1991) e inferência Bayesiana (DUDA; HART; STORK, 1973). Uma abordagem efetiva e investigada em ML para aumento do desempenho do modelo de predição consiste na definição de métodos para construção dos denominados ensembles ${ }^{5}$ de modelos (DIETTERICH, 2000), uma subárea de pesquisa também conhecida como aprendizado de ensemble.

Um ensemble é um modelo constituído por um conjunto de modelos componentes (MCs) cujas decisões individuais são combinadas, de alguma forma, para predizer novas instâncias. Os ensembles de modelos são freqüentemente mais acurados do que um único modelo e, ainda, do que qualquer um de seus MCs (HANSEN; SALAMON, 1990; DIETTERICH, 2000). Evidências teóricas e empíricas mostram que os melhores ensembles são aqueles dotados de modelos acurados e que apresentam erros descorrelacionados (diversidade) no espaço das instâncias ${ }^{6}$ (HANSEN; SALAMON, 1990; KROGH; VEDELSBY, 1995; DIETTERICH, 2000). Na prática é difícil garantir que os erros entre os MCs sejam completamente descorrelacionados; contudo, melhorias na acurácia são observadas com métodos de ensemble $\left(\mathrm{EMs}^{7}\right)$ que garantem apenas ligeiro descorrelacionamento (TAN; STEINBACH; KUMAR, 2005).

A literatura de aprendizado de ensemble apresenta diversas estratégias capazes de construir ensembles acurados para vários domínios (DIETTERICH, 2000; ROKACH, 2010). No Brasil, as pesquisas também têm visado a investigação do potencial de aplicação e/ou de novas estratégias para a construção de ensembles acurados (OLIVEIRA; MORITA; SABOURIN, 2006; BERNARDINI; MONARD; PRATI, 2006; SALGADO et al., 2006; PASTI et al., 2010; CASTRO; VON-ZUBEN, 2011). Trabalhos recentes introduziram um EM bastante eficiente, denominado "baseado em rotação" (RB ${ }^{8}$ ), que utiliza a técnica de extração de características de análise de componentes principais $\left(\mathrm{PCA}^{9}\right)$ como artíficio para rotacionar os eixos formados pelos subgrupos de atributos para construção de ensembles diversos e acurados (RODRíGUEZ; ALONSO, 2004; RODRÍGUEZ; ALONSO; PRIETO, 2005; RODRIGUEZ; KUNCHEVA; ALONSO, 2006; RODRÍGUEZ; MAUDES; ALONSO, 2006; KUNCHEVA; RODRÍGUEZ, 2007). Os resultados obtidos com o método RB foram estatisticamente equiparáveis ou, na maioria das análises, superiores aos obtidos por EMs clássicos como Bagging (BREIMAN, 1996), AdaBoost (FREUND; SCHAPIRE, 1996), Random Forest (BREIMAN, 2001) e subespaços aleatórios (HO, 1998).

O método RB cria subgrupos aleatórios dos atributos dos dados e aplica rotações

\footnotetext{
${ }^{5}$ Não há consenso na literatura a respeito da tradução do termo; é, por alguns autores, referido como comitês de modelos.

${ }^{6}$ Exemplos; padrões.

${ }^{7}$ Ensemble Methods.

${ }^{8}$ Rotation-Based.

${ }^{9}$ Principal Components Analysis.
} 
relativas aos eixos formados por esses atributos. A orientação dos eixos de rotação é a resultante de múltiplas transformações características da PCA. Antecedentemente, heurísticas de seleção de subconjuntos de classes e amostragem (bootstrap) de instâncias são aplicadas na tentativa de prover direções de rotação ${ }^{10}$ diferentes para cada MC. Mesmo que a rotação proporcionada pela PCA não contribua para direções discriminatórias, ela tem valor como heurística de diversificação (RODRIGUEZ; KUNCHEVA; ALONSO, 2006).

Os trabalhos de Rodríguez e colaboradores (RODRíGUEZ; ALONSO, 2004; RODRÍGUEZ; ALONSO; PRIETO, 2005; RODRIGUEZ; KUNCHEVA; ALONSO, 2006; RODRÍGUEZ; MAUDES; ALONSO, 2006; KUNCHEVA; RODRÍGUEZ, 2007) são precisos ao elucidar a eficácia do método RB para a tarefa de classificação utilizando árvores de decisão induzidas pelo algoritmo C4.5 (QUINLAN, 1993) ou, ainda, redes de base radial como MCs (RODRÍGUEZ; MAUDES; ALONSO, 2006). As contribuições científicas densamente concentradas na construção de florestas de decisão tornaram o método mais conhecido como floresta de rotação $\left(\mathrm{RF}^{11}\right)$. Para a tarefa de regressão, o método $\mathrm{RB}$ também apresentou resultados interessantes, comparáveis aos de outros EMs (ZHANG; ZHANG; WANG, 2008; KOTSIANTIS; PINTELAS, 2009).

Kuncheva e Rodríguez (KUNCHEVA; RODRÍGUEZ, 2007) estudaram os efeitos dos parâmetros e das heurísticas de aleatorização para evidenciar as razões da superioridade de desempenho do método RB na construção de florestas de decisão. A PCA foi substituída por outras técnicas de extração de características, incluindo uma supervisionada. Os resultados obtidos com a PCA foram um pouco, mas consistentemente melhores do que os obtidos com as outras técnicas de extração. Eles concluíram que o principal fator de sucesso do método RB é, aparentemente, a esparcidade da matriz de transformação construída com o auxílio da PCA.

O método RB é uma referência recente em termos de EM para classificação, recomendável em associação com SLTs sensíveis à rotação e instáveis, especialmente com indutores de árvores de decisão. No entanto, o método é originalmente inadequado para SLTs invariantes à rotação do espaço dos atributos como, por exemplo, o kNN ${ }^{12}$ (AHA; KIBLER; ALBERT, 1991) ou uma regressão linear múltipla (LEVINE et al., 2007).

\footnotetext{
${ }^{10} \mathrm{~A}$ expressão "direção de rotação" foi utilizada em referência à nova direção produzida pela transformaçao de rotação.

${ }^{11}$ Rotation Forest.

${ }^{12} k$-Nearest Neighbor.
} 


\subsection{Inserção e motivação da pesquisa}

Algumas técnicas para indução de modelos de classificação e regressão são instáveis sob a ótica de que pequenas perturbações provocadas no conjunto de treinamento podem causar grandes mudanças no modelo construído (BREIMAN, 1998). Árvores de decisão, ANNs e algoritmos de aprendizado de regras são todas instáveis (DIETTERICH, 2000). O aprendizado de classificadores Bayesianos (DUDA; HART; STORK, 1973) é relativamente estável (TING; ZHENG, 1999), enquanto a técnica estatística de regressão linear, kNN e os algoritmos de limiar linear são geralmente muito estáveis (DIETTERICH, 2000).

Perturbações provocadas no conjunto de dados de treinamento constituem uma importante estratégia para provocar diversidade na construção de ensembles, especialmente com SLTs instáveis. Tais perturbações são comumente dotadas de uma componente estocástica e podem atuar manipulando a variável dependente (DIETTERICH; BAKIRI, 1995; DIETTERICH, 2000); as instâncias, como em Bagging (BREIMAN, 1996) e AdaBoost (FREUnd; SCHAPIRE, 1996); ou os atributos, como os métodos de projeções em subespaços (HO, 1998; FERREIRA et al., 2009). Essa última forma de manipulação é particularmente interessante também para SLTs estáveis como, por exemplo, classificadores Bayesianos ingênuos (TSYMBAL; PUURONEN; PATTERSON, 2003).

O artifício da rotação foi apresentado por Rodríguez e Alonso (2004) como estratégia de perturbação "PCA-direcionada" para a construção de florestas de decisão. Trata-se de uma poderosa estratégia para a construção de ensembles fundamentada na obtenção de matrizes com direções de rotação diversificadas e atreladas ao requisito de associação a uma SLT sensível à rotação. Contudo, a estratégia e a rotação produzida pela PCA não objetivam diretamente e tão pouco garantem a obtenção de direções discriminatórias que possam produzir aumento do desempenho do MC induzido. Ainda que as direções discriminatórias possam ser freqüentemente providas pela PCA ou por qualquer outra técnica clássica de extração supervisionada, não há garantias de que serão otimizadas para a SLT adotada na construção dos MCs, tornando o método RB inadequado ou pouco eficiente para alguns domínios, SLTs e/ou tarefas de aprendizado. Embora o método utilize a informação da variável dependente como heurística de diversificação das rotações, ele não é dotado de mecanismos que visem, diretamente, a otimização das direções em prol da SLT escolhida para indução dos MCs.

Os aspectos supramencionados tornam o método RB essencialmente passivo, não supervisionado e com forte viés no que se refere à escolha da SLT. De acordo com os autores, o método RB é inadequado para SLTs robustas à rotação (RODRÍGUEZ; 
MAUDES; ALONSO, 2006). Ainda que os autores reconheçam que uma projeção em subespaço ${ }^{13}$ possa viabilizar o uso de SLTs invariantes à rotação (RODRÍGUEZ; ALONSO; PRIETO, 2005), nenhuma proposta de adaptação com esse apelo foi encontrada na literatura até o presente momento. Similarmente, também não foram encontrados trabalhos com estudo, validação e análise detalhada do desempenho do método RB original utilizando SLTs relativamente ou muito estáveis.

Nesse contexto de inadequação, carência de investigação e viés, evidencia-se a possibilidade de ampliar a aplicabilidade das transformações de rotação e projeção em ML, especialmente na construção de ensembles capazes de superar o desempenho daqueles construídos pelo método RB. Buscou-se enfrentar esse desafio investigando uma nova abordagem que explora o ajuste dos parâmetros das transformações geométricas de rotação e projeção em subespaço para ampliar funcionalidades, minimizar restrições e ineficiências e, principalmente, contribuir para melhoria significativa do desempenho de predição de ensembles. Especificamente, esta pesquisa introduz uma nova técnica de extração de características supervisionada baseada na transformação concatenada de rotação e projeção otimizada para e pela SLT, denominada roto-projeção otimizada $\left(\mathrm{ORP}^{14}\right)$, posteriormente utilizada como parte fundamental da proposta de um novo EM para construção de ensembles de alto desempenho de predição.

\subsection{Declaração da tese}

A otimização das direções de rotação em prol do aumento da eficiência da SLT não é alvo direto do método RB; outrossim não o é a exploração da projeção em subespaço como um possível artifício de adaptação às SLTs robustas à rotação ou mesmo para incutir diversidade com outras estáveis. Assim, esta tese sustenta as seguintes asserções:

1. "Uma transformação capaz de obter um rearranjo das instâncias por meio de uma direção de rotação e um subespaço de projeção otimizados para a SLT adotada deve apresentar como características a redução da dimensionalidade e/ou da complexidade dos dados e/ou, ainda, da complexidade do modelo induzido posteriormente que, sinergicamente, devem culminar com o aumento do desempenho de predição em tarefas de classificação e de regressão";

2. “A utilização da transformação da asserção anterior para a construção dos MCs

\footnotetext{
${ }^{13} \mathrm{~A}$ projeção em subespaço amplamente referida nesta tese é a projeção ortogonal no subespaço formado por um subconjunto de eixos do espaço original. A formalização matemática do conceito de projeção é provida no Capítulo 3, Seção 3.3.4.

${ }^{14}$ Optimized Roto-Projection.
} 
em um EM deve produzir ensembles com menores erros de generalização e menores restrições no que tange à SLT adotada (com sua estabilidade característica), domínio do problema e/ou tarefa de modelagem".

\subsection{Objetivos}

O objetivo embasador deste trabalho foi a pesquisa para proposição, desenvolvimento, implementação e validação de uma técnica de extração de características supervisionada baseada na otimização da transformação de roto-projeção para redução da dimensionalidade, da complexidade dos dados e/ou do modelo e/ou, ainda, a minimização do erro de generalização do modelo induzido a posteriori. Buscou-se comprovar a primeira asserção desta tese (vide seção anterior) por meio da análise da transformação e da validação do desempenho da conjunção de ORP com a mesma SLT focada para otimização. Convencionou-se denominar essa conjunção ${ }^{15}$ como: técnica baseada em roto-projeção otimizada $\left(\mathrm{ORPT}^{16}\right)$.

O objetivo principal e consolidador foi a proposição, desenvolvimento e validação de um novo EM que utiliza como base a transformação de ORP para construção de ensembles de modelos, visando comprovar a segunda asserção desta tese. Esse novo EM que utiliza a técnica de extração baseada em ORP foi denominado ensemble baseado em roto-projeção otimizada $\left(\mathrm{ORPE}^{17}\right)$. Conseqüentemente, foi meta principal a análise de desempenho e a comparação pareada de ORPE com o método "estado da arte" de Rodríguez e colaboradores (RODRIGUEZ; KUNCHEVA; ALONSO, 2006), além de outros baseados em projeções, utilizando SLTs estáveis e instáveis, de concepções diferenciadas, em bases de dados públicas e privadas de domínios e tarefas de modelagem variados.

As bases de dados privadas utilizadas na validação são relativas à pesquisa de instrumentação agropecuária desenvolvidas na Empresa Brasileira de Pesquisa Agropecuária - Embrapa. Essas bases são desafios de pesquisa categorizados como tarefas de regressão e classificação de padrões espectrais provenientes da técnica de espectroscopia de emissão ótica induzida por laser $\left(\mathrm{LIBS}^{18}\right)$ e de características de imagens de fluorescência induzida por laser, para os quais as técnicas estatísticas tradicionais têm apresentado eficiência relativamente baixa. Essas bases de dados foram fornecidas pela Embrapa Instrumentação Agropecuária (EIA) de São Carlos-SP.

\footnotetext{
${ }^{15}$ Detalhes no Capítulo 4.

${ }^{16}$ Optimized Roto-Projection Technique.

${ }^{17}$ Optimized Roto-Projection Ensemble.

${ }^{18}$ Laser Induced Breakdown Spectroscopy.
} 


\subsection{Síntese dos fundamentos}

Extração de características é uma parte do processo de reconhecimento de padrões que visa a captura das informações mais relevantes para análise ou classificação dos dados. É caracterizada por uma transformação que combina as variáveis de entrada de um conjunto de instâncias, tendo como propósito principal a redução da dimensionalidade. As técnicas de extração mais conhecidas e amplamente utilizadas são a PCA e a Análise de Discriminante Linear (ALPAYDIN, 2010).

A PCA é uma transformação linear não supervisionada (não utiliza a variável dependente) que pode ser vista como uma rotação dos eixos das coordenadas originais para um novo conjunto de eixos alinhados com a variabilidade dos dados (TAN; STEINBACH; KUMAR, 2005). Além do descorrelacionamento entre os novos eixos, denominados componentes principais, a PCA torna possível a exclusão de um subconjunto de componentes de menor variabilidade, o que lhe confere a característica de técnica projetiva. Sob outra ótica, a PCA é uma transformação que concatena projeção em subespaço e rotação direcionada à concentração da variância, ordenada e decrescentemente, nos primeiros eixos de coordenadas possibilitando, assim, a exclusão dos eixos nulos ou com variâncias desprezíveis. Foi sob essa ótica matemático-geométrica de transformação que este trabalho foi pautado, desenvolvido e consolidado.

Rotação e projeção são transformações geométricas amplamente utilizadas em computação gráfica (CG) (FOLEY et al., 1990; ANGEL, 2008). A rotação é matematicamente representada por uma matriz dotada de parâmetros que permitem ajustar os ângulos de rotação de cada plano componente do espaço. Assim, qualquer direção pode ser obtida por meio do ajuste adequado dos parâmetros angulares da matriz. Igualmente, a projeção também provê parâmetros que definem a dimensão e o subespaço de projeção.

No contexto das asserções deste trabalho, encontrar uma direção de rotação e um subespaço de projeção que beneficiem uma SLT qualquer implica em otimizar os parâmetros angulares da matriz de rotação e a dimensão do subespaço de projeção, tendo como objetivo a minimização do erro de um modelo induzido por uma técnica igual ou similar à SLT adotada. Introduz-se aqui o conceito de técnica diretora, cujo objetivo é prover uma estatística da qualidade da direção e da projeção durante o processo de otimização. Trata-se de uma estratégia análoga à abordagem de seleção de atributos wrapper (KOHAVI; JOHN, 1997), que utiliza o próprio modelo para estimar a qualidade do subconjunto de atributos durante a busca realizada pelo algoritmo de busca ou metaheurística.

Diferentemente do método RB, que visa diversificar as direções de rotação como estratégia para prover erros descorrelacionados entre os MCs, o novo EM proposto 
(ORPE) é baseado na diversidade de direções e projeções obtidas nas diferentes aproximações (execuções) do algoritmo de otimização. Contribui-se, assim, para a área de aprendizado de ensemble com uma nova abordagem para a construção de ensembles, baseada em ORP, mais robusta no que tange à definição da SLT para construção dos MCs e de maior desempenho.

\subsection{Organização do trabalho}

Este trabalho está organizado como apresentado a seguir:

- No Capítulo 2, é revisada a literatura de ensembles e os principais métodos de construção. Métodos clássicos e algumas variantes desses são descritos, incluindo detalhes sobre os principais EMs de projeção em subespaço e o método $\mathrm{RB}$;

- No Capítulo 3, são apresentados os fundamentos teóricos da ORP bem como o princípio de funcionamento do EM proposto. É introduzida também a abordagem matemática de transformações geométricas amplamente utilizada no escopo do trabalho. O efeito organizador das instâncias proporcionado pela ORP, no âmbito de ML, é abordado por meio de exemplos de modelagem com algumas SLTs. Finalmente, é apresentada e detalhada a proposta do EM ORPE;

- No Capítulo 4, é apresentada a metodologia de desenvolvimento e validação utilizada. A metaheurística do arrefecimento simulado escolhida para otimização da roto-projeção é apresentada no início do capítulo. Posteriormente, são apresentados detalhes das bases de dados públicas e da Embrapa, do préprocessamento, da metodologia de análise e validação e do delineamento dos experimentos com as configurações utilizadas;

- No Capítulo 5, são descritos os resultados obtidos e as discussões para cada experimento;

- No Capítulo 6, finalmente, são tecidas as conclusões e apresentadas as propostas de trabalhos futuros. 
CAPÍTULO 2

\section{Ensembles e métodos de construção}

A modelagem preditiva por meio de ensembles imita a sensatez humana quando busca outras opiniões para tomada de uma decisão crucial. A sabedoria coletiva na tomada de decisão sobre um determinado problema parece ser menos suceptível ao erro do que a opinião individual. No livro "A sabedoria das multidões" (SUROWIECKI, 2005), Surowiecki argumenta que, sob certas condições controladas, a agregação de informações de diversas fontes resulta em decisões que são freqüentemente superiores àquelas que poderiam ter sido tomadas por apenas um indivíduo, mesmo considerando um especialista no domínio. Quatro elementos são indicados para a obtenção da sabedoria coletiva (SUROWIECKI, 2005):

1. Diversidade de opiniões: cada membro deve ter informação privada, mesmo se essa é apenas uma interpretação excêntrica dos fatos conhecidos;

2. Independência: as opiniões dos membros não são diretamente influenciadas pelas opiniões daqueles em torno deles;

3. Descentralização: membros podem se especializar e tecer conclusões baseados no conhecimento local;

4. Agregação: algum mecanismo seja utilizado para transformar julgamentos privados em uma decisão coletiva.

Ao longo de décadas, a comunidade de aprendizado de ensemble e de áreas correlatas têm corroborado, teórica e empiricamente, a análise observacional de Surowiecki também em ML por meio de diversos trabalhos (HANSEN; SALAMON, 1990; KROGH; 
VEDELSBY, 1995; OPITZ; MACLIN, 1999; DIETTERICH, 2000; KUNCHEVA; WHITAKER, 2003; ROKACH, 2010), somente para citar alguns.

\subsection{Ensemble de modelos}

Suponha que, para um dado conjunto de treinamento $\mathbf{T}$, com $M$ instâncias na forma $\left\{\left(\mathrm{x}_{1}, y_{1}\right) \ldots\left(\mathrm{x}_{M}, y_{M}\right)\right\}$, onde $\mathrm{x}_{i}$ é um vetor de valores que representa uma instância de um problema qualquer de ML supervisionado e $y_{i}$ é a variável dependente que representa a classe (variável qualitativa) ou valor real (variável quantitativa) associada a essa instância; exista uma função desconhecida $f$ que mapeia todo $\mathrm{x}_{i} \mathrm{em}$ $y_{i}$ com um erro mínimo ou, simplificadamente, $f\left(\mathrm{x}_{i}\right)=y_{i}$. É tarefa dos algoritmos de ML supervisionados induzir modelos (hipóteses) como tentativa de representar a função $f$ que é intrínseca ao problema.

Um algoritmo de aprendizado pode ser analisado como um processo de busca por uma hipótese ótima dentro de um espaço H de hipóteses (DIETTERICH, 2000). Entretanto, encontrar a melhor hipótese no espaço H não é uma tarefa fácil. A insuficiência de dados, por exemplo, pode fazer o algoritmo de aprendizado encontrar diferentes hipóteses em $\mathrm{H}$ com a mesma acurácia para o mesmo conjunto de treinamento. $\mathrm{O}$ aspecto computacional também pode ser restritivo no que tange ao tempo de processamento demandado para encontrar a hipótese mais adequada, tornando a solução do problema intratável. Outros aspectos restritivos, que ocorrem principalmente com ANNs, são atribuídos aos mecanismos utilizados pelos algoritmos de minimização do erro de predição. O algoritmo back-propagation (RUMELHART; HINTON; WILLIAMS, 1988) utilizado no treinamento de um Perceptron de múltiplas camadas (MLP ${ }^{1}$ ), por exemplo, emprega o gradiente descendente da função erro para o conjunto de treinamento. Esse artifício pode estacionar a otimização em mínimos locais da função, não encontrando, assim, a hipótese ideal. Esses e outros fatores contribuem para a obtenção de um modelo com capacidade de generalização indesejável.

Uma forma de minimizar os problemas supracitados para obtenção de um modelo com uma aproximação mais adequada da função $f$, ou seja, com maior capacidade de generalização, é por meio da combinação das predições de um conjunto de modelos diversos, no denominado ensemble de modelos. Expressando matematicamente, um ensemble é denotado por:

$$
\Psi=\left\{h_{1}, h_{2}, h_{3}, \ldots, h_{L}\right\}
$$

\footnotetext{
${ }^{1}$ MultiLayer Perceptron.
} 
em que $h_{j}{ }^{2}$ é o $j$-ésimo MC e $L$ é o número total de MCs no ensemble $\boldsymbol{\Psi}$. Associado a $\boldsymbol{\Psi}$, um vetor de pesos $\mathrm{w}=\left[w_{1}, w_{2}, w_{3}, \ldots, w_{L}\right]^{T}$ pondera as saídas produzidas por cada MC para a entrada $\mathrm{x}_{i}$, representadas por $h_{j i}{ }^{3}$, para compor a saída $\mathrm{y}_{i}^{\Psi}$ do ensemble; onde $w_{j} \geq 0$ e $\sum w_{j}=1$. Assim, a saída produzida pelo ensemble é função da combinação das saídas de $h_{j}$ 's, ponderada por w. Logo, a saída do ensemble é dada por:

$$
\mathrm{y}_{i}^{\Psi}=g\left(\boldsymbol{\Psi}, \mathrm{x}_{i}, \mathrm{w} \mid \Phi\right)
$$

em que $\boldsymbol{\Phi}$ denota o conjunto de parâmetros da função de combinação $g(\cdot)^{4}$. A forma mais simples de produzir a saída $\mathrm{y}_{i}^{\Psi}$ para a entrada $\mathrm{x}_{i}$ é conhecida como votação ponderada, que corresponde à combinação linear das saídas $h_{j}{ }^{\prime}$ s tal como:

$$
\mathrm{y}_{i}^{\mathbf{\Psi}}=\sum_{j} w_{j} h_{j i}
$$

Vale observar que é amplamente utilizado o caso especial, denominado votação simples ou majoritária, cujos pesos são igualmente atribuídos, ou seja, $w_{j}=1 / L$.

De acordo com Dietterich (DIETTERICH, 2000), três razões fundamentais elucidam os motivos pelos quais os ensembles podem operar melhor do que um único modelo e que, na prática, possibilitam a construção de modelos mais acurados:

1. Estatística: quando há insuficiência de dados. A construção de ensemble de modelos pode mediar as saídas dos MCs e minimizar o risco da escolha de um modelo inadequado, decorrente da falta de representatividade do conjunto de treinamento;

2. Computacional: quando a tarefa de encontrar o modelo é computacionalmente intratável. A construção de um ensemble de diversos modelos mais simples e de menor custo computacional pode prover uma melhor aproximação da função $f$ desconhecida;

3. Representacional: quando a SLT pode não ser capaz de representar a verdadeira função $f$. Nesse caso, um ensemble das diversas hipóteses geradas pode expandir o espaço das funções representáveis.

A representação gráfica das razões fundamentais que elucidam a superioridade de

\footnotetext{
${ }^{2}$ Em tarefas de classificação é comum considerar que $h($.$) produza como saída um vetor de distri-$ buição das probabilidades das $c$-classes do problema. Logo, para $n$ atributos numéricos (reais): $h: \mathbb{R}^{n} \rightarrow \mathbb{R}^{c}$

${ }^{3}$ Mais especificamente: $h_{j}\left(\mathrm{x}_{j i}^{\Psi}\right)$, que denota a saída do $j$-ésimo MC para a $i$-ésima entrada $\mathrm{x}_{j i}^{\Psi} ; \mathrm{x}_{j i}^{\Psi}$ é o vetor de entrada resultante da transformação característica do EM (estratégia do EM para diversidade) na entrada $\mathrm{x}_{i}$ para o $j$-ésimo modelo.

${ }^{4}$ Também denominada função de fusão ou de integração.
} 
um ensemble com relação a um único modelo é apresentada na Figura 2.1; em que os MCs são denotados por $h_{j}$ (hipóteses) e a verdadeira função a ser modelada é representada por $f$ no espaço de hipóteses $H$.
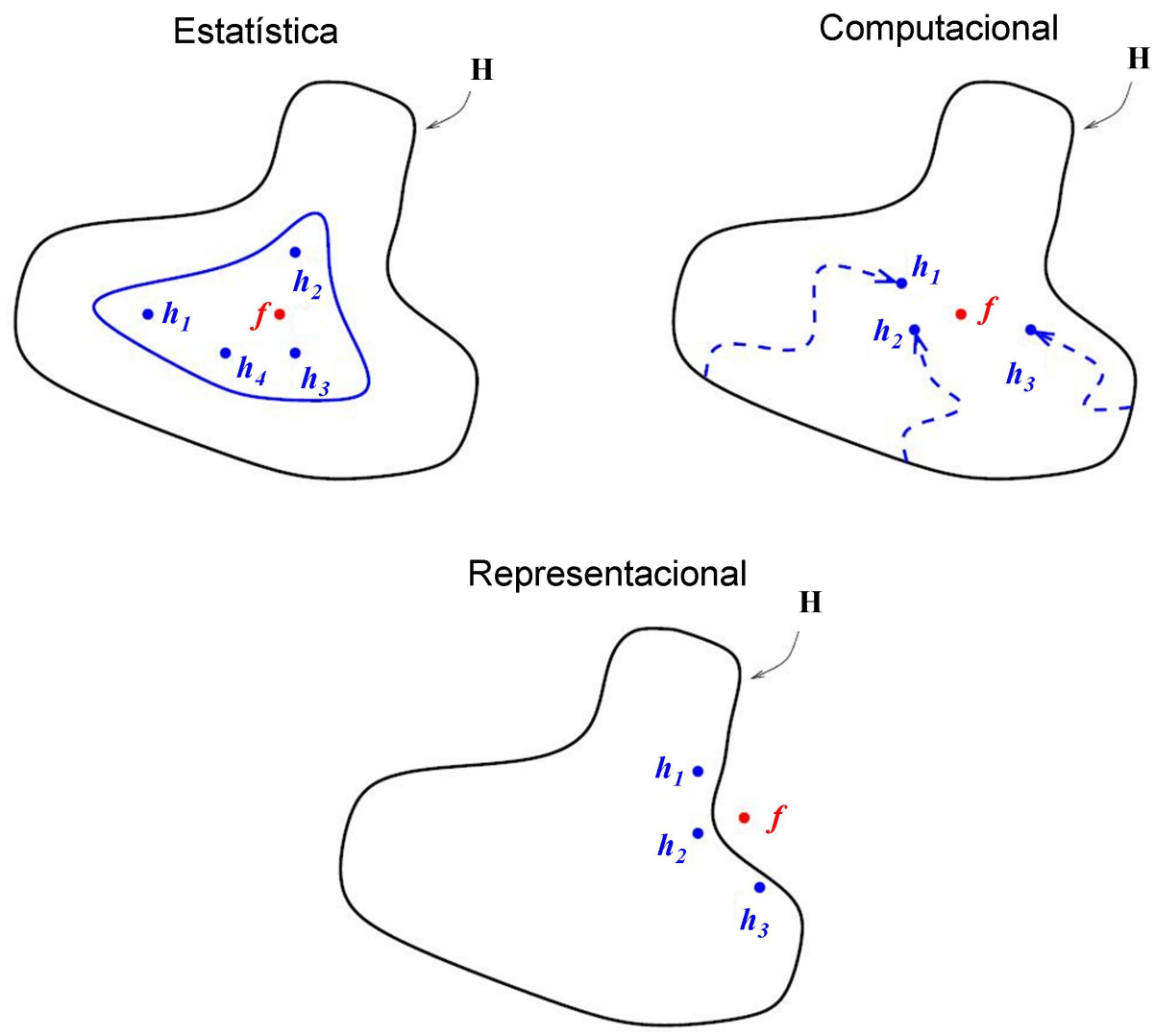

Figura 2.1: Razões fundamentais da superioridade de ensembles.

Krogh e Vedelsby (KROGH; VEDELSBY, 1995) demonstraram que o erro de generalização de um ensemble de ANNs para regressão é determinado pelo erro médio de generalização e pela diversidade média dos modelos que o constituem. A relação linear é estabelecida pela seguinte equação:

$$
E=\bar{E}-\bar{A}
$$

em que $E$ é o erro de generalização do ensemble; $\bar{E}$ é o erro médio de generalização dos MCs; $\bar{A}$ é a ambigüidade média do ensemble, matematicamente expressa pelo somatório das diferenças quadradas entre as predições dos MCs e a predição do ensemble dividido pelo total de MCs. Detalhes sobre a derivação da Equação 2.4 podem ser encontrados em (ZENOBI, 1999). Da Equação 2.4, é possível inferir que um EM deve estar focado na minimização dos erros de generalização de seus MCs, assim como na busca implícita ou explícita de diversidade de predições. 


\subsection{Diversidade de predição}

A questão chave para o sucesso de um EM reside na estratégia utilizada para criação de diversidade de predição entre os MCs. Em um ensemble, a combinação das saídas de vários MCs é útil somente se eles discordam nas predições de algumas instâncias de entrada. A diversidade pode ser entendida, portanto, com a descorrelação dos erros produzidos pelos MCs. Em tarefas de regressão, ferramentas como a decomposição de bias-variância-covariância e de ambigüidade permitem dissociar e quantificar a diversidade em ensembles (BROWN et al., 2005). Simplificadamente, a variância é freqüentemente utilizada para medir a diversidade entre os MCs (KROGH; VEDELSBY, 1995). Assim, um EM de regressão pode obter vantagens se objetivar a minimização do erro quadrático dos MCs e a maximização da variância entre eles.

Em problemas de classificação, o significado exato do conceito diversidade ainda não está completamente elucidado na literatura (BROWN et al., 2005; TANG; SUGANTHAN; YAO, 2006; ROKACH, 2010). O modo como alguns modelos produzem suas saídas, sem qualquer ordinalidade intrínseca em relação às entradas, ainda é um desafio para quantificação da diversidade (BROWN et al., 2005). Árvores de decisão e kNN, por exemplo, geralmente produzem saídas discretas que comprometem a relação de ordem do padrão na saída. Isso evidencia que o problema da diversidade em classificação é a obtenção de alguma forma de quantificar a correlação entre as saídas de modelos não-ordinais. Ainda assim, diversas medidas de diversidade foram propostas/adaptadas, estudadas, categorizadas e comparadas em tarefas de classificação utilizando EMs e SLTs diversas (CUNNINGHAM; CARNEY, 2000; ZENOBI; CUNNINGHAM, 2001; KUNCHEVA; WHITAKER, 2003; TSYMBAL; PECHENIZKIY; CUNNINGHAM, 2004; BROWN et al., 2005; TANG; SUGANTHAN; YAO, 2006).

Kuncheva e Whitaker (KUNCHEVA; WHITAKER, 2003) compararam diversas medidas de diversidade e mostraram que há uma correlação entre a maioria delas. Eles demostraram que as medidas de diversidade em $\operatorname{pares}^{5}$ são fortemente correlacionadas, mas que em tarefas específicas reais podem apresentar comportamentos diferentes. Também não foi encontrada uma conexão definitiva entre essas medidas e a melhoria da acurácia. Por isso, eles concluíram que não está claro se medidas de diversidade têm algum valor prático na construção de ensembles de classificadores.

Tang e colaboradores (TANG; SUGANTHAN; YAO, 2006) analisaram seis medidas de diversidade e demonstraram, teórica e experimentalmente, a ineficácia do uso de medidas de diversidade para construção de ensembles com significativo desempenho de generalização. Três razões foram especificadas para isso:

\footnotetext{
${ }^{5}$ Medidas que quantificam a diversidade por meio de estimativas entre pares de MCs do ensemble.
} 
1. A alteração nas medidas de diversidade não pode prover orientação consistente sobre se um conjunto de MCs porporciona um baixo erro de generalização;

2. As medidas de diversidade existentes são correlacionadas à acurácia média dos MCs. Portanto, elas não fornecem nenhuma informação adicional à medida de acurácia;

3. A maioria das medidas de diversidade não tem nenhum termo de regularização. Portanto, se seus valores forem maximizados é possível que ocorra overfitting do ensemble.

Assim, a otimização simultânea da acurácia dos modelos e de uma medida explícita de diversidade utilizando, por exemplo, algoritmos multiobjetivos (STEUER, 1986) ainda é bastante controversa.

Um EM é reconhecido por buscar diversidade explicitamente se o termo "diversidade" é definido e otimizado; caso contrário, a busca é considerada implícita. Diversas estratégias têm sido utilizadas em propostas de EMs para provocar diversidade implicitamente. Rockach (ROKACH, 2010) sugere uma taxonomia para classificá-las:

- Manipulação do indutor: manipula-se a forma como o indutor é utilizado na construção dos MCs. Por exemplo, cada SLT pode ter seus parâmetros diferentemente definidos ou, ainda, alguma forma de injeção de aleatoriedade;

- Manipulação do conjunto de treinamento: manipula-se a forma como as instâncias são apresentadas para indução dos MCs. Reamostragem e adição de instâncias artificialmente construídas são exemplos dessa estratégia (BREIMAN, 1996; FREUND; SCHAPIRE, 1996; MELVILLE; MOONEY, 2004);

- Modificação da variável dependente: manipula-se a variável alvo para modificar a forma como cada SLT enxerga o conjunto de treinamento. Por exemplo, diferentes versões do conjunto de treinamento com rótulos de classe aleatoriamente modificados para indução dos MCs (BREIMAN, 2000);

- Partição do espaço de busca: cada MC é treinado em espaços de busca diferentes. Por exemplo, os métodos de projeção em subespaços aleatórios (HO, 1998; FERREIRA et al., 2009; SCHCLAR; ROKACH, 2009), abordados na seção seguinte;

- Hibridização: a diversidade é obtida pelo uso de diversas SLTs ou mesmo estratégias de ensembles. 


\subsection{Métodos de construção de ensembles}

A combinação de modelos de predição de paradigmas diferentes é uma estratégia para construção de MCs diversos e acurados (MICHALSKI; TECUCI, 1994; ROKACH, 2010). Tal abordagem tem sido referida na literatura de reconhecimento de padrões como sistemas de múltiplos classificadores. Embora haja ambigüidade quanto ao uso da terminologia, "Método de ensemble" (EM) é, com maior freqüência, utilizado para se referir aos ensembles constituídos por modelos da mesma SLT, sendo essa a conotação utilizada neste trabalho.

\subsubsection{Métodos clássicos e suas variantes}

Os EMs clássicos geralmente utilizam intrinsecamente uma componente de perturbação estocástica para a produção de diversidade. Essa componente está inserida nos principais EMs que manipulam as instâncias ou mesmo os subespaços, tal como bootstrap (amostragem) no método de Breiman (BREIMAN, 1996) ou seleção aleatória de subespaços no método de Ho (HO, 1998). A seguir são sumariados alguns dos mais importantes métodos da literatura e algumas variantes, incluindo uma produzida no curso do trabalho de doutorado referente a esta tese.

\section{Bagging e Wagging}

Bagging (BREIMAN, 1996), derivado de "bootstrap aggregation", é um método baseado em bootstrap que constrói os MCs com diferentes amostras das instâncias retiradas do conjunto de treinamento. $L$ subconjuntos são aleatoriamente amostrados, com reposição, do conjunto de treinamento original. Cada subconjunto, denominado réplica bootstrap, é utilizado para construir um MC. O ensemble é constituído, portanto, por $L$ modelos induzidos com as diferentes réplicas bootstrap. A ambigüidade entre os MCs é decorrente das diferenças entre as réplicas. Finalmente, as predições dos modelos criados são integradas, tipicamente por meio de votação (voto majoritário) em tarefas de classificação ou pela média (aritmética ou ponderada) em regressão, para produzir a saída do ensemble.

Wagging (Weight aggregation) (BAUER; KOHAVI, 1999) é uma variante do método Bagging que requer que a SLT utilizada para construção de cada MC opere com pesos nas instâncias de treinamento. Wagging pode ser entendido como um método que realiza amostragem do conjunto de treinamento considerando os pesos aleatoriamente atribuídos às instâncias para indução de cada MC. Os pesos refletem a probabilidade de ocorrência da instância em cada amostra. A proposição original de Wagging utiliza uma distribuição Gaussiana, com média zero e desvio padrão pré-determinado, para 
adicionar perturbações aleatórias aos pesos das instâncias.

\section{Boosting e AdaBoost}

Boosting (SCHAPIRE, 1990) é um método geral, ou um precursor de uma classe de métodos, para aumentar o desempenho de indutores de classificadores fracos ${ }^{6}$. Diferente de Bagging e Wagging, o mecanismo de amostragem iterativo visa o reforço da amostra, realizada a cada iteração, com instâncias incorretamente classificadas pelos modelos induzidos nas iterações anteriores. Os classificadores fracos induzidos nesse processo são então combinados em um ensemble para dar origem a um classificador forte (acurado).

O AdaBoost (Adaptive Boosting) (FREUnd; SCHAPIRE, 1996) é uma variante de Boosting amplamente conhecido e estudado pela comunidade de aprendizado de ensemble. No método AdaBoost cada instância do conjunto de treinamento possui uma probabilidade de seleção associada por meio de um peso. Assim, a amostragem aleatória das instâncias do conjunto de treinamento considera essa probabilidade associada. Inicialmente, o mesmo peso é associado à todas as instâncias. A cada iteração, a probabilidade de seleção de cada instância é alterada em função do desempenho do classificador criado. Esse procedimento iterativo gera um conjunto de classificadores que se complementam entre si. Shapire e Freund (SCHAPIRE; FREUND, 1998) mostraram que o sucesso do AdaBoost é resultante da sua propriedade de aumentar a margem $^{7}$, o que torna seu objetivo similar ao das máquinas de vetores de suporte $\left(\mathrm{SVM}^{8}\right)$.

\section{Métodos de subespaços aleatórios}

Diferentemente de Bagging, Wagging e AdaBoost, alguns métodos utilizam a projeção das instâncias em subespaços como mecanismo para diversificação e/ou acurácia dos MCs. A vantagem de alguns desses métodos é inerente à redução da dimensionalidade e, conseqüentemente, cria-se a possibilidade de utilização em bases de dados de grandes dimensões com SLTs de alto custo computacional. O clássico representante desse tipo de estratégia é o método de subespaços aleatórios (RSM $\left.{ }^{9}\right)$ (HO, 1998).

Ao invés de construir os MCs a partir das instâncias integrais, no que se refere aos seus atributos, o RSM utiliza amostras do conjunto dos atributos (subespaços). Cada MC é induzido utilizando as instâncias projetadas no subespaço formado pelos atributos aleatoriamente selecionados. A mesma SLT pode ser, portanto, empregada

\footnotetext{
${ }^{6}$ Um classificador fraco é um modelo apenas ligeiramente melhor do que um procedimento de rotulação aleatória de instâncias.

${ }^{7} \mathrm{Na}$ teoria de máquinas de vetores de suporte, margem é a distância de um hiperplano de separação para instâncias mais próximas a ele.

${ }^{8}$ Support Vector Machines.

${ }^{9}$ Random Subspace Method.
} 
para indução dos modelos, uma vez que a diversificação é decorrente dos diferentes subespaços.

Algumas variantes do RSM tradicional também são encontradas na literatura. Tsymbal e colaboradores (TSYMBAL; PUURONEN; PATTERSON, 2003; TSYMBAL; PECHENIZKIY; CUNNINGHAM, 2005) utilizaram uma seleção probabilística de atributos, ao invés de uma seleção totalmente aleatória, e obtiveram ensembles com maior diversidade e, conseqüentemente, maior acurácia. Ferreira e colaboradores (FERREIRA et al., 2007) utilizaram o RSM no espaço das componentes principais visando a construção de um ensemble de ANNs (MLPs) para regressão em um conjunto de dados espectroscópicos de cafés obtidos por uma língua eletrônica. Essa variante do método, denominada método de subespaços aleatórios do espaço de componentes principais (RSM-PCS ${ }^{10}$ ), busca usufruir das peculiaridades de um espaço de atributos descorrelacionados (componentes principais) intrínsecas à transformação característica da PCA. Os resultados obtidos pelo RSM-PCS foram estatisticamente superiores ao RSM tradicional e a uma MLP treinada com todos os atributos.

Ferreira e colaboradores (FERREIRA et al., 2009) adaptaram a proposta do RSMPCS para usufruir simultaneamente das características do espaço dos atributos e do espaço das componentes principais. Essa outra variante constrói um subconjunto de MCs a partir dos dados originais, do espaço de características original das instâncias, e um outro subconjunto de MCs a partir dos dados projetados no espaço das componentes principais. Esse método, denominado método de subespaços aleatórios do espaço das instâncias e das componentes principais (RSM-IPCS ${ }^{11}$ ), foi validado para ensembles de árvores de decisão induzidas pelo C4.5 (QUINLAN, 1993) em 24 bases de dados obtidas do repositório da Universidade da Califórnia em Irvine (UCI) (FRANK; ASUNCION, 2010). O RSM-IPCS apresentou resultados expressivos quando comparado ao RSM e à variante RSM-PCS. O RSM-IPCS construiu ensembles mais acurados e estatisticamente superiores àqueles construídos pelo RSM-PCS para a grande maioria das bases utilizadas e, ainda, superiores ou sem diferenças estatisticamente significativas àqueles obtidos pelo RSM tradicional. RSM-IPCS apresentou também uma redução na variância das predições para a maioria das bases de benchmark. Os resultados obtidos conduziram à conclusão de que RSM-IPCS é no mínimo igual ao melhor dentre os dois outros métodos que operam em um único espaço (RSM e RSM-PCS). O pseudo-código do método RSM-IPCS utilizado por Ferreira e colaboradores (FERREIRA et al., 2009) é apresentado no Algoritmo 2.1.

A proposta original do RSM-IPCS está focada na utilização de toda a variância

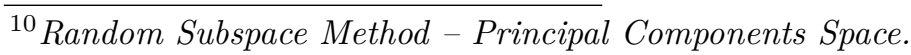

${ }^{11}$ Random Subspace Method - Instance and Principal Components Spaces. 


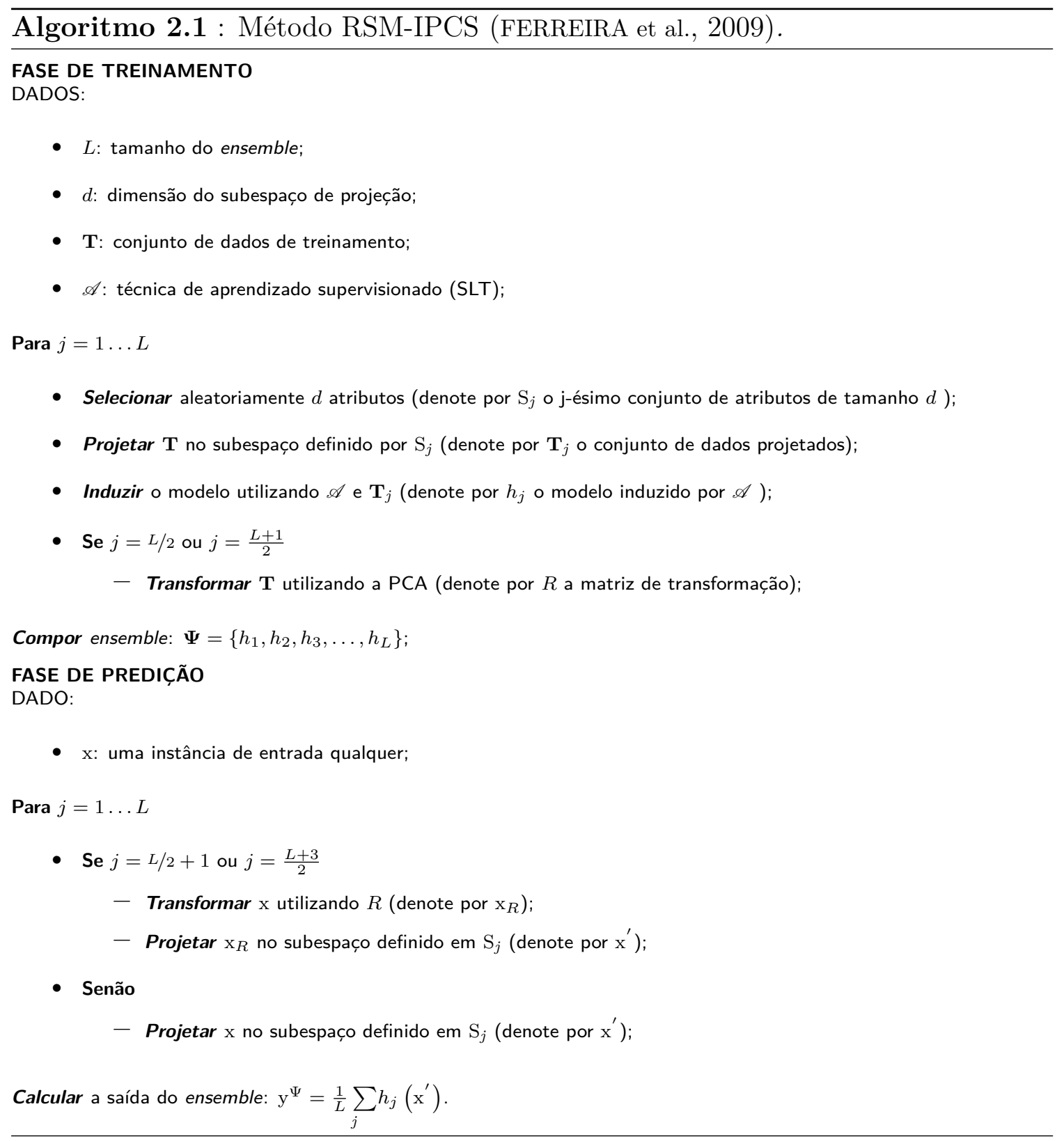

dos dados após a transformação. Assim, a PCA pode ser interpretada somente como artifício de descorrelacionamento ou, geometricamente, de rotações das instâncias no espaço original. O RSM-IPCS estabelece, portanto, uma analogia conceptual com o método RB no que se refere ao uso da PCA como estratégia de rotação.

\subsubsection{Método baseado em projeção aleatória}

A redução de dimensionalidade por meio de transformações projetivas aleatórias tem sido o foco de pesquisas recentes nas áreas de DM e ML (FRADKIN; MADIGAN, 2003). Esse tipo de abordagem de respaldo teórico oferece algumas vantagens computacionais, dentre elas: 
- Custo computacional da transformação relativamente reduzido;

- Eficácia quando associada aos algoritmos de ML.

A projeção aleatória é fundamentada no teorema de Johnson e Lindenstrauss (JOHNSON; LINDENSTRAUSS, 1984), um dos pilares da teoria moderna de redução de dimensionalidade. Em linhas gerais, o teorema declara que, para um conjunto de $m$ pontos no espaço Euclidiano $n$-dimensional, existe uma transformação linear para o espaço $d$-dimensional, em que $d$ é o logarítmico em $m$ e independente de $n$, que preserva as distâncias par-a-par dentro de um pequeno fator arbitrário (ACHLIOPTAS, 2003).

Achlioptas (ACHLIOPTAS, 2003) propôs dois métodos computacionalmente simples e eficientes para produzir matrizes de projeção aleatórias. Esses métodos, representados por matrizes $n \times d$ de projeção aleatória $(P A)$, são apresentados na Equação 2.5 e na Equação 2.6.

$$
\begin{gathered}
p a_{u v}=\left\{\begin{array}{cl}
+1 & \text { probabilidade }^{1 / 2} \\
-1 & \text { probabilidade }^{1 / 2}
\end{array}\right. \\
p a_{u v}=\sqrt{3} \times\left\{\begin{array}{cc}
+1 & \text { probabilidade }^{1 / 6} \\
0 & \text { probabilidade }^{2 / 3} \\
-1 & \text { probabilidade } 1 / 6^{1 / 2}
\end{array}\right.
\end{gathered}
$$

Schclar e Rokach (SCHCLAR; ROKACH, 2009) propuseram o EM baseado em projeções aleatórias $\left(\mathrm{RPEM}^{12}\right)$. O RPEM é um método bastante simples que realiza $L$ projeções aleatórias para a indução dos MCs do ensemble. Segundo seus autores, a projeção aleatória contribui para a redução da complexidade de classificação e remoção de ruído dos dados. A diversidade nesse método é explicada como conseqüência da aleatoriedade incutida nas projeções. O RPEM foi validado utilizando o $\mathrm{kNN}$, com $k=1$, e apresentou desempenho superior ao RSM e Bagging na maior parte das bases de benchmark. Apesar dos resultados promissores, não foram encontrados trabalhos específicos de validação do desempenho do RPEM com algoritmos de árvores de decisão, técnicas Bayesianas, ANNs, nem mesmo em tarefas de regressão.

\subsubsection{Método baseado em rotação}

Trabalhos recentes introduziram e caracterizaram um novo EM de alto desempenho que utiliza o artifício da rotação em conjunto com SLTs sensíveis a essa transfor-

$\overline{{ }^{12} \text { Random Projection Ensemble Method }}$. 
mação, especialmente árvores de decisão, para a construção de ensembles de modelos diversos e acurados (RODRíGUEZ; ALONSO, 2004; RODRÍGUEZ; ALONSO; PRIETO, 2005; RODRIGUEZ; KUNCHEVA; ALONSO, 2006; RODRÍGUEZ; MAUDES; ALONSO, 2006; KUNCHEVA; RODRÍGUEZ, 2007). Originalmente denominado RB, mas popularizado como RF (Rotation Forest) por seu potencial em construir florestas de decisão, o método transforma o conjunto de treinamento, mas preserva toda a informação contida nos dados. Inicialmente, o conjunto de atributos $\mathbf{F}$ é aleatoriamente particionado em $K$ (parâmetro do algoritmo) subgrupos. Esses subgrupos podem ser disjuntos ou apresentar alguma intersecção. Nos dados respectivos a cada subgrupo, um subconjunto de classes (não-vazio) é aleatoriamente selecionado e uma porcentagem das instâncias é removida (ou realizada uma amostragem bootstrap). Posteriormente, a PCA é utilizada para obter as direções de rotação de cada subgrupo por meio dos coeficientes das componentes principais. Os coeficientes extraídos para todos os subgrupos são utilizados para compor a matriz de rotação $R_{j}^{a}$, que é posteriormente empregada na transformação dos dados de treinamento utilizados na indução do $j$ ésimo MC. Esse procedimento é, então, repetido para os $L$ MCs do ensemble. No Algoritmo 2.2, é apresentado o pseudo-código do método RB (ou RF).

O método RB tende a gerar MCs mais acurados do que os criados por AdaBoost e Random Forest e mais diversos do que os criados por Bagging. A comparação com implementações padrão de Bagging, Adaboost e Random Forest em 33 bases de dados de domínio público mostram que o método RB supera os outros métodos com uma margem relativamente grande (RODRIGUEZ; KUNCHEVA; ALONSO, 2006). Para explicar o desempenho superior do método RB, Rodríguez e colaboradores (RODRÍGUEZ; ALONSO; PRIETO, 2005) compararam-no com Bagging, AdaBoost e Random Forest utilizando a decomposição de bias-variância. Os resultados mostraram que o método RB é, na maior parte das comparativas, superior aos demais considerados.

Kuncheva e Rodríguez (KUNCHEVA; RODRÍGUEZ, 2007) estudaram os efeitos dos parâmetros bem como a adequabilidade da PCA para entender a influência dos parâmetros e das heurísticas de aleatorização no desempenho do método RB. Para isso, eles propuseram, investigaram e responderam quatro questões julgadas fundamentais:

1. O particionamento do subconjunto de atributos é essencial para o sucesso do método RB?

2. Como o número de subgrupos, $K$, afeta o desempenho do método RB?

3. Como o método RB se compara com Bagging, Random Forest e AdaBoost em ensembles de tamanhos variados?

4. A PCA é a melhor técnica para rotacionar os subgrupos de atributos? 


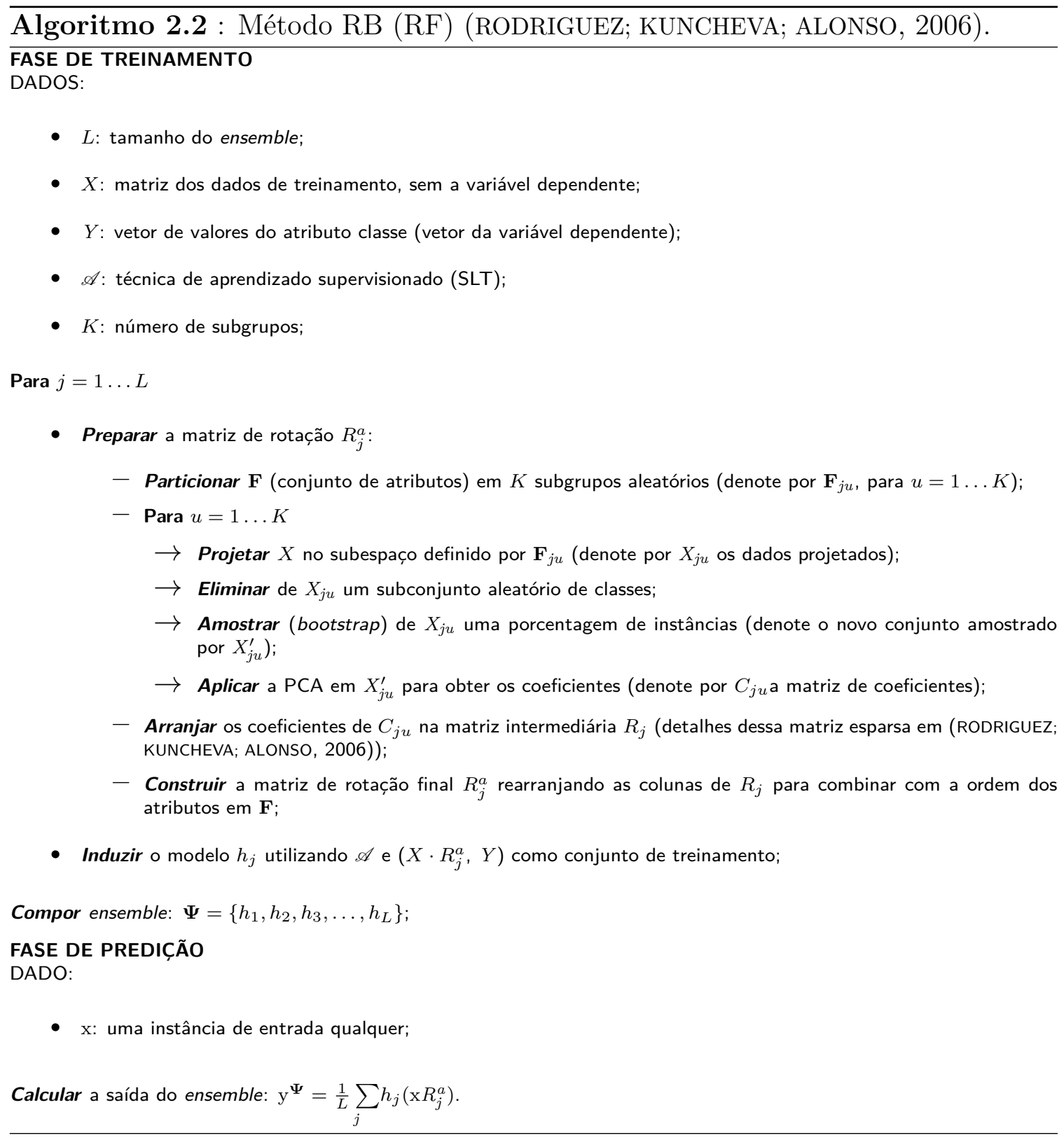

Eles demonstraram que o particionamento é necessário (Questão 1) para provocar esparcidade na matriz (conseqüentemente diversidade), porém não encontraram nenhum padrão de dependência entre $K$ e a acurácia do ensemble (Questão 2), propondo o uso de $K=3$ em aplicações futuras. Concluíram ainda que o método RB foi melhor que os outros métodos, especialmente para ensembles de menores tamanhos (Questão 3). Finalmente, a PCA foi um pouco, mas consistentemente melhor (Questão 4) do que as outras técnicas de extração analisadas (análise de discrimante linear nãoparamétrica (FUKUNAGA; MANTOCK, 1983) e transformações similares às projeções aleatórias da Seção 2.3.2).

O método RB também apresentou desempenho superior aos métodos Bagging, AdaBoost e Random Forest com outra SLT instável e sensível à rotação: rede de fun- 
ção de base radial (RBF ${ }^{13}$ ) (RODRÍGUEZ; MAUDES; ALONSO, 2006). Adicionalmente, o método desempenhou razoavelmente com árvores de regressão, especialmente na comparação com Bagging e Random Forest (ZHANG; ZHANG; WANG, 2008). Resultados importantes em tarefas de regressão também foram obtidos por meio de uma adaptação/acoplamento de estimadores locais ao método RB (KOTSIANTIS; PINTELAS, 2009). Assim, o método RB se apresenta como um método candidato e/ou uma base conceitual potencial à solução tanto de problemas de classificação como regressão.

\subsection{Considerações finais}

A literatura de aprendizado de ensemble dispõe de um considerável número de EMs que adotam estratégias conceitualmente simples ou, algumas vezes, complexas para composição de ensembles acurados. Os dois métodos mais conhecidos e amplamente aplicados são Bagging (BREIMAN, 1996) e AdaBoost (FREUND; SCHAPIRE, 1996). Por outro lado, o desempenho significativamente superior do método RB frente a Bagging, AdaBoost, além de outros, traz para si o foco em termos de EM, tornando-o uma referência com SLTs sensíveis à rotação.

O estudo experimental de Kuncheva e Rodríguez (KUNCHEVA; RODRÍGUEZ, 2007) evidencia um dos principais efeitos responsáveis pelo ótimo desempenho do método RB: a esparcidade da matriz de rotação. Todavia, a transformação da matriz de rotação não objetiva, diretamente, uma direção que possa beneficiar certa SLT na busca pelo aumento da acurácia do MC. Adicionalmente, o método não explora, na sua concepção primária, a característica projetiva da PCA para uso associado com SLTs estáveis ou insensíveis somente à rotação, embora os autores reconheçam que alterações na dimensionalidade dos dados transformados poderiam contribuir para isso (RODRÍGUEZ; ALONSO; PRIETO, 2005).

Diferentemente da abordagem utilizada no método de Rodríguez e colaboradores, a premissa desta tese está pautada na idéia de que uma transformação de ORP para a SLT deve contribuir para o aumento da acurácia e/ou para a minimização da complexidade na construção de modelos individuais e, com maior tônica, na contribuição que essa transformação pode proporcionar na construção de ensembles. No próximo capítulo são detalhados os fundamentos teóricos e práticos que alicerçam esta tese, bem como a proposta do novo EM baseado em ORP: ORPE.

\footnotetext{
${ }^{13}$ Radial Basis Function.
} 
CAPÍTULO 3

\section{Fundamentos da proposta}

Uma instância de um conjunto de dados é um padrão característico representado por uma série de valores atribuídos aos seus respectivos atributos. A transformação de dados é um processo pelo qual a representação das instâncias é modificada para dar origem à um novo espaço de atributos. Esses novos atributos podem ser simplesmente um subconjunto selecionado ou uma combinação dos atributos originais. Existem diferentes técnicas de transformação de dados que podem ser utilizadas em várias aplicações. A PCA, as técnicas de projeções aleatórias apresentadas no capítulo anterior, discretização (DOUGHERTY; KOHAVI; SAHAMI, 1995), entre outras são transformações bastante utilizadas nas áreas de ML e correlatas.

A transformação na qual um conjunto de dados é submetido impacta diretamente no desempenho e na complexidade do modelo induzido posteriormente. Uma discretização adequada precedente à indução, por exemplo, além de viabilizar a utilização de alguns algoritmos exclusivamente restritos às variáveis discretas, pode aumentar a acurácia do modelo gerado (DOUGHERTY; KOHAVI; SAHAMI, 1995). Similarmente, o uso de seleção de atributos ou extração de características como um processo de transformação pré-indução pode viabilizar a construção de modelos mais simples, robustos e acurados.

A extração de características é um processo que tem por finalidade a obtenção de um subconjunto de novos atributos a partir do conjunto original por meio de algum mapeamento funcional. Mais especificamente, visa-se encontrar um novo conjunto de $d$ dimensões que são combinações das $n$ dimensões originais, tal que $0<d<n$. Exis- 
tem inúmeras abordagens interessantes na literatura para extração de características. Somente para citar algumas (DIAMANTARAS; KUNG, 1996): a análise discriminante linear, PCA, codificação fractal, transformação wavelet, uso de informação mútua e diferentes tipos de ANNs. Essas técnicas podem ser classificadas como supervisionada ou não supervisionada dependendo do uso ou não, respectivamente, da variável dependente. A análise de discriminante linear, por exemplo, é uma extração supervisionada, enquanto a técnica mais comum não supervisionada ainda é, provavelmente, a PCA.

\subsection{Interpretação contextualizada da PCA}

A PCA, também conhecida por transformação de Karhunen-Loève (HAYKIN, 1999), é uma técnica utilizada para projetar dados de alta dimensionalidade em espaços de dimensões menores com uma pequena perda de informação. O objetivo é encontrar um novo conjunto de atributos de dimensões reduzidas que capture melhor a variabilidade dos dados. Mais especificamente, a primeira dimensão, ou primeira componente principal, deve reter tanto da variabilidade quanto possível. A segunda componente principal, ortogonal à primeira, também deve reter tanto quanto possível do restante da variância; e assim sucessivamente até a $n$-ésima componente.

As componentes principais são combinações lineares dos atributos originais e são determinadas pelos auto-vetores extraídos da matriz de covariância dos dados. Cada auto-vetor tem um auto-valor associado que provê a informação da proporção da variância retida por aquela componente. Essa transformação tem algumas características interessantes, como a redução de dimensionalidade, descorrelacionamento dos dados, eliminação de ruído, possibilidade de identificação de padrões intrínsecos e fortes, entre outras (TAN; STEINBACH; KUMAR, 2005).

Analisando a PCA sob uma ótica geométrica, no espaço Euclidiano, pode-se interpretá-la como uma concatenação de transformações otimizadas de rotação capaz de obter uma direção que maximiza a variância ordenadamente nos eixos de coordenadas viabilizando, assim, uma projeção ortogonal no subespaço formado pelos $d$ primeiros eixos. Algoritmicamente, a otimização seqüencial e iterativa de $n-1$ subproblemas, caracterizados pela maximização exclusiva da variância em apenas um eixo ortogonal por vez ( $v$-ésimo eixo), deve produzir uma transformação similar à obtida pela PCA. No Algoritmo 3.1 é apresentado um pseudo-código que detalha essa abordagem baseada na otimização de transformações geométricas de rotação finalizada por uma projeção no subespaço.

Evidentemente, o pseudo-código apresentado no Algoritmo 3.1 para obtenção 


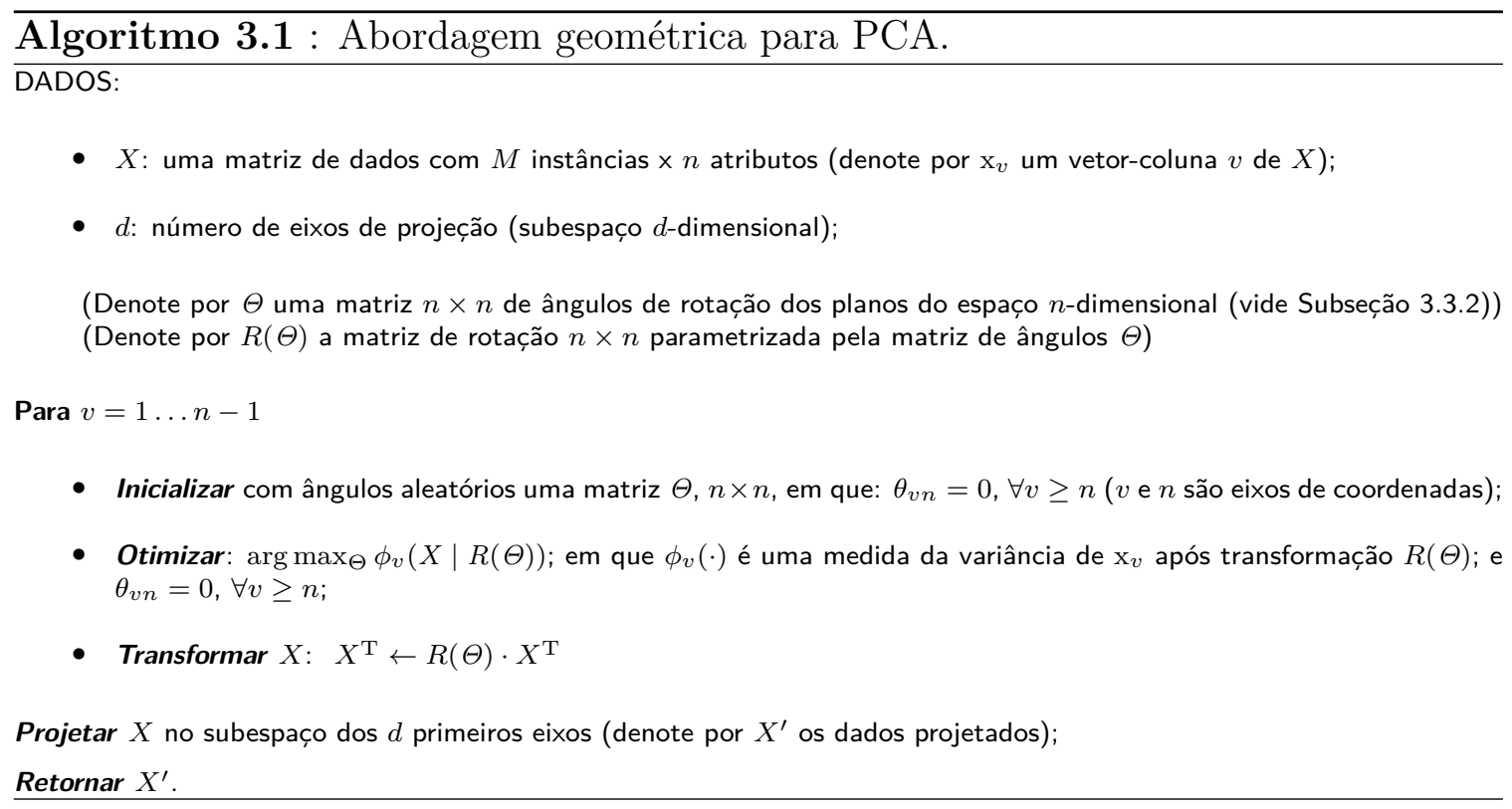

das componentes principais é meramente ilustrativo ${ }^{1}$. Contudo, a forma matemáticogeométrica de apresentar o problema é bastante interessante por possibilitar a parametrização da matriz de transformação linear na forma de ângulos que direcionam a rotação dos planos do espaço $n$-dimensional. Tal abordagem viabiliza a otimização de direção e sentido de acordo com qualquer critério pré-estabelecido.

\subsection{Abordagem matemático-geométrica}

Considere o domínio das instâncias de um problema de ML supervisionado como pertencente ao espaço $n$-dimensional, em que $n$ é o número de atributos reais do conjunto de dados representado pela matriz $X_{M \times n}$; e $Y_{M \times c}$ é a matriz de saída para as $M$ instâncias de $c$ classes. Assim, um modelo de aprendizado $h$ pode ser reescrito matematicamente como:

$$
h: \mathbb{R}^{n} \ni \mathrm{x} \rightarrow \mathrm{y} \in \mathbb{R}^{c},
$$

em que x é o vetor que representa uma instância de entrada e y é o vetor com as distribuições de probabilidades estimadas das $c$ classes do problema ${ }^{2}$. Considerando apenas o domínio de $h$, cada instância definida no espaço $\mathbb{R}^{n}$ pode ser representada geometricamente como um ponto (entidade) no espaço Euclidiano. Assim, uma transformação

\footnotetext{
${ }^{1}$ Embora seja computacionalmente ineficiente, o Algoritmo 3.1 obtém componentes similares àquelas obtidas pela transformação típica da PCA. Testes e comparações utilizando uma implementação em Java desse algoritmo foram realizados para corroborar sua funcionalidade. Na prática, quando máximos locais são providos como soluções pela metaheurística, observam-se erros cumulativos que resultam na imprecisão da transformação.

${ }^{2}$ Para tarefas de regressão, $c=1$.
} 
geométrica operada sobre um ponto no espaço é genericamente expressa por:

$$
P^{\prime}=A \cdot P
$$

em que $P^{\prime}$ define as novas coordenadas do ponto $P$ sujeito à matriz de transformação A. No contexto de ML, essa transformação geométrica pode modificar a posição das instâncias de um conjunto de dados no espaço. Em síntese, cada instância de um problema de ML é representada como um ponto no espaço Euclidiano sujeito a qualquer transformação geométrica explicitada em $A$. Considere, por exemplo, uma instância na forma vetorial $\left[x_{1}, x_{2}, x_{3}\right]^{\mathrm{T}}$; as novas coordenadas $\left[x_{1}^{\prime}, x_{2}^{\prime}, x_{3}^{\prime}\right]^{\mathrm{T}}$ geradas por uma transformação geométrica em $A$ são matricialmente calculadas como:

$$
\left[\begin{array}{l}
x_{1}^{\prime} \\
x_{2}^{\prime} \\
x_{3}^{\prime}
\end{array}\right]=\left[\begin{array}{lll}
a_{11} & a_{12} & a_{13} \\
a_{21} & a_{22} & a_{23} \\
a_{31} & a_{32} & a_{33}
\end{array}\right] \cdot\left[\begin{array}{l}
x_{1} \\
x_{2} \\
x_{3}
\end{array}\right]
$$

em que $a_{i j} \in \mathbb{R}$.

\subsection{Transformações geométricas}

Uma transformação geométrica é uma função que mapeia um ponto (ou um vetor) em outro ponto (ou outro vetor). Transformações no espaço bi ou tridimensional fundamentam e são amplamente utilizadas na área de CG (FOLEY et al., 1990; ANGEL, 2008). Dentre as transformações mais conhecidas e utilizadas em CG, destacam-se: rotação, translação, escala, reflexão, shear (cisalhamento) e a projeção. Em particular, rotações e/ou projeções devidamente controladas produzem ângulos de visualização que facilitam a distinção ou a sobreposição/interposição de objetos gráficos em uma cena, algo particularmente potencial para o rearranjo de classes de padrões em ML.

A aplicação de algumas transformações geométricas no escopo de ML requer um tratamento diferenciado de aspectos pouco convencionais em CG, principalmente no que tange à dimensão do espaço em que essas operações podem ocorrer. Por isso, uma generalização de algumas dessas transformações para o espaço $n$-dimensional se faz necessária para lidar com dimensões geralmente muito maiores que três. Nas próximas seções são apresentadas transformações de rotação e projeção para o espaço bi ou tridimensional, seguidas das generalizações para um espaço $n$-dimensional, imprescindíveis para o propósito deste trabalho. 


\subsubsection{Rotação}

A rotação é uma transformação geométrica conhecida como transformação de corpo rígido, pois não altera a forma/volume de um objeto (ANGEL, 2008) ou as relações em um aglomerado de pontos. Pontos podem ser rotacionados de um ângulo $\theta$ em torno de uma origem ou de um eixo. A rotação de um ponto $P\left(x_{1}, x_{2}\right)$ no plano $\mathbb{R}^{2}$ em torno de sua origem é matematicamente definida por:

$$
\begin{aligned}
& x_{1}^{\prime}=x_{1} \cdot \cos \theta-x_{2} \cdot \sin \theta, \\
& x_{2}^{\prime}=x_{1} \cdot \sin \theta+x_{2} \cdot \cos \theta
\end{aligned}
$$

ou na forma matricial:

$$
\left[\begin{array}{l}
x_{1}^{\prime} \\
x_{2}^{\prime}
\end{array}\right]=\left[\begin{array}{cc}
\cos \theta & -\sin \theta \\
\sin \theta & \cos \theta
\end{array}\right] \cdot\left[\begin{array}{l}
x_{1} \\
x_{2}
\end{array}\right],
$$

em que, no contexto de ML, $x_{1}^{\prime}$ e $x_{2}^{\prime}$ são as novas coordenadas de uma instância $\mathrm{x}$ qualquer. Na Figura 3.1 é ilustrado o efeito de uma rotação de $\theta=-45^{\circ}$ em um conjunto de dados artificiais de ML com duas classes representadas por pontos nas cores vermelha e azul. Note-se que, as instâncias originalmente positivas assumem valores negativos após a rotação em torno da origem.
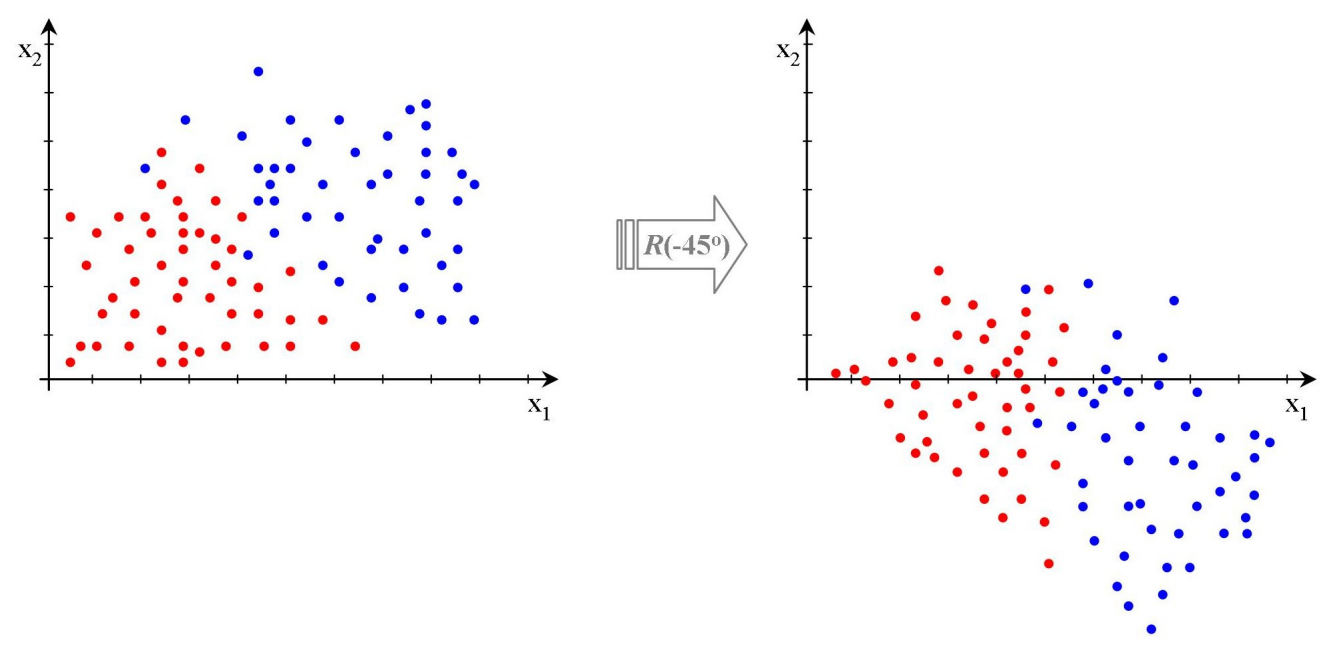

Figura 3.1: Efeito da rotação em ML.

\subsubsection{Rotação $n$-dimensional}

Em três dimensões, rotações são especificadas em termos do ângulo $\theta$ em torno de um eixo arbitrário. No entanto, é mais correto pensar na rotação como o giro de um plano embutido no espaço (NOLL, 1967). Na rotação no espaço tridimensional, por exemplo, esse é o plano perpendicular ao eixo de rotação. Assim, desde que um 
plano no espaço seja especificado juntamente com um centro de rotação, a rotação é univocamente definida (DUFFIN; BARRETT, 1994). A partir das idéias apresentadas por Noll (NOLL, 1967), Duffin e Barrett (DUFFIN; BARRETT, 1994) definiram uma matriz geral para rotação do eixo $\mathrm{x}_{a}$ em direção ao eixo $\mathrm{x}_{b}$ por um ângulo $\theta$, ou seja, a rotação do plano formado pelos eixos $\mathrm{x}_{a}$ e $\mathrm{x}_{b}$ do espaço Euclidiano $n$-dimensional é matricialmente definida por:

$$
R_{a b}(\theta)=\left[r_{i j} \mid \begin{array}{ccc}
r_{i i}= & 1 & \text { se } i \neq \text { ae } i \neq b \\
r_{a a}= & \cos \theta \\
r_{b b}= & \cos \theta \\
r_{a b}= & -\sin \theta \\
r_{b a}= & \sin \theta \\
r_{i j}= & 0 & \text { demais }
\end{array}\right]
$$

A matriz de rotação completamente parametrizada para rotações no espaço $n$ dimensional é composta por $\left(\begin{array}{l}n \\ 2\end{array}\right)$ possíveis planos combinados por meio do produto de suas respectivas matrizes, arranjadas conforme apresentado na Equação 3.6. Para cada plano formado pelos eixos coordenados $\mathrm{x}_{\mathrm{a}}$ e $\mathrm{x}_{b}$, há um parâmetro angular $\theta_{a b}$. Em notação matricial, a rotação geral no espaço Euclidiano $n$-dimensional é obtida por:

$$
R(\Theta)=\prod_{a=1}^{n-1} \prod_{b=a+1}^{n} R_{a b}\left(\theta_{a b}\right),
$$

em que $\Theta$ é a matriz dos parâmetros angulares $\theta_{a b}$, tal que $\theta_{a b}=0, \forall a \geq b$. Qualquer direção (ou sentido) arbitrária pode ser obtida se os parâmetros angulares de $\Theta$ forem apropriadamente ajustados. Essa forma parametrizável da transformação $R$ por meio de $\Theta$ pode ser computacionalmente representada por um vetor de variáveis angulares restritas aos valores no intervalo $[-\pi, \pi]$ radianos (ou $[-180,180]$ graus).

\subsubsection{Projeção ortogonal}

A projeção é uma operação que transforma pontos de um sistema de coordenadas $n$-dimensional em pontos de um sistema de coordenadas de dimensão $d$, tal que $0<$ $d<n$. Há diversos tipos de projeções estudadas e aplicadas em geometria projetiva, CG e DM (FOLEY et al., 1990; FRADKIN; MADIGAN, 2003; DUFFIN; BARRETT, 1994; ANGEL, 2008). A projeção ortogonal é um tipo especial de transformação paralela que projeta os pontos em um subespaço. O que caracteriza a projeção ortogonal é a perpendicularidade entre o raio de projeção do ponto e o subespaço de projeção. Em três dimensões, por exemplo, a projeção ortogonal de um ponto com coordenadas 
$\left(x_{1}, x_{2}, x_{3}\right)$ sobre o plano formado pelos eixos $\mathrm{x}_{1}$ e $\mathrm{x}_{2}$ é definida matricialmente por:

$$
\left[\begin{array}{l}
x_{1}^{\prime} \\
x_{2}^{\prime} \\
x_{3}^{\prime}
\end{array}\right]=\left[\begin{array}{lll}
1 & 0 & 0 \\
0 & 1 & 0 \\
0 & 0 & 0
\end{array}\right] \cdot\left[\begin{array}{l}
x_{1} \\
x_{2} \\
x_{3}
\end{array}\right] .
$$

\subsubsection{Projeção ortogonal $n$-dimensional}

A projeção ortogonal de um ponto do espaço $n$-dimensional em um subespaço de dimensão $d$ é definida na forma vetorial por (DUFFIN; BARRETT, 1994):

$$
\mathrm{x}_{(p r o j)}^{\prime}=\sum_{i=1}^{d} \mathrm{x} \cdot \mathrm{b}_{i},
$$

em que $\mathrm{b}_{i}$ é o $i$-ésimo vetor da base do subespaço $d$-dimensional. Se $\mathrm{b}_{i}{ }^{\prime}$ s são equivalentes $^{3}$ aos vetores da base original do espaço $n$-dimensional, ao qual x pertence, então a projeção de x sobre o subespaço $d$-dimensional é simplesmente definida pelas coordenadas $i$ 's de $\mathrm{x}$, sendo essa forma simplificada da transformação projetiva adotada e amplamente referida como projeção em subespaço no escopo deste trabalho.

\subsubsection{Concatenação roto-projeção}

Conforme definido genericamente na Equação 3.3, uma transformação geométrica de um ponto $P$ qualquer é determinada pela matriz $A$. Essa matriz pode concatenar seqüências ordenadas da mesma transformação ou de transformações distintas. A concatenação de transformações sucessivas para produção da matriz final é obtida por meio do produto matricial. A transformação resultante em $A$ reflete, portanto, a ordem pré-estabelecida no produto das matrizes. Por exemplo, a composição da matriz de rotação $n$-dimensional completamente parametrizada, apresentada na Equação 3.7, é uma concatenação de rotações de eixos, par-a-par, que obedece uma ordem específica, ou seja, $R_{1,2}\left(\theta_{1,2}\right)$ é a primeira transformação, seguida por $R_{1,3}\left(\theta_{1,3}\right)$, $R_{1,4}\left(\theta_{1,4}\right)$, e assim sucessivamente até $R_{n-1, n}\left(\theta_{n-1, n}\right)$.

As transformações de rotação concatenadas em $R(\Theta)$ sucedida por uma projeção ortogonal em um subespaço das $d$ primeiras dimensões, tal como mencionado na Subseção 3.3.4, delimita o escopo deste trabalho. Essa transformação concatenada, denominada roto-projeção, é simplificada por:

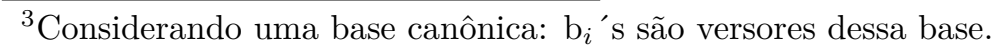




$$
R P(\Theta, d)=Q_{d \times n} \cdot R_{n \times n}(\Theta)
$$

em que $Q_{d \times n}$ é a matriz de projeção ortogonal definida como uma submatriz com as $d$ primeiras linhas e $n$ colunas da matriz identidade $I_{n}$.

A transformação de roto-projeção apresenta uma propriedade interessante, advinda da projeção ortogonal, relativa às mudanças nas razões entre pontos no espaço e no subespaço de projeção. Especificamente, a distância Euclidiana entre dois pontos projetados no subespaço $d$-dimensional é menor ou, no máximo, igual à distância entre eles no espaço $n$-dimensional. Em termos práticos, isso significa que a roto-projeção pode aproximar pontos no subespaço de projeção, algo particularmente interessante no contexto de ML. Na Figura 3.2 é ilustrada a projeção no subespaço $x_{1}$ antes (esquerda) e após (direita) rotação de $30^{\circ}$. É possível observar que a distância entre as projeções de $P_{1}$ e $P_{2}$ foi reduzida para menos da metade após a rotação. Ilustrações do efeito dessa propriedade no contexto de ML são apresentados na seção seguinte.
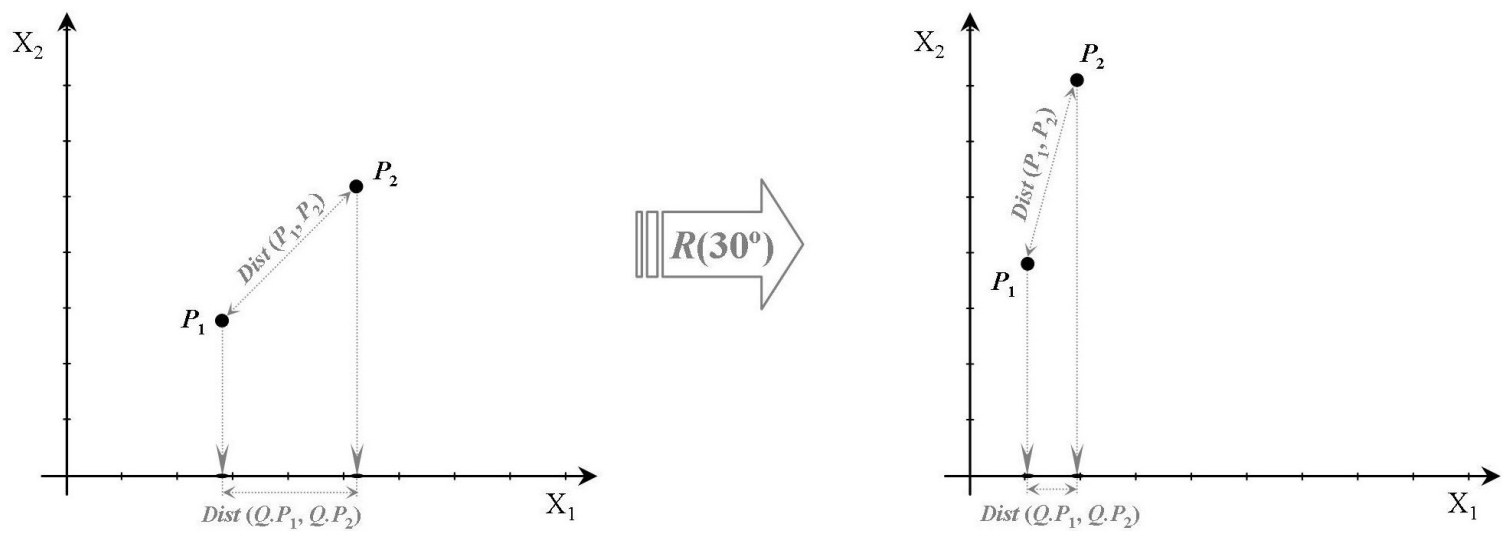

Figura 3.2: Propriedade da roto-projeção no espaço e subespaço de projeção.

\subsection{Princípios da roto-projeção otimizada}

A projeção em subespaço já é bastante conhecida e utilizada em ML, DM e na construção de ensembles. O RSM (HO, 1998), por exemplo, explora a diversidade combinatória de subespaços de projeção para provocar diversidade de predição entre seus MCs. A PCA também é uma técnica projetiva que modifica a base original visando a representação dos dados em dimensão reduzida. As projeções aleatórias (FRADKIN; MADIGAN, 2003) e o EM de Schclar e Rokach (SCHCLAR; ROKACH, 2009), nelas baseado, também buscam usufruir das características peculiares à redução de dimensionalidade. A redução de dimensionalidade apresenta vantagens como (TAN; STEINBACH; KUMAR, 2005; ALPAYDIN, 2010): 
1. Redução de complexidade de indução: na maior parte das SLTs, a complexidade computacional de indução do modelo é fortemente dependente da dimensão e do número de instâncias de treinamento. Reduzir a dimensionalidade implica em aumentar o desempenho do processo de indução do modelo;

2. Minimização do custo de aquisição e de armazenamento: se um subconjunto de atributos é julgado desnecessário para uma determinada tarefa, menor será o custo para sua aquisição/extração, assim como do espaço demandado para seu armazenamento;

3. Compreensibilidade: poucos atributos podem facilitar a extração de conhecimento;

4. Visualização: dados representados em poucas dimensões, sem perda de informação, podem ser analisados visualmente;

5. Complexidade do modelo: modelos com menores complexidades podem ser obtidos de espaços de dimensões reduzidas. Modelos mais simples geralmente apresentam menor variância;

6. Aumento da acurácia: a redução do efeito da maldição da dimensionalidade ${ }^{4}$ pode levar à indução de modelos mais acurados.

Indubitavelmente, a projeção em subespaço é um artifício de redução de dimensionalidade que pode contribuir sobremaneira para o aumento de acurácia e/ou redução de complexidade do modelo posteriormente induzido. Contudo, encontrar um subespaço adequado do espaço $n$-dimensional não é uma tarefa computacionalmente fácil, pois requer a otimização combinatorial de $2^{n}-1$ subespaços possíveis. Esse é um tema de ML conhecido como seleção de subconjunto de atributos (BLUM; LANGLEY, 1997), também explorado no aprendizado de ensemble (OPITZ, 1999; TSYMBAL; PUURONEN; PATTERSON, 2003; TSYMBAL; PECHENIZKIY; CUNNINGHAM, 2005).

No enfoque deste trabalho a projeção é computacionalmente simples, complexidade de ordem $O(d)$, pois requer somente a seleção dos $d$ primeiros atributos dentre $n$ do espaço original. Especificamente, a projeção é $O(d)=\Omega(d)$, uma vez que seu propósito na transformação de ORP não é dispor de uma combinação adequada de atributos, mas apenas de uma dimensão do subespaço, $d$, adequada para projeção das instâncias rotacionadas.

O objetivo da extração baseada na otimização da transformação concatenada de roto-projeção é rearranjar as instâncias em prol de uma SLT. Em problemas de classificação significa encontrar uma disposição das instâncias, no espaço ou no subespaço,

\footnotetext{
${ }^{4} \mathrm{~A}$ esparcidade dos dados em dimensões muito grandes faz com que os algoritmos induzam modelos de baixa acurácia.
} 
com conformações de separabilidade das classes que possam beneficiar uma SLT específica, de acordo com seu princípio de concepção. Similarmente, em problemas de regressão significa encontrar um arranjo de ordenamento das instâncias apropriado para a SLT escolhida. As expectativas sobre a ORP em conjunção a uma SLT estão resumidas em três pilares fundamentais, porém não mutuamente exclusivos:

1. Redução da complexidade dos dados e do modelo: a redução de dimensionalidade por meio de projeção em um subespaço de dimensão adequada, por si só, deve contribuir para redução da complexidade dos dados e, conseqüentemente, do modelo posteriormente induzido. Contudo, a otimização da rotação, concatenada ou não à projeção, também deve contribuir para encontrar direções que representem combinações lineares dos atributos originais capazes de viabilizar a indução de modelos mais simples e robustos;

2. Adaptabilidade quanto à técnica: algumas SLTs não são sensíveis à rotação das instâncias no espaço como, por exemplo, o kNN. Com isso, um desempenho insatisfatório no espaço original pode acarretar na decisão de exclusão dessa SLT do rol de candidatas à modelagem do problema. Nesse caso, a projeção em um subespaço de menor dimensão pode promover adaptabilidade à uma SLT insensível à rotação;

3. Aumento do desempenho: o aumento da acurácia dos modelos preditivos quando associados às técnicas de extração de características é, geralmente, a expectativa mais provável na modelagem supervisionada. A redução da complexidade ou mesmo da dimensionalidade devem culminar com a melhoria do desempenho do modelo.

Para elucidar os mecanismos de como as instâncias podem ser rearranjadas em prol da SLT na redução da complexidade, aumento de acurácia e/ou adaptabilidade, considerar-se-á um conjunto de dados artificiais com rótulos de classes dispostos como apresentado no gráfico da Figura 3.3 para modelagem de classificação. Adicionalmente, um segundo conjunto de dados artificiais, apresentado na Figura 3.4, para modelagem de regressão.

Os pontos em preto na Figura 3.3 correspondem aos exemplares da classe 1 e os pontos em vermelho às instâncias da classe 2. Note que parece haver formação de agrupamentos dispersos no espaço, especialmente das instâncias da classe 1. Por outro lado, não parece existir uma coesão entre grupos de uma mesma classe, especialmente para a classe 2.

Na tarefa de regressão (Figura 3.4), o valor em vermelho próximo a cada quadrado em preto corresponde ao valor da variável dependente. Note que parte das instâncias estão um pouco mais correlacionadas com as coordenadas de $\mathrm{x}_{1}$, porém 


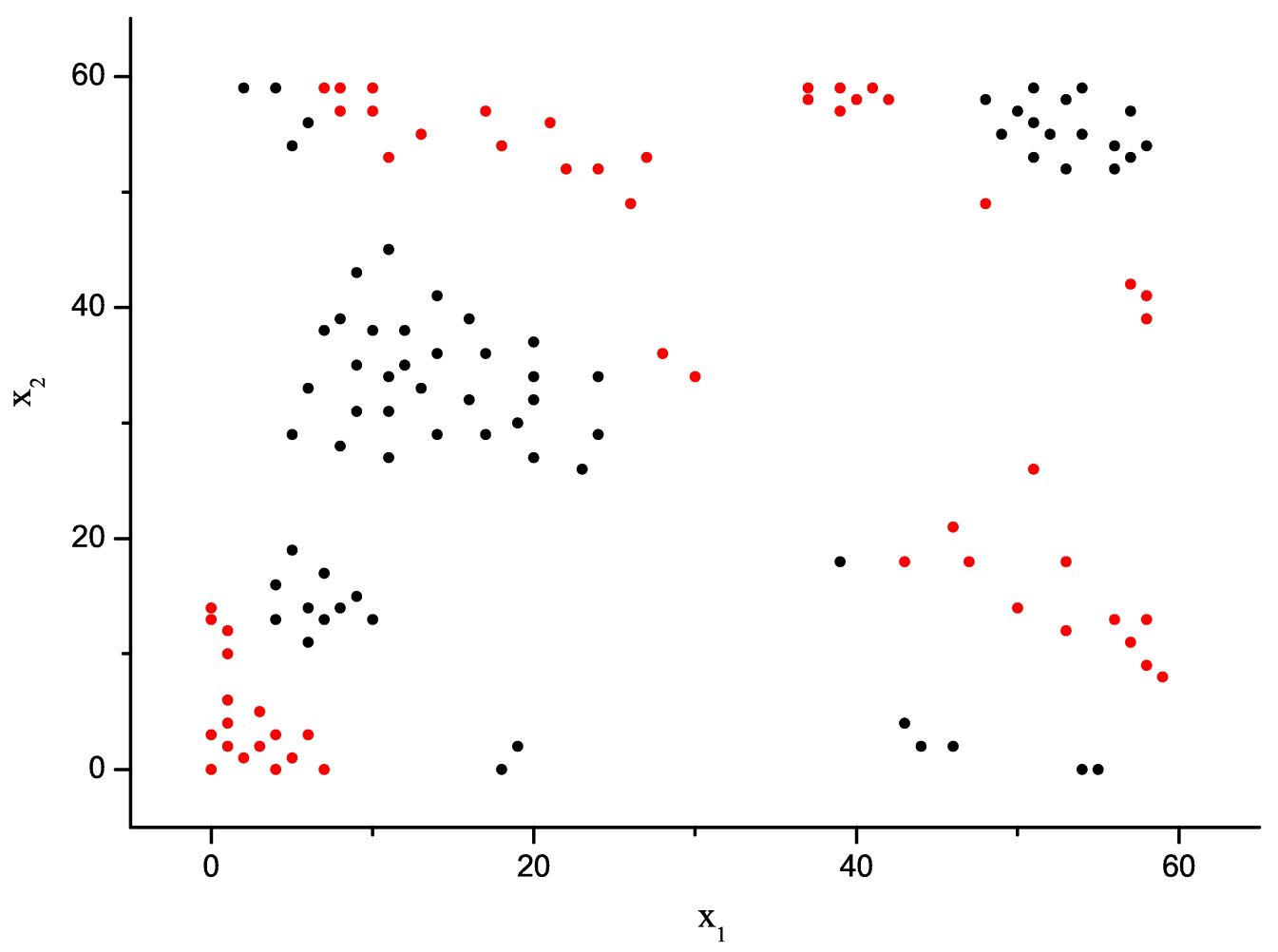

Figura 3.3: Dados artificiais para modelagem de classificação.

sem uma ordem bem estabelecida. Por outro lado, as coordenadas das instâncias em $\mathrm{x}_{2}$ não apresentam um arranjo de ordem visualmente correlacionado com a variável dependente. Assim, em ambas as tarefas o sucesso da modelagem preditiva depende, exclusivamente, das características da SLT adotada para indução do modelo. Nas subseções seguintes, ambos os problemas de predição são modelados utilizando SLTs tradicionais para evidenciar o efeito promissor da ORP no contexto de ML.

\subsubsection{Modelagem de classificação utilizando árvore de decisão}

Os algoritmos clássicos para indução de árvores de decisão realizam particionamentos do espaço por meio de hiperplanos ortogonais aos eixos dos atributos. A cada passo, uma função de avaliação determina qual atributo tem maior capacidade de discriminação das classes. Com base no atributo escolhido, o conjunto de treinamento é particionado e o processo repetido até que nenhuma discriminação adicional seja possível. Esse tipo de abordagem é utilizada pelo algoritmo C4.5 (QUINLAN, 1993). É intrínseco ao C4.5 também, assim como em outros, um procedimento de poda para evitar uma árvore super ajustada (overfitting do modelo).

A complexidade da árvore induzida está diretamente ligada à conformação espacial das instâncias. Problemas linearmente separáveis, porém apenas por hiperplanos oblíquos, fazem com que algoritmos como o C4.5 busquem uma aproximação da 


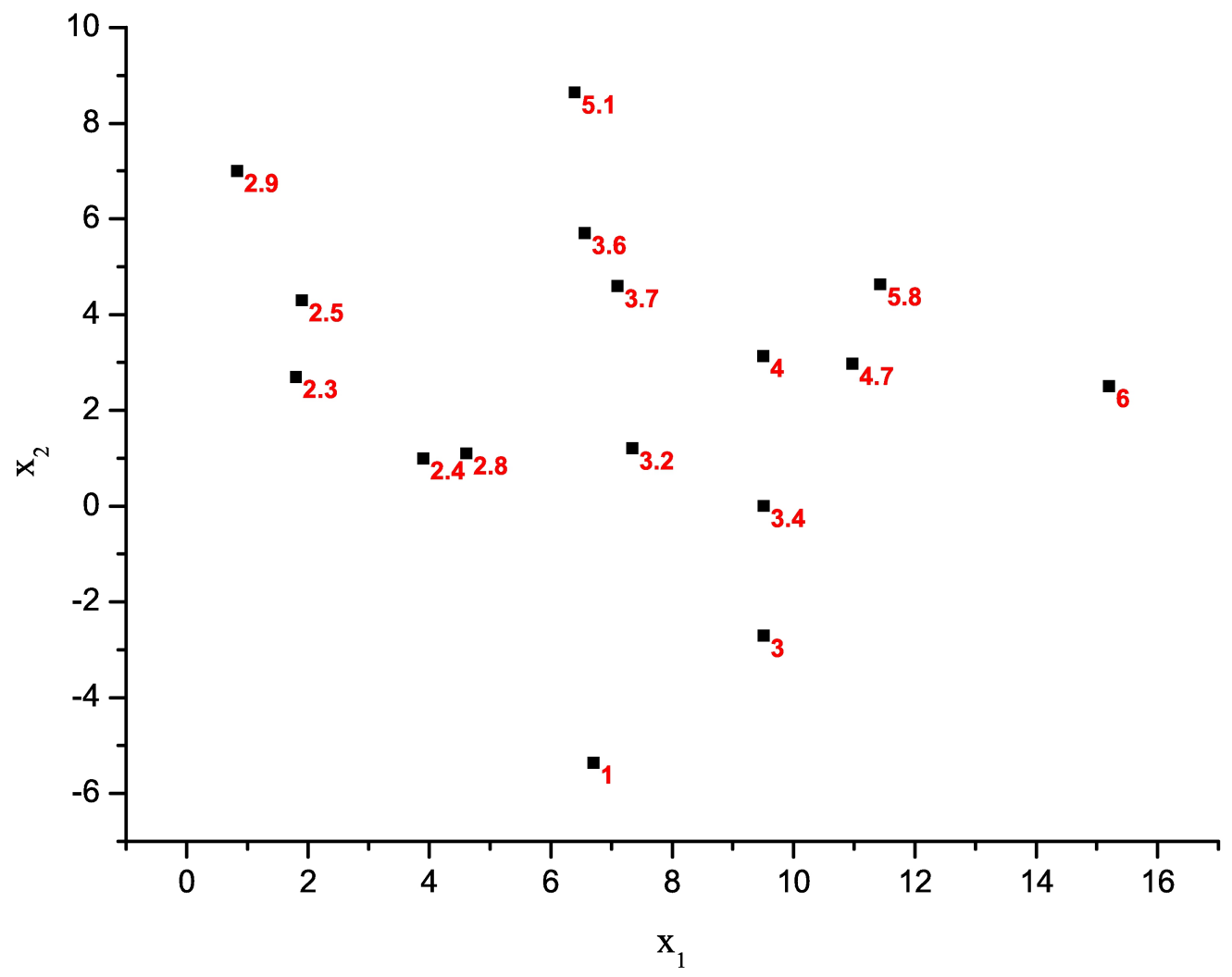

Figura 3.4: Dados artificiais para modelagem de regressão.

fronteira de decisão por uma série de particionamentos ortogonais mais complexos. Modelos mais complexos tendem a apresentar baixo desempenho de generalização.

Duas métricas razoáveis para estimar a complexidade da árvore induzida são: número de folhas (NF) e o tamanho da árvore (TA), sendo essa última o NF somado ao total de nós da árvore. A árvore podada induzida pelo algoritmo C4.5 (J48, implementação do Weka com configuração padrão) com os dados apresentados na Figura 3.3 é ilustrada na Figura 3.5. Os valores apresentados nas folhas (entre parênteses) indicam o número de acertos/erros daquele particionamento e nos nós internos estão os atributos escolhidos para decisão. A árvore induzida e podada do conjunto original tem $\mathrm{NF}=11$ e $\mathrm{TA}=21$. Na Figura 3.6 é representado o particionamento do espaço produzido por essa árvore de decisão. A maioria das instâncias foi coberta por todas as partições produzidas pela árvore podada, apresentando uma instância incorretamente classificada.

Suponha agora que uma transformação de rotação em torno da origem dos eixos $\mathrm{x}_{1}$ e $\mathrm{x}_{2}$, no sentido horário, por um ângulo $\theta^{*}$ ( $\theta$ ótimo), rearranje os dados no espaço conforme apresentado na Figura 3.7. Com essa nova disposição das instâncias no espaço, o particionamento perpendicular a $\mathrm{x}_{1}$ (por limiares) fica simplificado. Assim, apenas a rotação dos pontos no espaço é suficiente para beneficiar o C4.5 na indução de uma nova árvore, menos complexa e mais acurada. O resultado do novo 


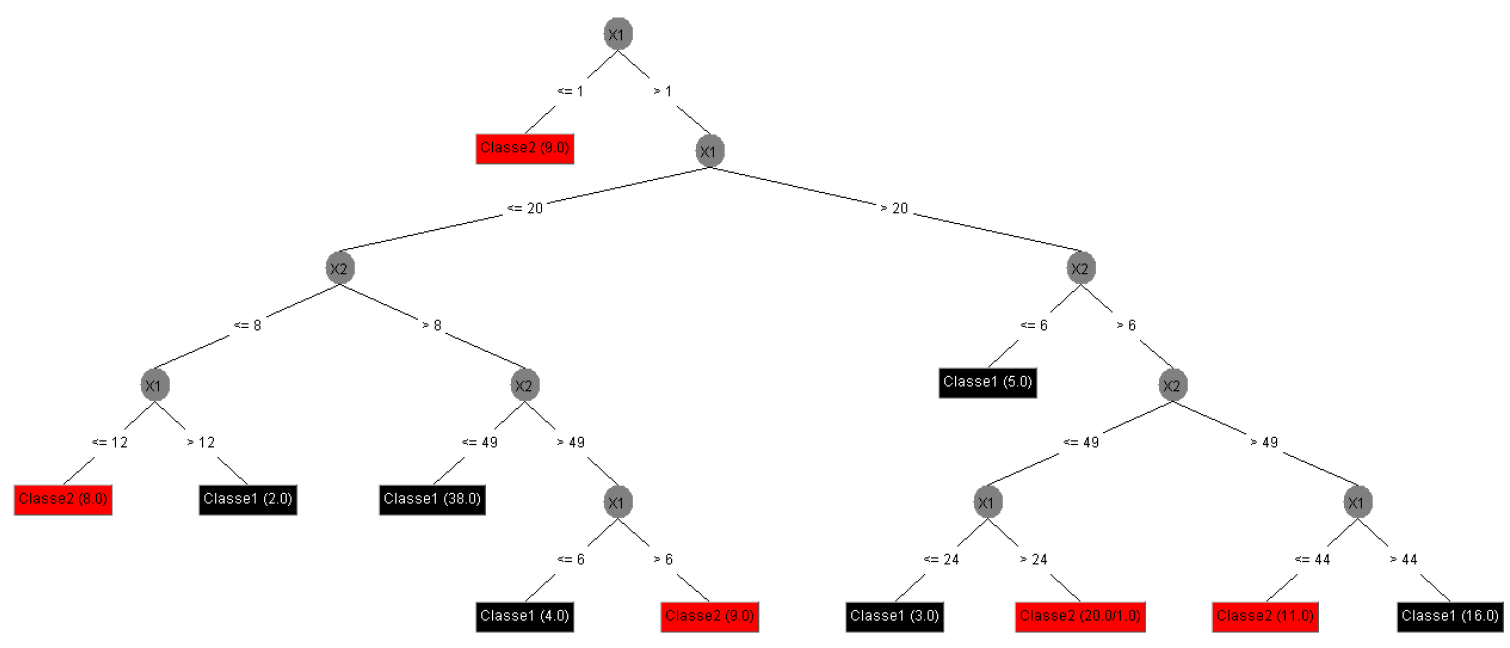

Figura 3.5: Árvore induzida pelo C4.5 (J48) com os dados artificiais.

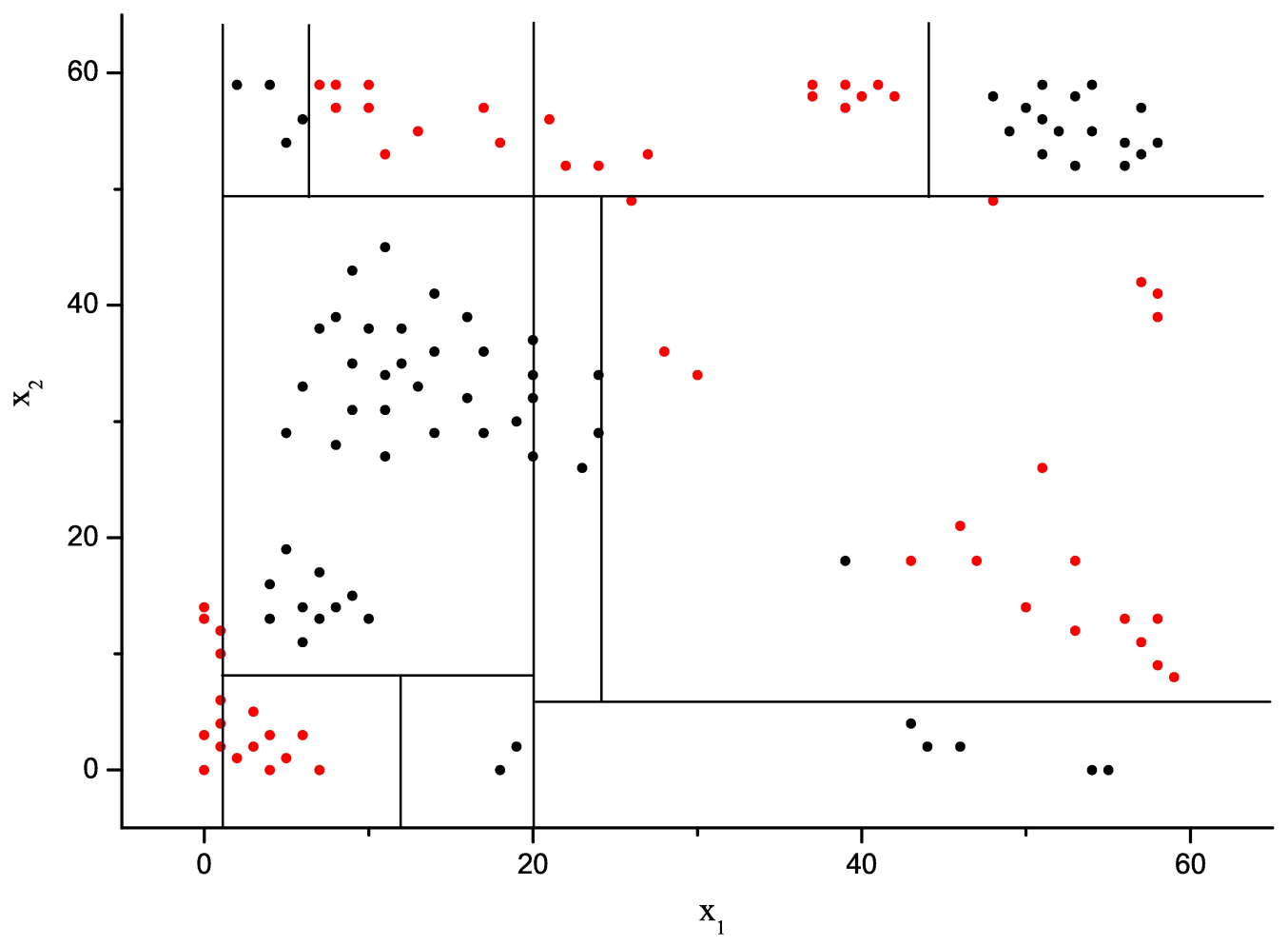

Figura 3.6: Particionamento do espaço - C4.5 (J48).

particionamento no espaço pode ser observado na Figura 3.8. A árvore de decisão podada responsável por esse particionamento dos dados rotacionados é apresentada na Figura 3.9. Observa-se que, a árvore induzida das instâncias rotacionadas é consideravelmente mais simples (modelo de menor complexidade) do que a induzida dos dados originais, com $\mathrm{NF}=4$ e $\mathrm{TA}=7$; outrossim, cada folha cobre apenas instâncias de uma mesma classe, sem erros decorrentes da poda. 


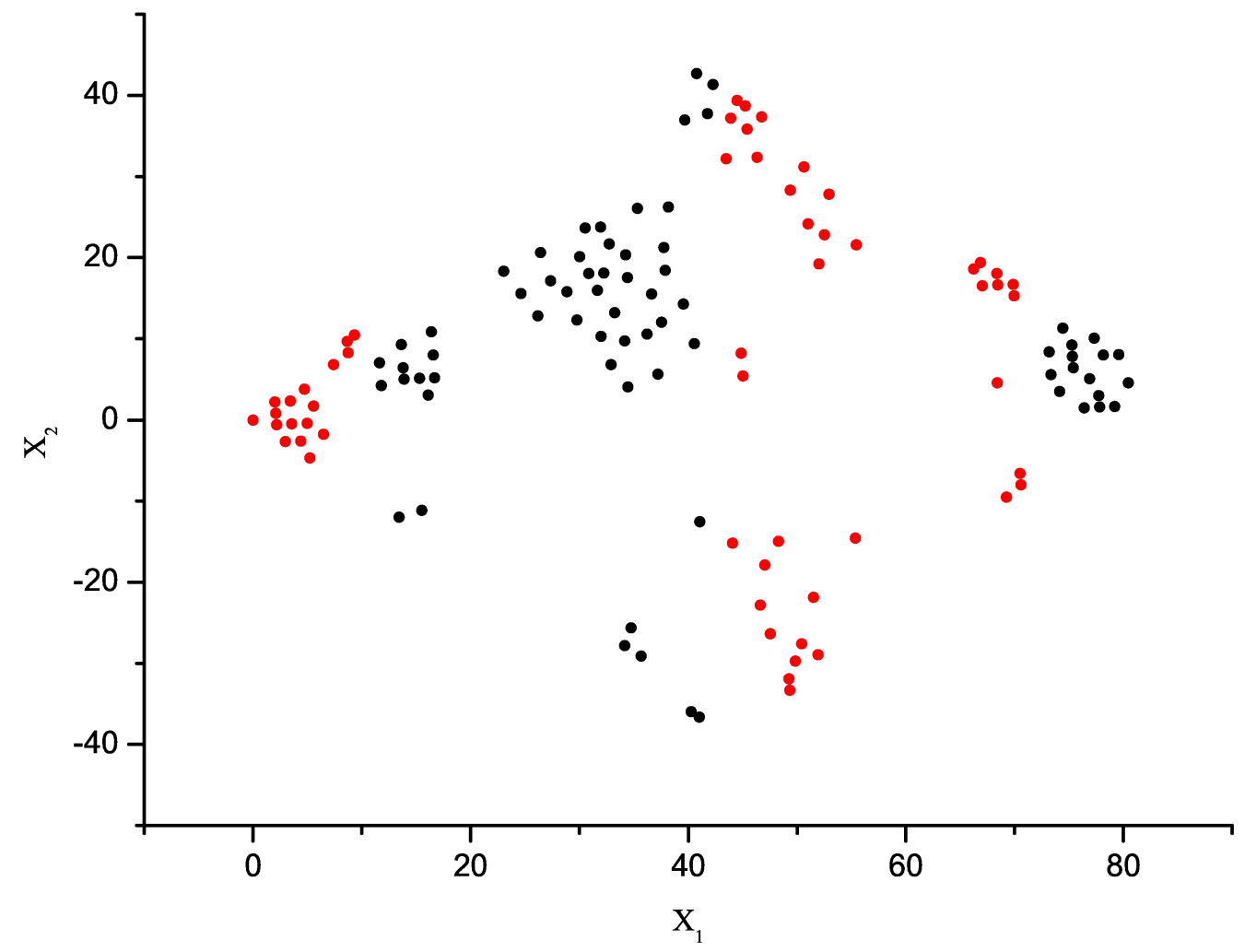

Figura 3.7: Dados de classificação rotacionados em prol do C4.5 (J48).

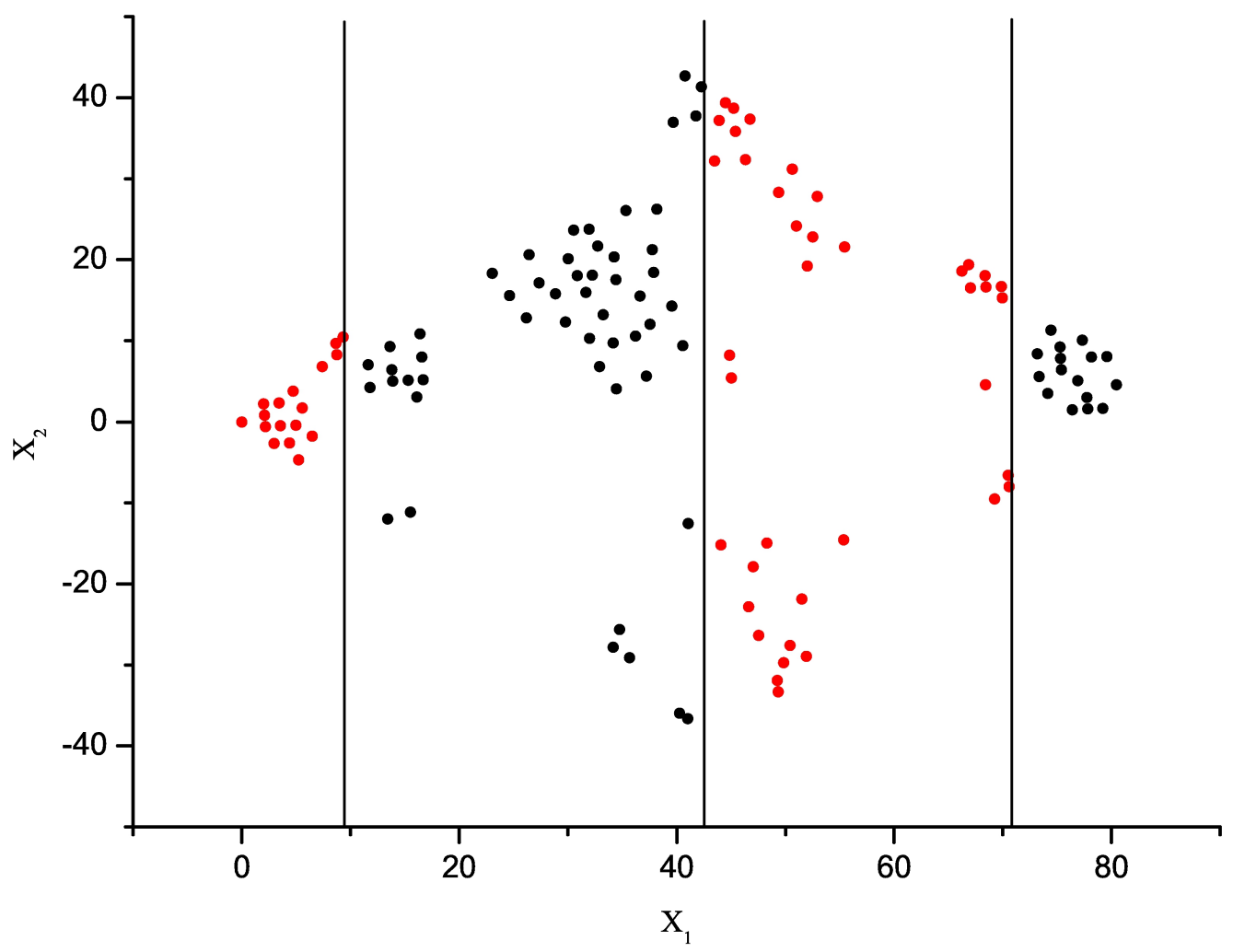

Figura 3.8: Particionamento produzido pelo C4.5 (J48) nos dados rotacionados. 


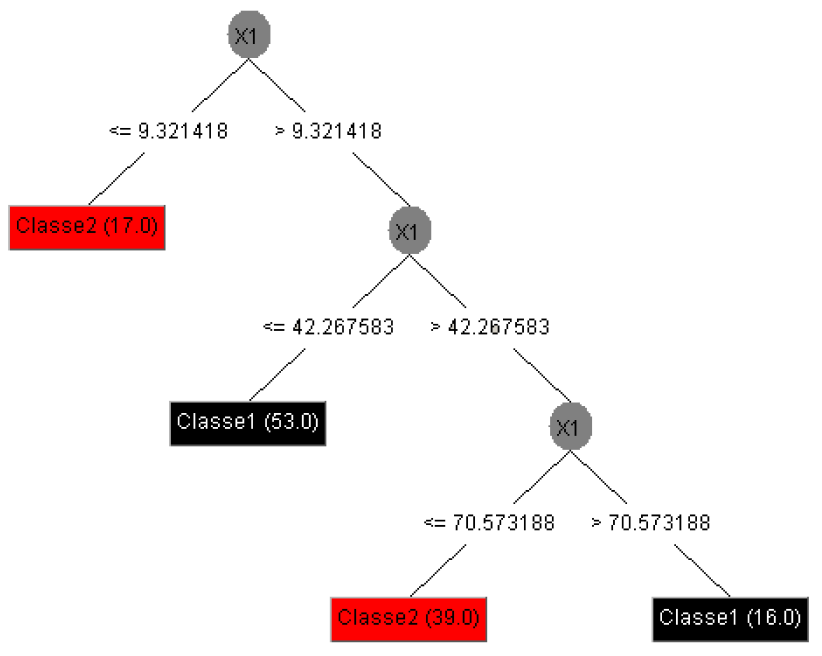

Figura 3.9: Árvore de decisão induzida dos dados rotacionados.

\subsubsection{Modelagem de classificação utilizando o kNN}

O algoritmo dos $k$ vizinhos mais próximos (kNN) é uma SLT simples que se baseia na proximidade dos vizinhos para produzir a classificação de instâncias. Tipicamente, a classe de uma instância desconhecida é obtida pelo voto da maioria de seus $k$ vizinhos mais próximos. O sucesso do $\mathrm{kNN}$ depende fortemente do arranjo espacial das instâncias do problema bem como de uma adequada definição de $k$. O parâmetro $k$ é determinante na complexidade do modelo induzido. Um alto valor de $k$ tem tendência para gerar fronteiras de decisão mais simples, o número das regiões isoladas torna-se menor e "cantos vivos" tendem a ser suavizados (ANDERSSON; DAVIDSSON; LINDéN, 1998). Em outras palavras, quanto maior o $k$, menor a complexidade do modelo.

Na modelagem utilizando árvore de decisão (Subseção 3.4.1), apenas a rotação das instâncias no espaço foi suficiente para simplificar o problema e o modelo de classificação. Todavia, essa transformação não provoca alterações no desempenho do kNN, uma vez que a rotação não modifica as relações e as distâncias entre as instâncias. Nesse caso, a projeção pode ser benéfica se rearranjar os pontos aproximando instâncias da mesma classe. Na rotação apresentada na Figura 3.7 é possível observar que a projeção dos dados no eixo $\mathrm{x}_{1}$ é suficiente para aproximar todas as instâncias da mesma classe e reduzir a complexidade dos dados no subespaço. Tal transformação beneficia o desempenho do kNN uma vez que aumenta a densidade de vizinhos da mesma classe no subespaço e minimiza a probabilidade de erro na fronteira de decisão. Na Figura 3.10 é apresentado o conjunto de dados artificiais rotacionado (da Figura 3.7) e projetado no subespaço $\mathrm{x}_{1}$. A transformação de roto-projeção dos dados visualizada no novo arranjo das instâncias em $x_{1}$ (Figura 3.10) também é benéfica 
para o aumento do desempenho de diversas outras SLTs, incluindo o próprio C4.5.

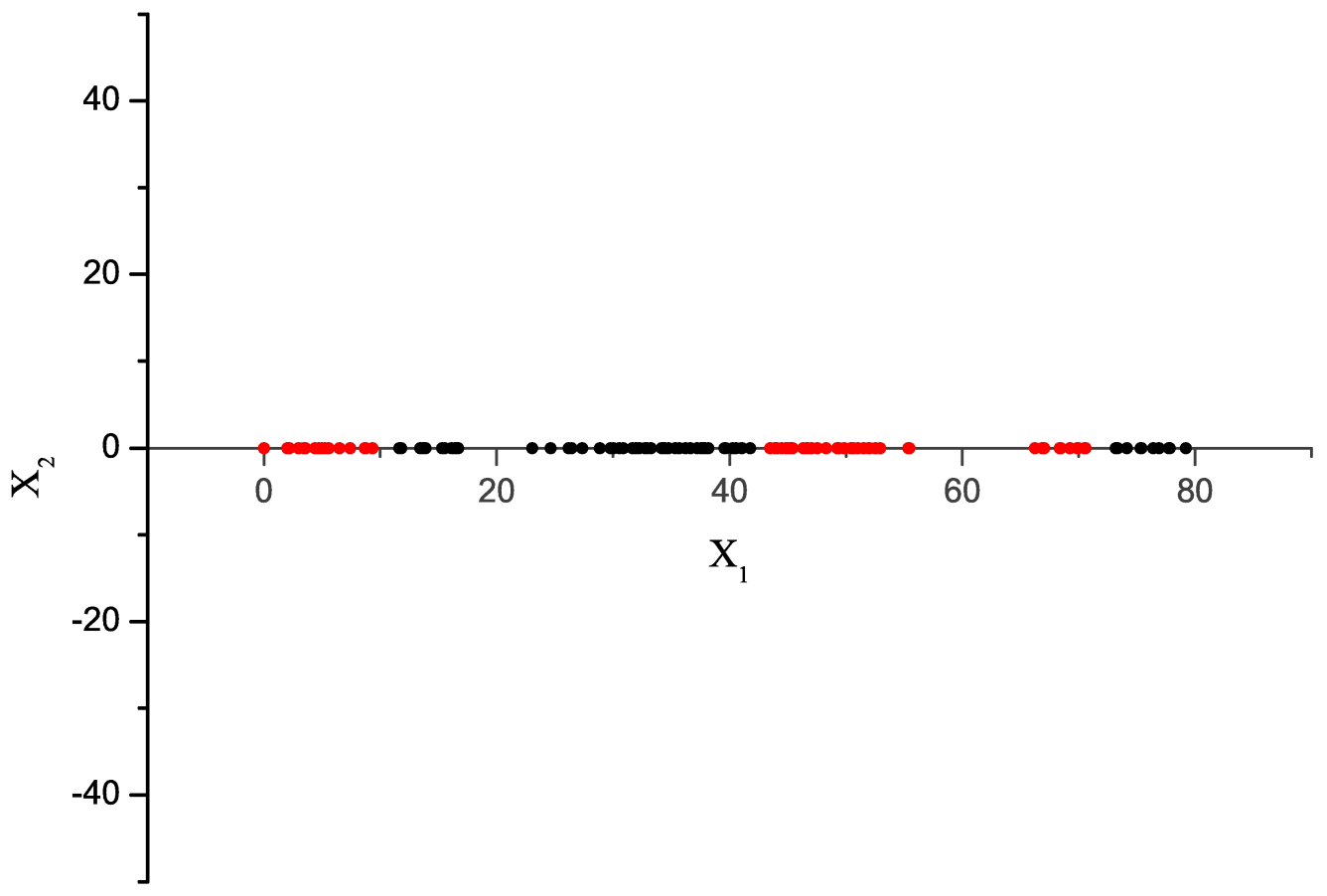

Figura 3.10: Dados de classificação rotacionados e projetados em prol do kNN.

\subsubsection{Modelagem de regressão utilizando o kNN}

O kNN também pode ser utilizado para regressão pela simples atribuição da média dos valores dos seus $k$-vizinhos mais próximos à variável dependente da nova instância. Pode ser útil também ponderar as contribuições dos vizinhos de modo que os mais próximos contribuam mais para a média do que os mais distantes. Um esquema de ponderação comum é atribuir um peso de um menos a distância Euclidiana para cada vizinho, considerando atributos normalizados. Esse esquema garante que vizinhos mais distantes terão menores interferências na estimativa do valor da variável dependente da nova instância.

Na modelagem do problema de regressão apresentado no gráfico da Figura 3.4, o kNN pode produzir estimativas menos precisas, pois o arranjo dos pontos no espaço bidimensional não é completamente favorável à estimativa por vizinhos mais próximos. Por exemplo, a instância cujo valor da variável dependente é igual a 1 tem como vizinhos mais próximos os pontos 3, 3,4 e 3,2. Nesse arranjo espacial, estimar o valor da referida instância utilizando a média aritmética $(k=3)$ provocaria um erro relativo superior a 300\%. Mais uma vez, uma ORP pode melhorar o arranjo das instâncias para que os pontos se apresentem com alguma ordem que minimize o erro da estimativa do modelo induzido. 
Similarmente à roto-projeção para classificação, o kNN pode se beneficiar de uma rotação por um ângulo $\theta^{*}$, sentido horário, seguida por uma projeção no subespaço $\mathrm{x}_{1}$, que promova a redução da complexidade dos dados por meio do ordenamento por proximidade. Na Figura 3.11 é apresentada uma direção de rotação, com a ilustração dos raios de projeção (setas em cinza), que minimiza o erro de predição no subespaço $\mathrm{x}_{1}$ utilizando o $\mathrm{kNN}$.

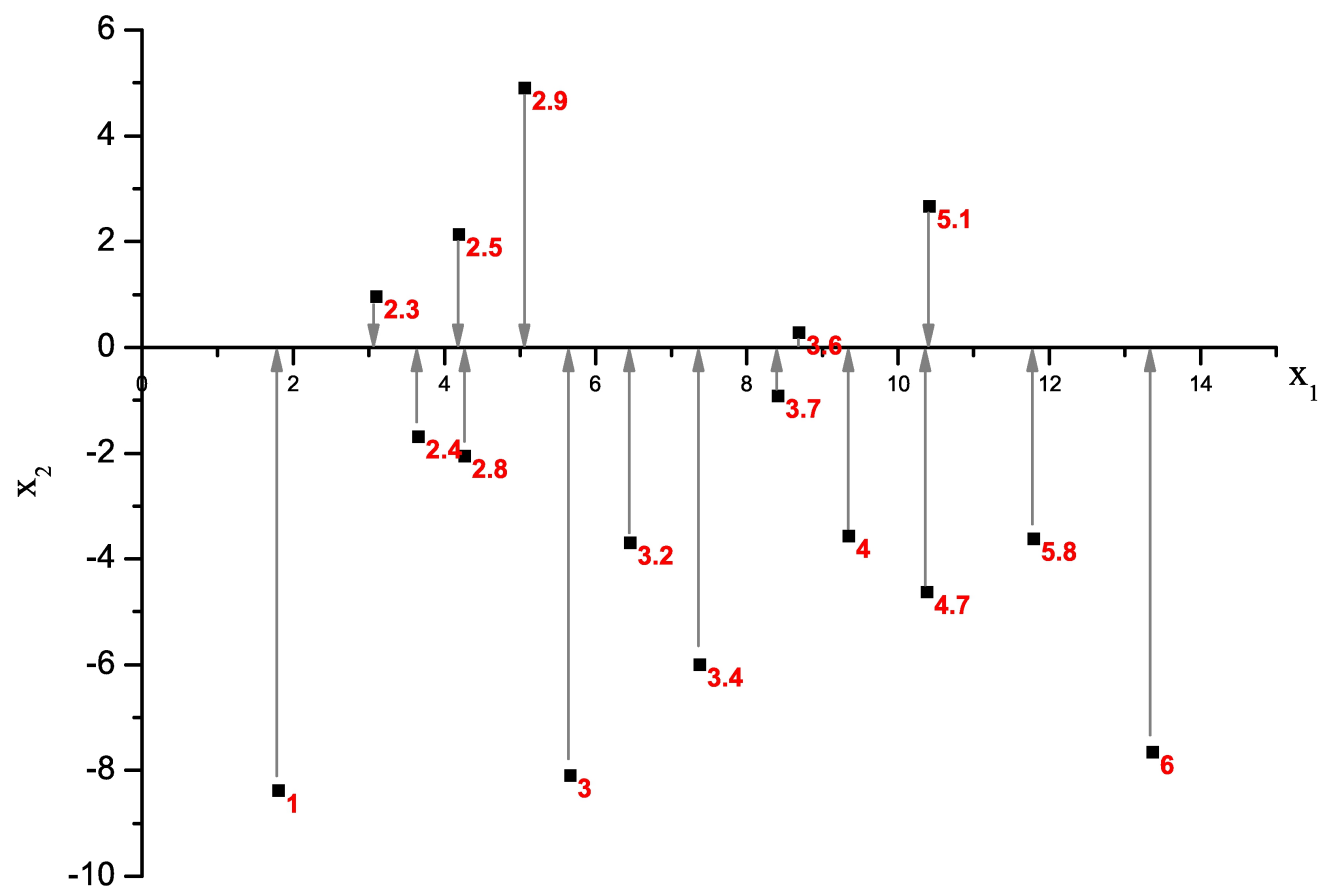

Figura 3.11: Dados de regressão rotacionados e ilustração da projeção em prol do $\mathrm{kNN}$.

Observando os raios de projeção na Figura 3.11, é possível notar que no subespaço $\mathrm{x}_{1}$ as instâncias apresentam um ordenamento por proximidade de maior coerência do que no espaço original. A instância de valor 1, por exemplo, está mais próxima das instâncias de valores imediatamente superiores. Dessa forma, o kNN tende a apresentar menores erros de predição de treinamento e de validação para qualquer $k$.

Na Figura 3.12 é apresentado o gráfico dos valores reais versus preditos que permite comparar o desempenho do $\mathrm{kNN}$, para $k=3(3 \mathrm{NN})$, no espaço original e no subespaço da transformação da ORP utilizando o erro no próprio conjunto de dados (erro de treinamento). A linha diagonal no gráfico tem por objetivo guiar os olhos na interpretação do gráfico. Maior dispersão é observada para predições do 3NN nos dados originais para toda a faixa da variável dependente, o que demonstra que uma roto-projeção adequada tem potencial para minimizar o erro médio e/ou a variância das predições. 


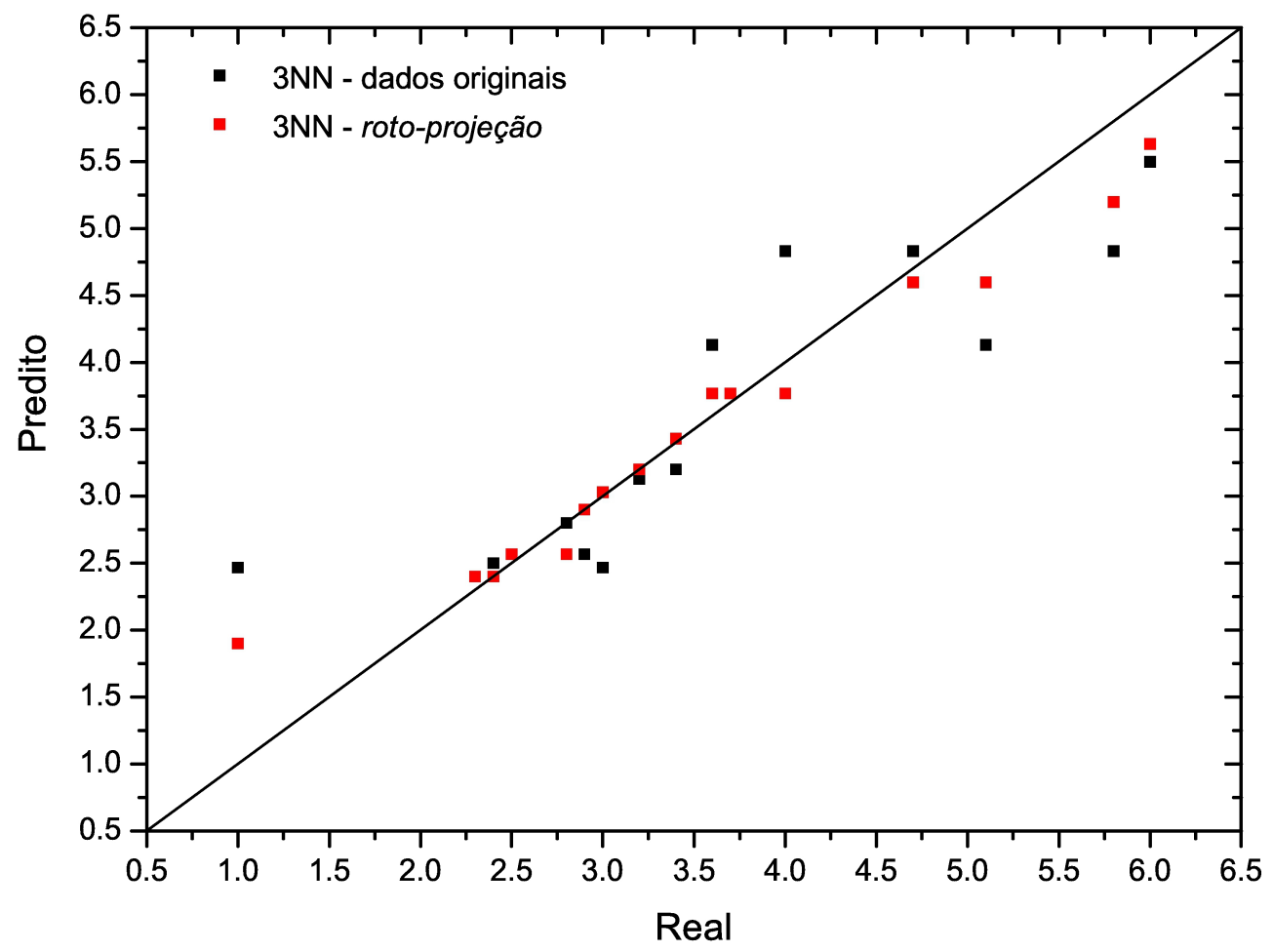

Figura 3.12: Predições do 3NN com e sem ORP.

\subsubsection{Modelagem de predição utilizando regressão linear}

A natureza da relação entre duas variáveis pode assumir inúmeras formas, abrangendo desde funções matemáticas simples até funções extremamente complexas. A relação mais simples e direta é a relação linear. Um modelo de regressão linear simples busca capturar essa relação linear entre a variável independente e a variável dependente.

Alguns problemas multivariados podem ser simplesmente resolvidos pelo ajuste de uma regressão linear utilizando apenas uma de suas variáveis independentes. Ferramentas como o Weka (HALL et al., 2009), por exemplo, permitem que um modelo de regressão linear simples seja ajustado para cada atributo do conjunto de dados. Nesse caso, o atributo que apresenta menor erro residual é eleito representante da base de dados na solução do problema de regressão.

Para a base artificialmente criada da Figura 3.4, conforme mencionado anteriormente, as coordenadas das instâncias em $\mathrm{x}_{1}$ apresentam maior correlação com os valores assumidos pela variável dependente. Tomando apenas $\mathrm{x}_{1}$ como representante do conjunto de dados para solução do problema de regressão, obtêm-se o modelo linear apresentado na Figura 3.13. Nesse modelo, o erro residual do ajuste é visivelmente alto. Embora exista uma correlação direta, expressa por um coeficiente $r$ de 0,7 , a alta dispersão dos pontos em relação à reta de ajuste (em vermelho) é um forte 
indicativo de que o modelo tem pouca utilidade prática.

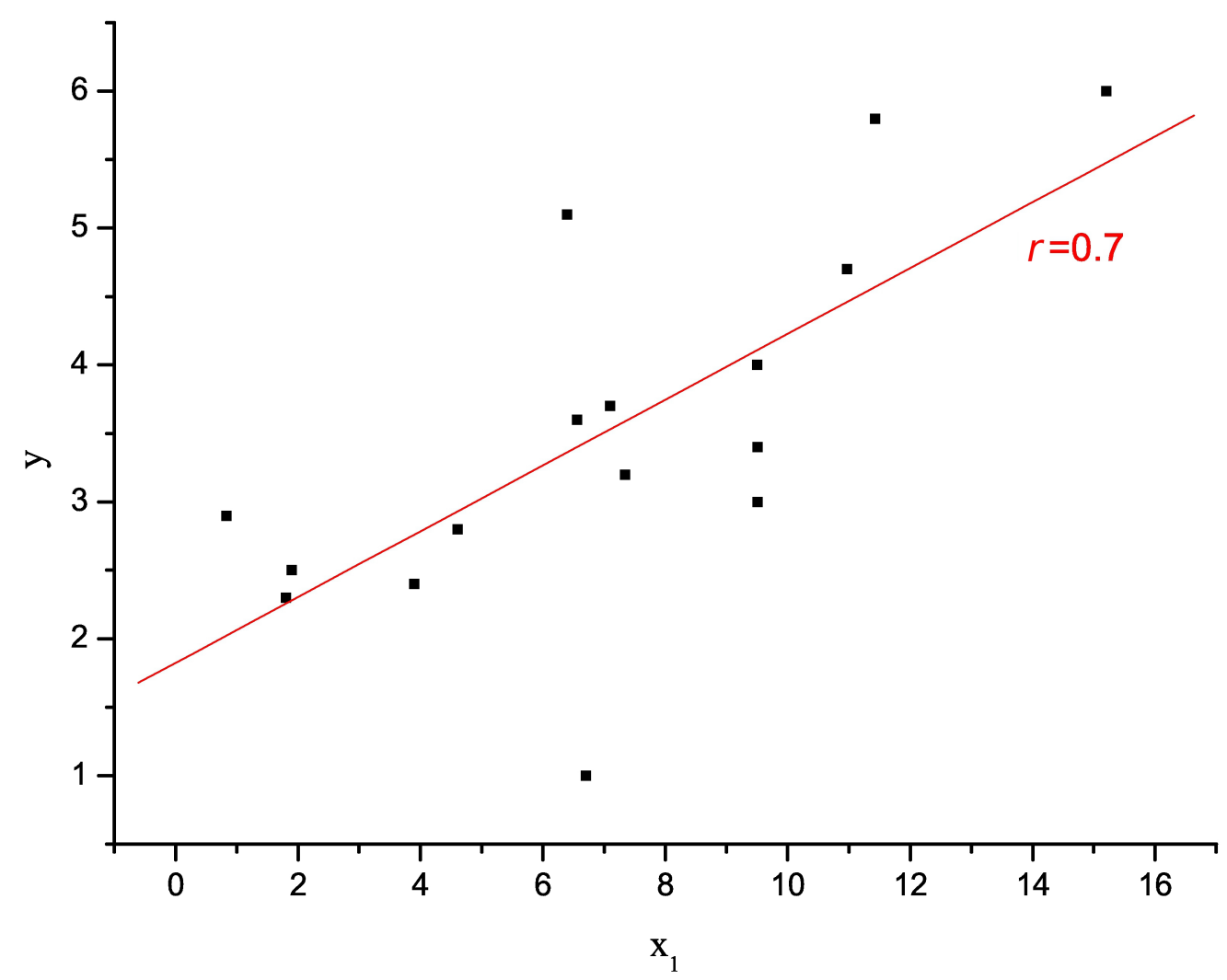

Figura 3.13: Regressão linear simples utilizando a variável independente $\mathrm{x}_{1}$.

Nesse tipo de modelagem linear, a roto-projeção tem o papel de prover uma combinação linear apropriada, projetada ou não em subespaço, em prol do melhor ajuste do modelo, ou seja, que apresente menor erro residual e maior $r$. Assim, considere que o conjunto de dados para modelagem de regressão seja rotacionado por um ângulo $\theta^{*}$ e obtenha a direção apresentada na Figura 3.14.

Analogamente ao arranjo obtido na modelagem com kNN, a projeção das instâncias no subespaço $\mathrm{x}_{2}$ cria uma ordem inversamente proporcional à variável dependente, porém, tal direção contribui consideravelmente para o aumento da correlação linear. Assim, utilizando apenas $\mathrm{x}_{2}$, que representa a combinação linear de $\mathrm{x}_{1}$ e $\mathrm{x}_{2}$ antes da rotação, o modelo linear produzido é inversamente correlacionado, mas muito superior em poder de predição, conforme mostrado na Figura 3.15.

Comparando o modelo da Figura 3.13 ao modelo da Figura 3.15 é visivelmente notável que a rotação proporcionou um arranjo em $\mathrm{x}_{2}$ que reduz consideravelmente o erro residual do modelo (menor dispersão). A melhoria também é notável quando se compara os coeficientes de correlação linear de ajuste dos modelos. Para os dados rotacionados, o $r$ absoluto do ajuste obtido foi de aproximadamente 0,98 , valor expressivamente superior ao obtido com os dados sem qualquer transformação $(r=0,7)$. 


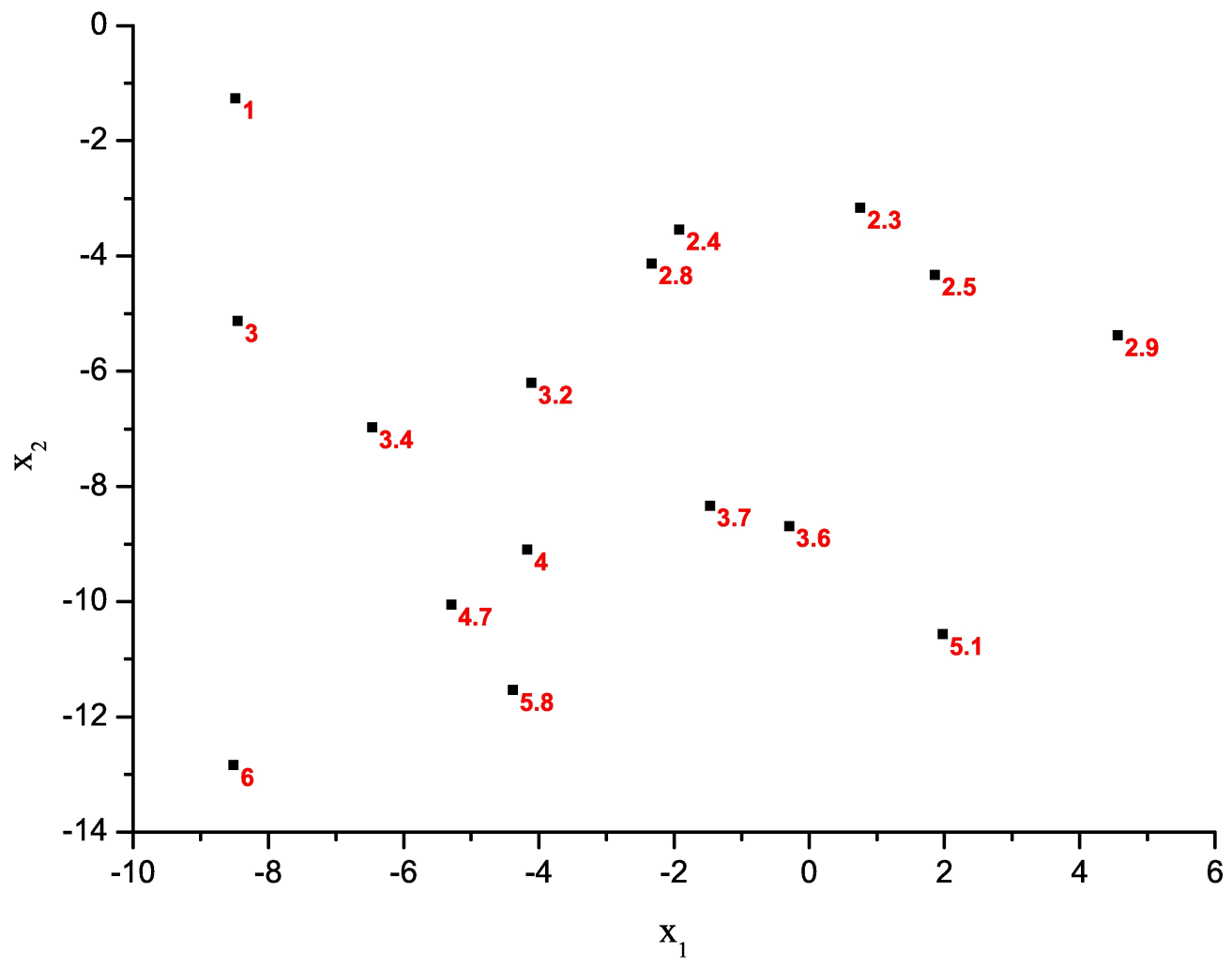

Figura 3.14: Dados de regressão rotacionados em prol da regressão linear.

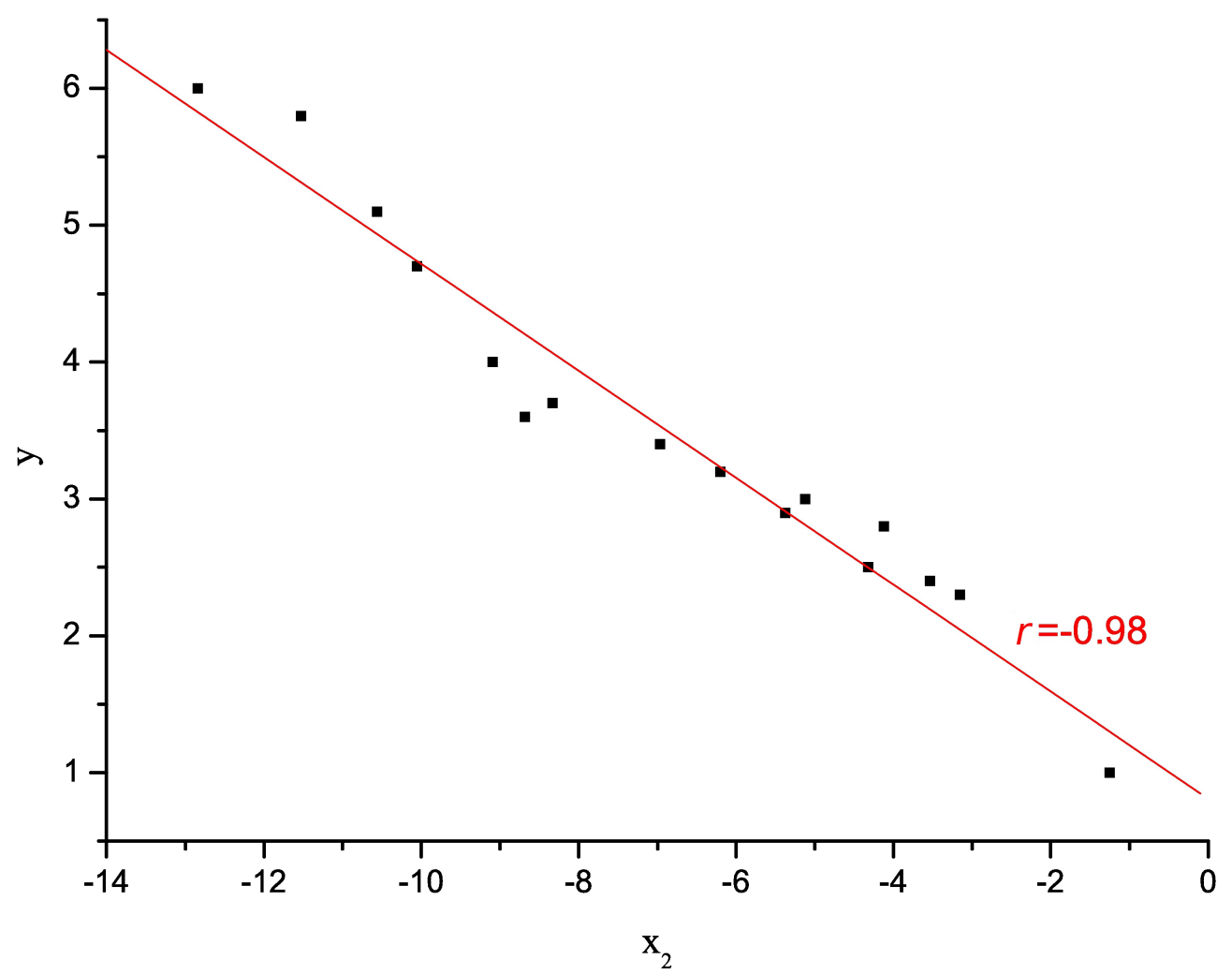

Figura 3.15: Regressão linear simples utilizando a variável $x_{2}$ após rotação. 


\subsubsection{Considerações sobre modelagem e roto-projeção otimizada}

A transformação de ORP apresenta potencial para conjunção à qualquer SLT, tanto em tarefas de classificação como de regressão. Os efeitos da roto-projeção nas modelagens preditivas, apresentadas nas seções anteriores, elucidam algumas das potencialidades no contexto de ML. A transformação deve proporcionar redução da complexidade dos dados em prol da SLT escolhida para posterior indução do modelo de predição. Isso torna possível a redução de complexidade do modelo, adaptabilidade quando a SLT é insensível à rotação e/ou aumento do desempenho de predição. Adicionalmente, as vantagens advindas desses princípios fundamentais entusiasmam o engajamento também no aprendizado de ensembles.

É esperado que cada SLT apresente uma "preferência" por uma direção de rotação e/ou por uma determinada dimensão para projeção no subespaço. Nas modelagens preditivas anteriores, o parâmetro $\theta$ da transformação de rotação e o subespaço $d$-dimensional foram propositalmente $\operatorname{ajustados}^{5}$ para viabilizar a maximização da acurácia do modelo induzido. Assim, otimizar os parâmetros angulares de $\Theta$ e a dimensão $d$ é uma tarefa para um algoritmo de otimização contínua. Porém, prover uma estimativa da qualidade da roto-projeção que seja capaz de guiar o algoritmo no processo de otimização em prol da SLT é algo que somente a própria SLT pode fazer. Esse é o diferencial da ORP frente à outras técnicas de extração de características supervisionadas encontradas na literatura. A otimização é dirigida pela mesma SLT posteriormente utilizada, estabelecendo o conceito de técnica diretora.

\subsection{Técnica diretora e aspectos da otimização}

Todas as expectativas sobre a ORP convergem para uma questão fundamental: como obter uma transformação de roto-projeção otimizada para a SLT adotada? A resposta para essa pergunta procede da analogia com a abordagem wrapper para seleção de atributos (KOHAVI; JOHN, 1997). Nessa abordagem, um subconjunto candidato de atributos é apresentado à SLT para indução de um modelo. O desempenho do modelo induzido é utilizado para estimar a qualidade do subconjunto. Novos subconjuntos de atributos são gerados, segundo alguma heurística de busca, até que algum critério de parada seja satisfeito. O melhor subconjunto é aquele que apresenta melhor estimativa de desempenho. Na Figura 3.16 é ilustrada a abordagem wrapper para seleção de atributos.

A principal desvantagem da abordagem wrapper é o custo computacional, pois

\footnotetext{
${ }^{5}$ Deveras, $\theta^{*}$ e a dimensão $d^{*}$ para cada modelagem preditiva dos exemplos foram obtidos com auxílio da técnica de extração ORP desenvolvida nesta tese.
} 


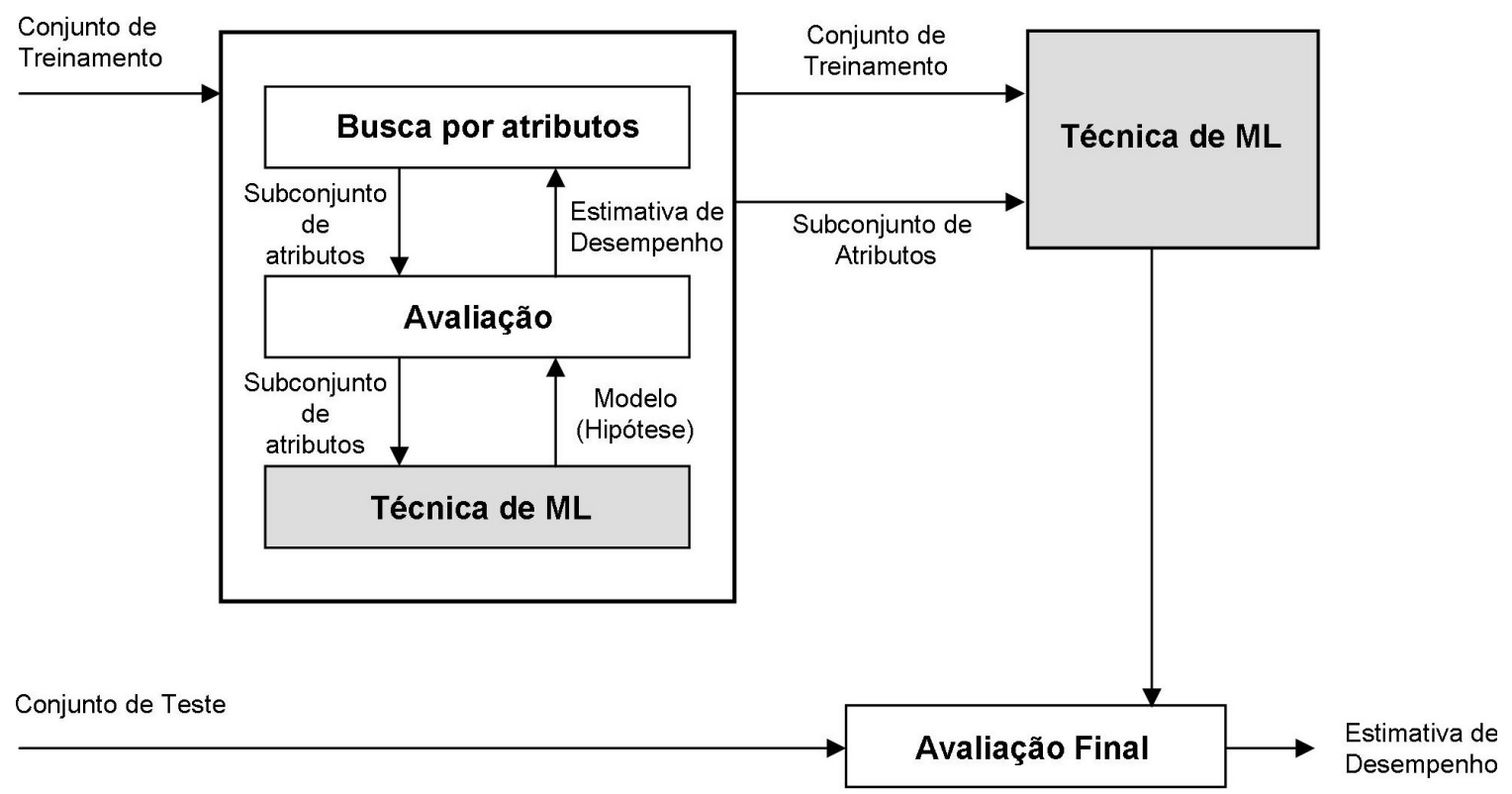

Figura 3.16: Abordagem wrapper para seleção de atributos (KOHAVI; JOHN, 1997).

para cada subconjunto é necessária a indução de um modelo e, posteriormente, uma estimativa de seu desempenho. Esse fator encarece computacionalmente todo o processo de busca pelo subconjunto adequado. Entretanto, a principal vantagem é que o subconjunto dos atributos selecionados é otimizado para o modelo final.

Analogamente à abordagem wrapper, para cada par formado pela matriz de ângulos $\Theta$ e dimensão $d$, ou seja $(\Theta, d)$, uma matriz de roto-projeção pode ser construída, conforme Equação 3.10, para transformar os dados de treinamento. Posteriormente, um modelo é induzido a partir dos dados transformados por $R P(\Theta, d)$ e seu desempenho estimado. Novos pares $(\Theta, d)$ são gerados por alguma estratégia de exploração do espaço de busca a fim de encontrar um par com melhor estimativa de desempenho do modelo. O processo de otimização de $(\Theta, d)$ é dirigido, portanto, pelo desempenho do modelo induzido pela SLT escolhida. A vantagem de uma SLT que guia o processo de otimização, similarmente à abordagem wrapper, é que os ângulos e o subespaço encontrados, $\left(\Theta^{*}, d^{*}\right)$, são otimizados para o mesmo tipo de SLT utilizada como diretora do processo. Assim, a abordagem para otimização da roto-projeção utilizando uma técnica diretora pode ser vista como uma adaptação da abordagem wrapper para seleção de atributos, como apresentado na Figura 3.17.

\subsubsection{Framework da otimização}

Solucionar um problema de otimização consiste em encontrar os argumentos adequados que maximizam ou minimizam a função que modela esse problema. A solução de um problema de otimização real requer, portanto, um modelo matemático 


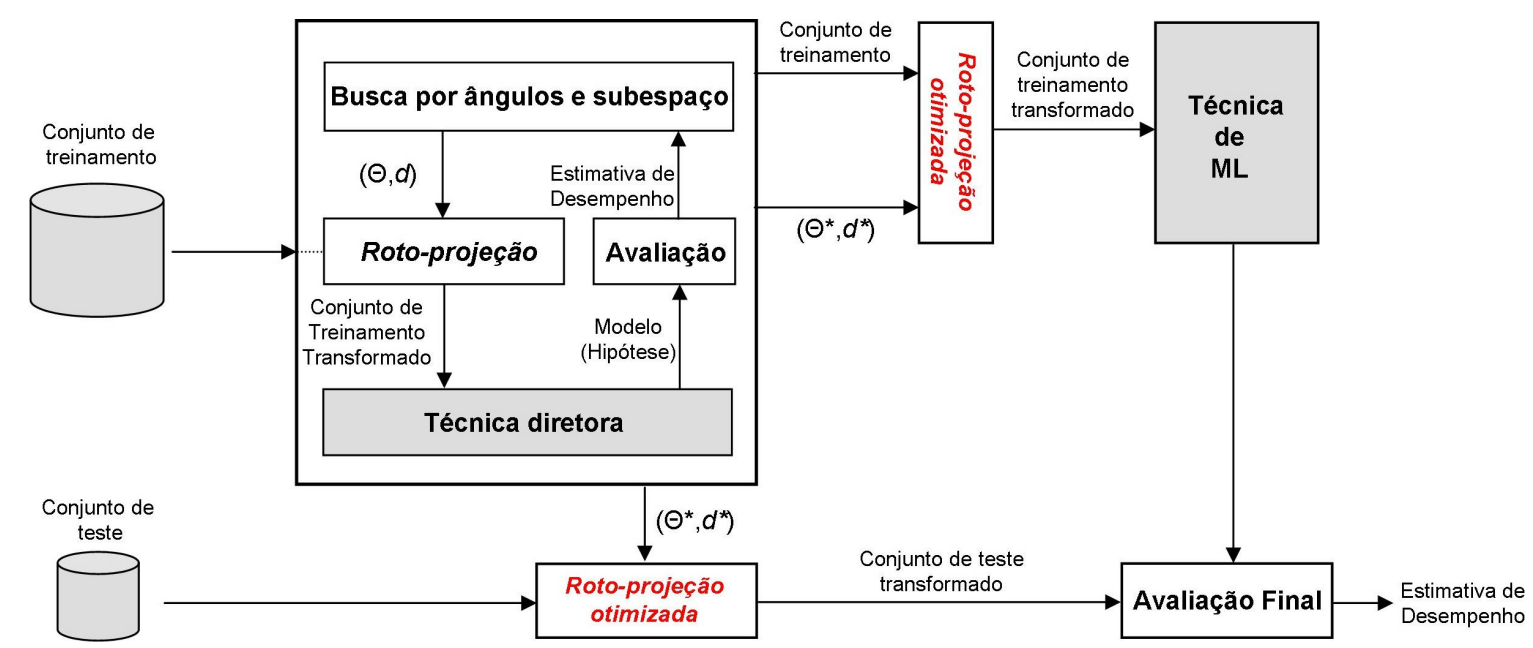

Figura 3.17: Abordagem para otimização da roto-projeção utilizando técnica diretora.

que represente o fenômeno em questão. A etapa de definição da função do problema é conhecida como modelagem para otimização. O modelo do problema é geralmente expresso como uma função matemática denominada função-objetivo. Um problema de otimização matemática é basicamente delineado por três componentes:

1. Função-objetivo: modela o fenômeno que se deseja otimizar;

2. Conjunto de variáveis: define o espaço de busca da solução ótima ou sub-ótima;

3. Conjunto de restrições: delimita a região de factibilidade das soluções.

De maneira geral, um problema de otimização se apresenta da seguinte forma:

$$
\begin{array}{cc}
\underset{\mathrm{u} \in \mathrm{Z}}{\text { Otimizar }} & \phi(\mathrm{u}) \\
\text { Sujeito } a & \omega_{i}(\mathrm{u}) \leq b_{i}, i=1 \ldots t,
\end{array}
$$

em que Z é o espaço de busca; u é um vetor do $\mathbb{R}^{n}$ que contém o conjunto de variáveis a serem otimizadas; $\phi: \mathbb{R}^{n} \rightarrow \mathbb{R}$ é a função-objetivo que modela o problema; as funções $\omega_{i}: \mathbb{R}^{n} \rightarrow \mathbb{R}, i=1 \ldots t$ são as restrições impostas e que garantem a factibilidade da solução; e as constantes $b_{i}{ }^{\prime}$ s são os limitantes para essas restrições. O vetor u* é o conjunto de valores com a solução ótima do problema, ou seja, aquele que maximiza ou minimiza $\phi(\cdot)$.

Conforme apresentado anteriormente (Seção 3.5), a abordagem de otimização da roto-projeção é pautada na estimativa de desempenho do modelo induzido pela técnica diretora da otimização. O desempenho do modelo induzido é por sua vez influenciado pela transformação de roto-projeção, pelos dados de treinamento, pelos parâmetros e características da técnica diretora, dentre outros. Embora o conjunto das variáveis seja claramente estabelecido por $(\Theta, d)$ e praticamente inexistam restri- 
ções de factibilidade, a descrição matemática completa da função-objetivo é bastante complexa. Assim, $\phi$ funciona como uma "caixa preta" em termos de compreensibilidade matemática, mas sua saída numérica pode ser obtida utilizando uma métrica de avaliação do modelo de predição. Uma estimativa de desempenho pode ser facilmente obtida utilizando qualquer medida tipicamente utilizada na avaliação de um modelo preditivo como, por exemplo, acurácia, precisão, recall, medida $F$, raiz do erro quadrático médio (REQM), erro absoluto médio, entre outras (vide (REZENDE, 2003)). Considerando uma métrica baseada em alguma estimativa do erro de classificação ou de regressão, o problema de otimização da roto-projeção pode ser expresso, com notação simplificada, como:

$$
\arg \min _{(\Theta, d)} \phi^{\mathscr{A}}(X, Y \mid(\Theta, d))
$$

em que, reitera-se, $\Theta$ é a matriz das variáveis angulares $\theta_{a b}$, tal que $\theta_{a b}=0, \forall a \geq b$; $X$ é a matriz dos dados de treinamento; $Y$ é a matriz com as probabilidades de saída; $d$ é dimensão do subespaço de projeção $\left(d \in \mathbb{Z}_{+}^{*}\right.$ e $\left.d \leq n\right)$ e $n$ a dimensão do espaço original (número de atributos do problema); e, finalmente, $\phi^{\mathscr{A}}$ é a função-objetivo "caixa preta" que utiliza a SLT $\mathscr{A}$.

Em linhas gerais, a saída de $\phi^{\mathscr{A}}(X, Y \mid(\Theta, d))$ é produzida por uma seqüência de passos bem definida, conforme apresentada a seguir:

1. Compor a matriz de rotação: $R(\Theta)$;

2. Compor a matriz de projeção ortogonal $Q$ utilizando $d$;

3. Compor a matriz de roto-projeção: $R P(\Theta, d)$ (vide Equação 3.10);

4. Transformar a matriz de dados: $X^{\prime}=R P(\Theta, d) \cdot X^{\mathrm{T}}$;

5. Induzir, utilizando $\mathscr{A}$, o modelo preditivo $h \operatorname{com} X^{\prime}$ e $Y$;

6. Estimar o erro de $h$ utilizando alguma medida pré-estabelecida;

7. Retornar o erro estimado.

Assim, embora seja uma função-objetivo "caixa preta", sua saída é relativamente simples e algoritmicamente obtida. Isso estabelece um framework sob o qual qualquer algoritmo de otimização heurístico ou uma metaheurística podem ser utilizados e/ou adaptados para obtenção da ORP. 


\subsubsection{Complexidade do modelo}

Em termos matemáticos, para um modelo representar um fenômeno físico ou biológico, o fato representado deve possuir solução dentro das condições estudadas (existência de solução), o comportamento do modelo deve sempre se repetir sob as mesmas condições (unicidade da solução) e pequenas modificações realizadas no sistema não devem alterar sensivelmente o fenômeno (estabilidade da solução). Um sistema com essas três condições é denominado problema bem-posto ${ }^{6}$. Ao contrário de um problema bem-posto, as SLTs induzem modelos a partir de conjuntos de dados muitas vezes de dimensões e número de instâncias incompatíveis. A falta de representatividade dos dados utilizados na indução faz com que diferentes modelos possam ser encontrados no espaço de hipóteses H (vide Seção 2.1). Esse é um exemplo típico de um problema mal-posto em que o conjunto de dados, por si só, não é suficiente para encontrar uma solução única.

Em decorrência do aprendizado de modelos ser um problema mal-posto, as SLTs precisam fazer algumas suposições extras para ter uma única solução com os dados disponíveis. Esse conjunto de suposições que torna o aprendizado possível é chamado de viés indutivo do algoritmo de aprendizado (ALPAYDIN, 2010). Sem o viés indutivo não há aprendizado. Em regressão linear simples, por exemplo, assumir uma função linear é um viés indutivo e, entre todas as linhas possíveis, escolher aquela que minimiza o erro quadrático é um outro viés indutivo.

À medida que as suposições sob o conjunto de dados disponível se tornam mais rebuscadas, maior também se torna o espaço de hipóteses e mais complexas as hipóteses nele contidas. Em regressão, por exemplo, quanto maior o grau do polinômio considerado, maior a flexibilidade para modelar os dados permitindo modelos mais complexos. Entretanto, modelos muito complexos podem modelar o ruído e apresentar baixa capacidade de generalização, um efeito bastante conhecido em ML denominado overfitting. Por outro lado, se um modelo é excessivamente simples, os dados podem não ser modelados corretamente, incorrendo no efeito chamado underfitting. Assim, o desafio de selecionar o modelo de complexidade ótima no espaço das hipóteses é conhecido em ML como seleção de modelos (MYUNG, 2000; ALPAYDIN, 2010).

Um procedimento prático e bastante utilizado para selecionar uma complexidade ótima é por meio de validação cruzada. Nesse caso, o conjunto de dados é dividido em duas partes: treinamento e validação. Diferentes modelos (complexidades diferentes) são induzidos com o conjunto de treinamento e seus desempenhos avaliados no con-

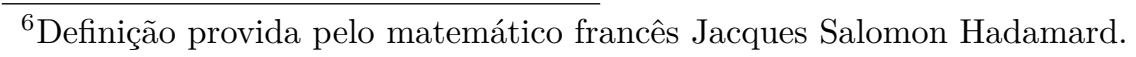


junto de validação ${ }^{7}$. À medida que a complexidade aumenta, o erro de treinamento diminui. Porém, o erro de validação pode estagnar ou aumentar com o aumento da complexidade. Assim, o erro de validação torna-se um importante indicador da complexidade ótima.

A ORP associada à qualquer SLT não é imune, em especial, ao efeito de overfitting. Uma direção de rotação e um subespaço de projeção quaisquer podem tornar propícia a indução de um modelo ainda mais complexo, com erros de treinamento mínimo, mas com baixa capacidade de generalização. Assim, considerar apenas a estimativa de desempenho do modelo induzido pela técnica diretora no conjunto de treinamento pode levar ao overfitting. Nesse caso, o uso de validação cruzada é uma alternativa interessante, mas que representa um custo computacional extra. Adicionalmente, uma das expectativas sobre a ORP é o rearranjo das instâncias para redução da complexidade dos dados e do modelo induzido posteriormente.

Uma solução simples para lidar com o problema do overfitting e da complexidade na otimização da roto-projeção é por meio de restrições aos parâmetros da técnica diretora que impactam diretamente na complexidade do modelo induzido. Esses parâmetros estão disponíveis em algumas SLTs clássicas. O C4.5, por exemplo, possui o parâmetro fator de confiança da poda que interfere diretamente na complexidade final da árvore induzida. No kNN, o parâmetro $k$ atua de forma inversamente proporcional à complexidade do modelo (ANDERSSON; DAVIDSSON; LINDéN, 1998; CHERKASSKY; MA; TANG, 2003). Em uma regressão polinomial, o grau do polinômio é diretamente proporcional à complexidade. Em ANNs do tipo MLP, o número de neurônios e a norma dos pesos são determinantes na complexidade do modelo final induzido (TEIXEIRA et al., 2000).

Restringir a complexidade por meio dos parâmetros da técnica diretora implica em reduzir o tamanho do espaço de hipóteses e delimitá-lo na complexidade das hipóteses nele contidas. A idéia é que, quando possível, a técnica diretora guie a otimização da roto-projeção para melhorar o desempenho de modelos limitados em suas complexidades para obtenção de um arranjo conformacional das instâncias também de menor complexidade. Conseqüentemente, arranjos mais simples das instâncias tenderão à indução de modelos de menores complexidades, tal como nos exemplos de modelagem apresentados na Seção 3.4. A busca e a preferência por modelos mais simples está de acordo com a lâmina de Occam ou princípio da parcimônia, apresentado na seqüência.

\footnotetext{
${ }^{7}$ Esse procedimento pode ser repetido algumas vezes para maior confiabilidade da estimativa.
} 


\subsubsection{Princípio da parcimônia}

Willian de Occam foi um filósofo inglês do século XIV a quem é atribuída a proposição do princípio da parcimônia ou, comumente chamada, lâmina de Occam. O princípio declara que a explicação de qualquer fenômeno ou teoria deve ser feita com o menor número de explicações possíveis. A lâmina de Occam encontra alinhamento filosófico-científico com a frase proferida por Albert Einstein: "Tudo deve ser tornado tão simples quanto possível, mas não mais simples". De acordo com Domingos (DOMINGOS, 1999) há duas interpretações diferentes para a lâmina de Occam no contexto de reconhecimento de padrões:

1. Dados dois modelos com o mesmo erro de generalização, o mais simples deve ser preferido porque simplicidade é desejável;

2. Dados dois modelos com o mesmo erro de treinamento, o mais simples deve ser preferido, porque é provável que ele apresentará um erro de generalização menor.

A preferência pelo modelo mais simples é freqüentemente incorporada, explícita ou implicitamente, em muitas SLTs (vide, por exemplo, a poda em árvores de decisão (QUINLAN, 1986)). Em particular, a segunda interpretação é interessante no propósito da ORP para redução da complexidade do modelo e aumento do desempenho. Porém, essa interpretação da lâmina ainda é bastante controvertida na literatura de ML (DOMINGOS, 1999; ZAHALKA; ZELEZNY, 2011).

A redução da complexidade do modelo é uma das expectativas em relação à transformação de ORP. A complexidade do modelo está diretamente correlacionada à complexidade dos dados. Assim, mesmo que a segunda interpretação do princípio da parcimônia seja insólita, restrições de complexidade impostas por meio dos parâmetros da técnica diretora devem, ao menos, produzir uma transformação ótima para um modelo mais simples. Isso significa que a otimização também busca reduzir a complexidade dos dados possibilitando que, posteriormente, o ajuste de complexidade (um artifício agregado à algumas SLTs) obtenha algum tipo de redução da complexidade do modelo final, tal como apresentado no exemplo de modelagem utilizando árvore de decisão da Subseção 3.4.1.

\subsubsection{Complexidade dos dados}

Um forma de entender o sucesso do desempenho de modelos em problemas de predição é por meio da análise da complexidade dos dados. Os estudos experimentais tradicionais geralmente utilizam a acurácia do modelo induzido como um indicador, 
sem analisar os motivos pelos quais um modelo supera outros. Enquanto a maioria das pesquisas relacionadas à complexidade estão focadas na simplicidade dos modelos induzidos, tal como sugere a lâmina de Occam, o conjunto de treinamento tem recebido relativamente pouca atenção (LI; ABU-MOSTAFA, 2006). Alguns pesquisadores têm buscado caracterizar a complexidade de dados e relacioná-la com o desempenho de modelos (SOHN, 1999; HO; BASU, 2002; SÁNCHEZ; SOTOCA; MOLLINEDA, 2005; LI; ABU-MOSTAFA, 2006; LI, 2006). Essa análise da complexidade do conjunto de dados pode revelar informações úteis sobre a tarefa de modelagem subseqüente.

Uma forma teórica de abordar o problema da complexidade dos dados é por meio da complexidade de Kolmogorov (LI; VITNYI, 2008). A complexidade de Kolmogorov é uma medida universal para a simplicidade ou complexidade de padrões. Em síntese, essa medida diz que um padrão é simples se ele pode ser gerado por uma concisa descrição algorítmica ou se ele pode ser compactado, o que essencialmente significa que o padrão possui alguma regularidade estrutural. Contudo, a complexidade de Kolmogorov é reconhecidamente incomputável e a sua determinação pode apenas ser aproximada (LI; VITNYI, 2008). Uma medida de aproximação tipicamente adotada é a taxa de compressão obtida por algumas ferramentas de compactação de dados disponíveis, como zip, arj, gzip, entre outras.

Na literatura específica de caracterização de dados de ML são apresentadas e utilizadas diversas medidas alternativas para complexidade (SOHN, 1999; HO; BASU, 2002; SÁNCHEZ; SOTOCA; MOLLINEDA, 2005; MOLLINEDA; SáNCHEZ; SOTOCA, 2005; LI; ABU-MostafA, 2006; LI, 2006). Essas medidas são dependentes dos descritores escolhidos e podem ser categorizadas como (SÁNCHEZ; SOTOCA; MOLLINEDA, 2005):

- Medidas estatísticas;

- Medidas de separabilidade de classes;

- Medidas de sobreposição;

- Medidas de geometria e densidade.

Dessas categorias, uma medida de densidade bastante simples e aplicável também em problemas de regressão é o número médio de pontos por dimensão ou, convencionalmente chamada, medida T2 (SÁNCHEZ; SOTOCA; MOLLINEDA, 2005). Essa medida fornece a informação sobre a densidade de distribuição espacial das instâncias por meio da relação entre o número de instâncias do conjunto de dados $(M)$ e número de dimensões de atributos característicos $(n)$, ou seja:

$$
\mathrm{T} 2=\frac{M}{n},
$$

Trata-se de uma medida simples, com propósito limitado, mas diretamente corre- 
lacionada com a dimensionalidade do problema e, portanto, alinhada com as vantagens apresentadas no início da Seção 3.4. Quanto menor a dimensão do espaço n-dimensional, maior será T2 ou ainda, por uma ótica estatística, quanto maior a representatividade das instâncias (maior $M$ ), maior T2. Assim, essa medida foi escolhida para prover algum indício sobre a redução da complexidade dos dados transformados pela ORP.

Em suma, a otimização da roto-projeção apresenta potencial para redução da complexidade dos dados e/ou do modelo induzido posteriormente. Adicionalmente, a expectativa é que esse fato também culmine com a indução de modelos com melhores desempenhos. Contudo, a transformação é fortemente dependente do arranjo conformacional das instâncias do conjunto de treinamento, da SLT e do processo de otimização. Essas dependências fazem com que a transformação possa não suprir, ou suprir parcialmente, as expectativas nela depositadas. Ainda assim, a ORP tem valor como heurística de aproximação para construção de ensembles de modelos. Na próxima seção são apresentados alguns aspectos da ORP que tornam interessante sua aplicação na construção de ensembles.

\subsection{Roto-projeção otimizada para ensembles}

Alguns aspectos intrínsecos ao problema da otimização da roto-projeção são intuitiva e previamente esperados no contexto de ML e podem impactar negativamente no desempenho de generalização do modelo posteriormente induzido. Por exemplo, algumas SLTs não dispõem de parâmetros para controle da complexidade ou disponibilizam apenas parâmetros que interferem indiretamente, mas de forma complexa, não linear e incerta. Nesse caso, a técnica diretora deve adotar a mesma configuração de parâmetros a ser utilizada posteriormente, tornando a transformação suceptível ao overfitting do modelo final.

O processo de otimização da roto-projeção também apresenta um aspecto de imprecisão ou de estocasticidade localizada. Intuitivamente, a expectativa sobre a otimização da roto-projeção é que o algoritmo utilizado encontre uma única solução ótima dada por $\left(\Theta^{*}, d^{*}\right)$. Porém, a função-objetivo $\phi^{\mathscr{A}}(X, Y \mid(\Theta, d))$ apresenta algumas particularidades que tornam o problema altamente multimodal, multi-platôs e/ou com grandes regiões de platô ótimas. Conforme mencionado no capítulo anterior (Seção 2.2), o modo como alguns modelos produzem suas saídas, sem qualquer ordinalidade intrínseca, impede que uma direção de rotação seja precisa e inequivocamente definida. As saídas discretas produzidas por árvores de decisão, por exemplo, comprometem a relação de ordem das instâncias na saída do modelo, inviabilizando uma estimativa precisa do erro para uma determinada direção de rotação. Em outras 
palavras, trata-se da incapacidade ou imprecisão característica do modelo em produzir uma distribuição de probabilidade de saída adequada, pertinente e passível de ranqueamento para uma instância por ele classificada. Esse aspecto compromete a relação de ordem entre as instâncias na saída do modelo e, conseqüentemente, produz um impacto negativo na precisão da estimativa da direção de rotação (até mesmo da projeção) no processo de otimização da roto-projeção.

Na Figura 3.18 é representado o particionamento produzido por uma árvore de decisão (decision stump) em um problema linearmente separável, com duas classes (diferenciadas por pontos em vermelho e azul), em seis ângulos de rotação distintos $\left(R\left(\theta_{1}\right) \ldots R\left(\theta_{6}\right)\right)$. Observa-se que, para qualquer uma das direções de rotação, o erro de classificação é indiferente e igual a zero. Esse efeito faz com que inúmeras direções de rotação produzam sempre o mesmo erro de classificação, uma característica de uma grande região de platô ótima e/ou de multi-platôs ótimos. Esse aspecto faz com que um algoritmo de otimização estocástica possa encontrar o ótimo em qualquer parte do platô, ou seja, apresente algum tipo de estocasticidade localizada na região de platô ótima. Essa imprecisão sobre o ótimo tem impacto direto no erro de generalização do modelo, especialmente quando os dados de treinamento não são estatisticamente representativos.

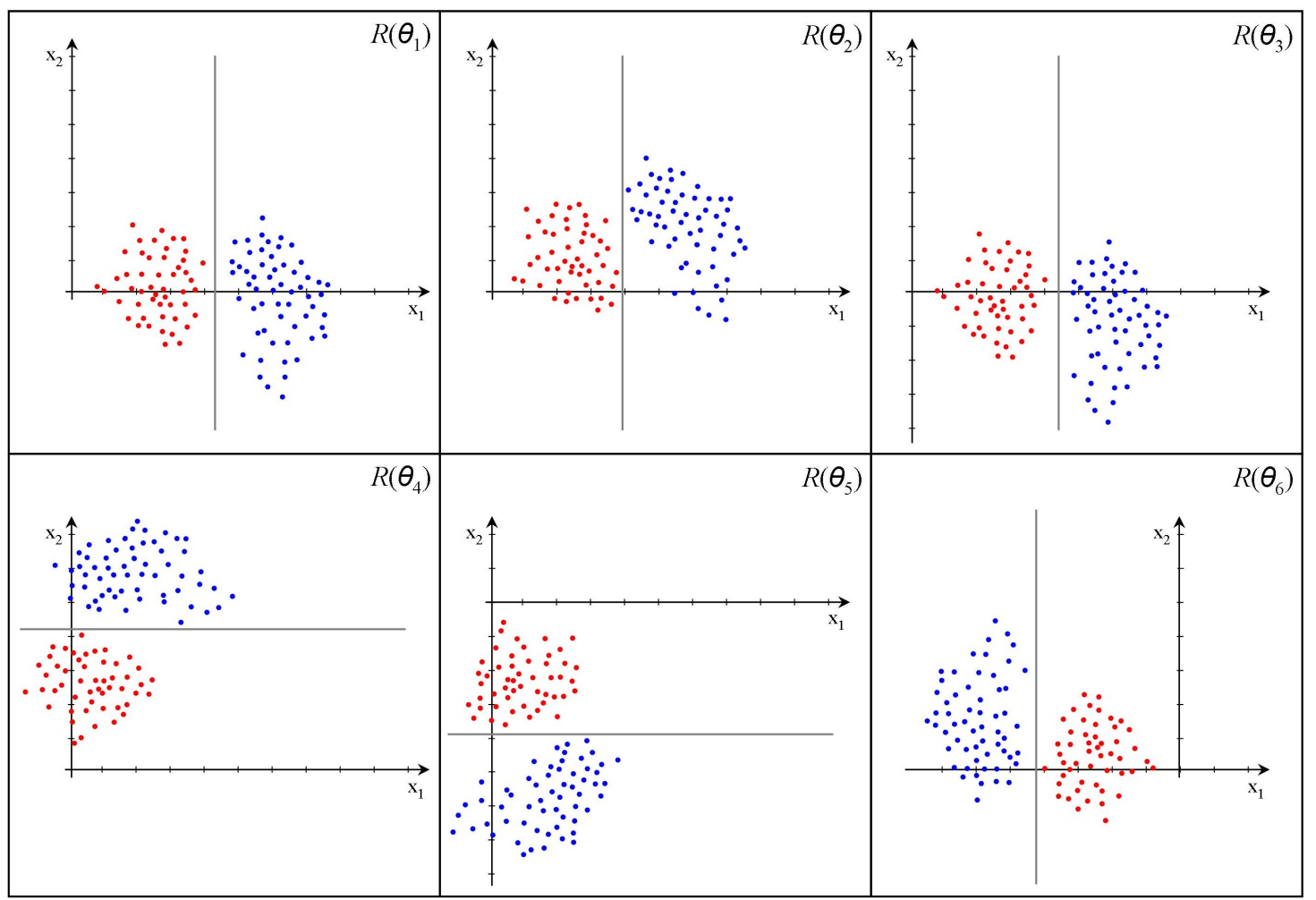

Figura 3.18: Imprecisão da direção de rotação ótima no processo de otimização.

Somente em casos muito particulares é que modelos não-ordinais devem possibilitar uma única solução (única direção de rotação). Adiciona-se a isso o fato de 
direções distintas poderem apresentar erros iguais ou muito próximos, mas em classes diferentes do problema. Assim, mesmo que um algoritmo de otimização ideal seja capaz de obter sempre o ótimo global, é possível que a direção de rotação seja distinta, uma vez que a função-objetivo pode apresentar também características multimodal. Ainda sobre a otimização, é amplamente conhecida a atração que ótimos locais exercem no processo de busca pelo ótimo global. Logo, uma metaheurística qualquer de minimização do erro da roto-projeção está sujeita a estacionar a busca em mínimos locais. Isso significa que soluções subótimas podem ser encontradas de forma a proporcionar erros em diferentes partes do espaço de instâncias.

A projeção em subespaço também apresenta características de multimodalidade. Subespaços diferentes podem proporcionar erros mínimos, porém idênticos para uma mesma SLT. Uma projeção em um subespaço $d$-dimensional $(0<d<n)$ pode ser indiferente para uma SLT que realiza algum tipo de ponderação ou seleção dos atributos. Por exemplo, no particionamento realizado pela árvore de decisão induzida na modelagem apresentada na Subseção 3.4.1, Figura 3.8, o subespaço $\mathrm{x}_{2}$ não foi utilizado na indução da árvore, tornando indiferente a projeção para o desempenho de classificação.

Os aspectos supramencionados, além de outros, embutem na ORP uma componente de imprecisão ou, em outras palavras, uma estocasticidade localizada da direção resultante da rotação e/ou do subespaço de projeção decorrente da inércia da saída da função-objetivo. É exatamente essa componente que torna a ORP interessante para construção de MCs diversos e acurados para composição de um ensemble de modelos. Em oposição à filosofia de concepção do método RB de Rodríguez e colaboradores (RODRIGUEZ; KUNCHEVA; ALONSO, 2006) que objetiva, diretamente, a diversificação das direções de rotação, o método proposto explora a componente de imprecisão da ORP para construção dos MCs. Esse novo EM, referido como ORPE, está descrito no pseudo-código do Algoritmo 3.2.

A idéia fundamental do método ORPE é utilizar pontos de partida aleatórios no espaço de busca como artifício para aumentar a probabilidade de uma metaheurística qualquer encontrar soluções de roto-projeção distintas para cada MC, contribuindo assim para a diversidade no ensemble.

O método ORPE permite a implementação paralela da construção dos MCs. Contudo, ressalta-se que, por fundamentar-se em otimização, o método ORPE não objetiva e não tem a pretensão de superar outros EMs no quesito do tempo computacional demandado para construção do ensemble. Nesse aspecto, ORPE configura-se, obviamente, como um EM de custo computacional relativa e comparativamente alto, especialmente em bases de dados com muitos atributos. 


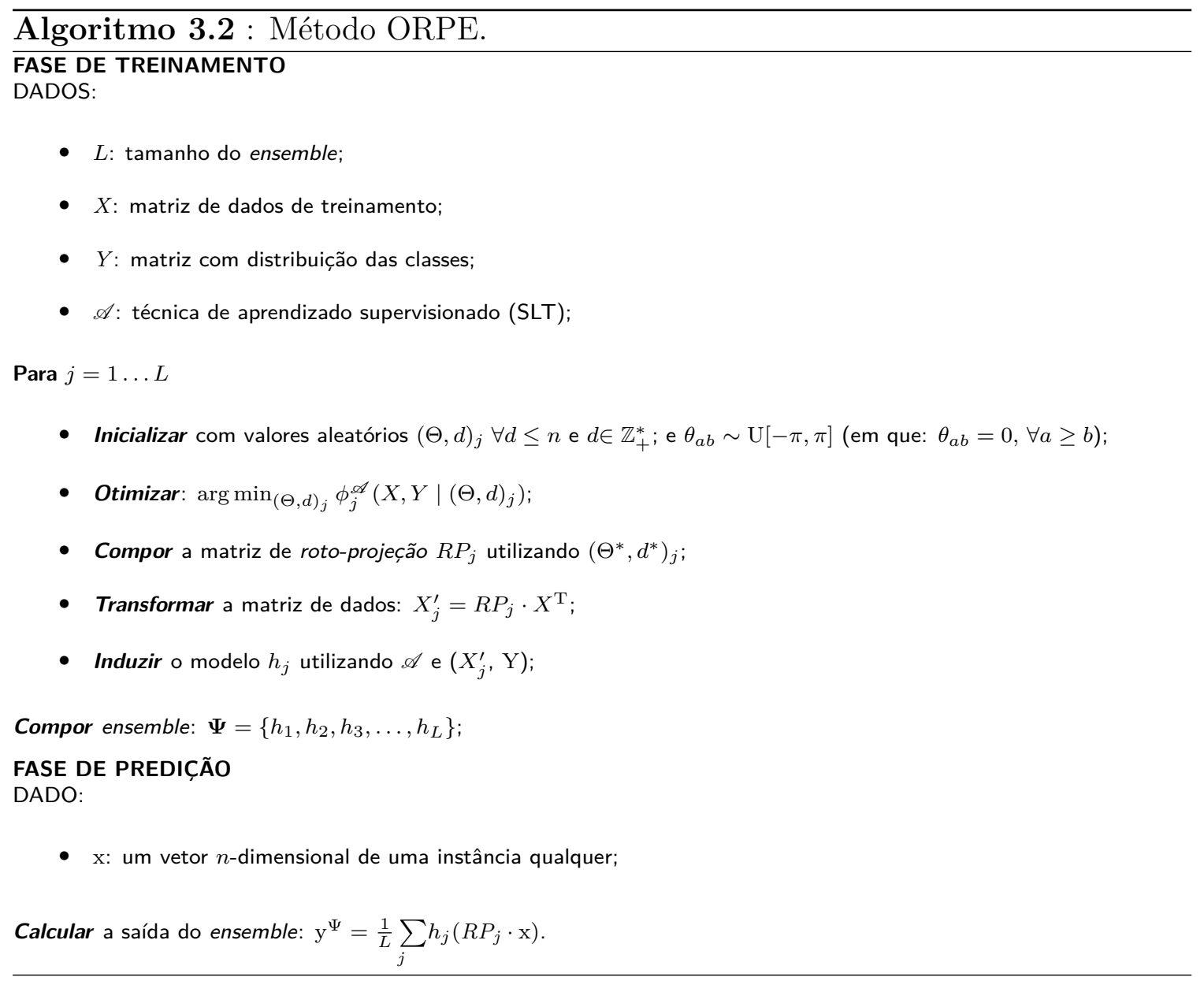

\subsection{Considerações finais}

A abordagem matemático-geométrica da roto-projeção permite que uma otimização dos parâmetros angulares e da dimensão de subespaço produza uma transformação capaz de promover arranjos de instâncias apropriados para uma SLT específica. Uma forma de guiar a otimização para esse fim é por meio do desempenho de uma técnica diretora do processo. A restrição imposta aos parâmetros de controle de complexidade da técnica diretora é um artifício importante que limita o espaço e a complexidade das hipóteses e visa a simplificação dos dados e/ou redução da complexidade do modelo final; outrossim é uma forma de minimizar o efeito de overfitting e aumentar o desempenho do modelo induzido posteriormente. Essa é a base teórica para a primeira asserção desta tese, apresentada na Seção 1.2 do Capítulo 1.

A otimização da roto-projeção lida com uma componente de imprecisão uma vez que a função-objetivo do problema é impactada pela não-ordinalidade da saída do modelo induzido, pela natureza multimodal e multi-platô do problema, por ótimos locais, por projeções não diferenciáveis, pela insuficiência dos dados de treinamento, dentre outros. Essa componente de imprecisão é o princípio de funcionamento do método ORPE. O método ORPE é a concretização sustentada pela segunda asserção 
desta tese (vide Seção 1.2 do Capítulo 1). No próximo capítulo são apresentados os detalhes da metodologia de desenvolvimento e validação da ORP, assim como do método ORPE. 

CAPÍTULO 4

\section{Metodologias de desenvolvimento e validação}

A consolidação computacional da transformação de ORP é dependente da especificação de algum algoritmo de minimização do erro da técnica diretora. A grande quantidade de variáveis e a complexidade de alguns problemas reais de otimização fazem com que algoritmos de otimização que garantem encontrar uma solução exata para o problema muitas vezes apresentem baixo desempenho ou sequer possam ser aplicados na busca por uma solução, cedendo espaço à aplicação de métodos baseados em busca heurística ou metaheurísticas que encontram boas soluções em tempo satisfatório. A otimização da roto-projeção é uma dessas aplicações reais que lida com uma função-objetivo com peculiaridades importantes (vide Seção 3.6) e, principalmente, com um grande número de variáveis angulares a serem otimizadas. Logo, algoritmos baseados em heurísticas e metaheurísticas são mais apropriados para obtenção da ORP.

Na avaliação do impacto produzido pela ORP na modelagem preditiva é relevante considerar aspectos pertinentes à complexidade e dimensionalidade dos dados por ela transformados e/ou à complexidade do modelo final induzido desses dados. Um outro aspecto imprescindível para análise é o desempenho de predição obtido pela conjunção de ORP com a SLT escolhida e utilizada posteriormente. Convencionou-se referenciar como ORPT o procedimento algorítmico de transformar os dados com ORP e, posteriormente, induzir um modelo de predição (a partir dos dados transformados) utilizando a mesma SLT usada como diretora do processo de otimização. Assim, ORPT constitui-se em uma nova SLT que aplica a transformação de ORP nos dados antes da indução do modelo pela SLT escolhida. De outra forma, ORPT fun- 
ciona como uma "SLT de invólucro" tal como ilustrado na Figura 4.1. Nesse sentido, toda a análise e validação relativa aos aspectos supramencionados foram extraídos de ORPT.

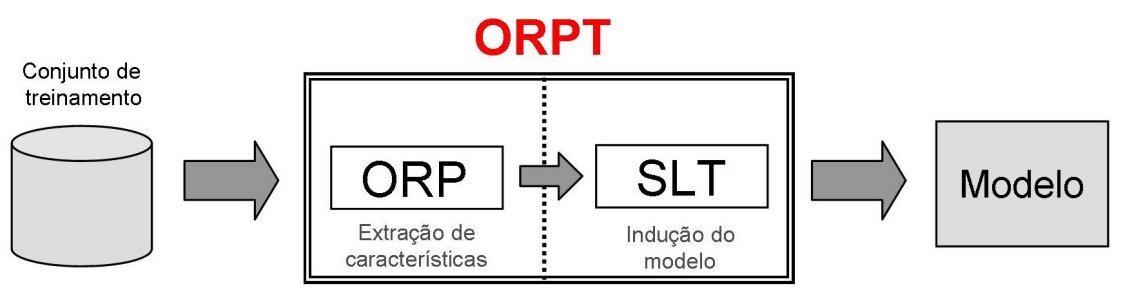

Figura 4.1: Técnica ORPT.

$\mathrm{Na}$ análise dos desempenhos de predição de ORPT e ORPE torna-se importante considerar algumas SLTs diferenciadas para modelagem de classificação e regressão. Especificamente, além das tarefas de modelagem, a segunda asserção desta tese (Capítulo 1) estabelece a necessidade de se avaliar o desempenho com SLTs instáveis e estáveis; outrossim a expectativa de adaptabilidade (vide Seção 3.4) com alguma SLT insensível à rotação das instâncias.

Nas próximas seções são apresentados detalhes do modus faciendi da metaheurística, da implementação e da metodologia de análise e validação do desempenho de ORPT e ORPE. Adicionalmente, é fornecida uma breve descrição das bases de dados privadas relativas aos problemas da pesquisa de instrumentação agropecuária em desenvolvimento na EIA.

\subsection{Metaheurísticas}

Em otimização, heurística é um conjunto de regras utilizadas para buscar soluções para um problema em um tempo computacional aceitável. Um algoritmo de aproximação é considerado heurístico se utiliza informações a respeito do problema na estratégia de busca da solução para resolvê-lo de forma rápida. Por outro lado, a convergência para o ótimo não é uma constante observável nas diversas execuções de algoritmos heurísticos.

Existe uma classe de algoritmos que utilizam heurísticas mais generalizadas ou, as denominadas metaheurísticas. Metaheurísticas são heurísticas genéricas mais sofisticadas que utilizam heurísticas mais simples para explorar inteligentemente o espaço de busca das soluções. De acordo com Voß (VOß, 2001), uma metaheurística é um processo mestre iterativo que guia e modifica as operações de heurísticas subordinadas para produzir, de forma eficiente, soluções de alta qualidade. Existem diversas metaheurísticas para otimização tais como: algoritmos de colônia de formigas 
(DORIGO; BIRATTARI; STüTZLE, 2006), algoritmos de enxame de partículas (KENNEDY; EBERHART, 2001), algoritmos evolutivos (GOLDBERG, 1989; BACK; SCHWEFEL, 1993), arrefecimento simulado (SA ${ }^{1}$ ) (KIRKPATRICK; GELATT; VECCHI, 1983) e suas formas híbridas. Optou-se pelo arrefecimento simulado ou, especificamente, por uma versão ligeiramente modificada do SA original. O mecanismo estocástico de aproximação da solução ótima ou subótima (interessante à diversidade no contexto de ensembles) e a expertise com essa metaheurística foram os principais fatores para sua escolha.

\subsubsection{Arrefecimento simulado}

O arrefecimento simulado (SA) é uma metaheurística para otimização, inspirada na termodinâmica, que efetua uma busca local probabilística. É um processo análogo ao resfriamento de metais observado na metalurgia. Em síntese, a temperatura de um material sólido é aumentada a fim de fundi-lo. Posteriormente, um processo de resfriamento é lenta e controladamente aplicado até a solidificação do material. Isso faz com que os átomos se arranjem em uma estrutura uniforme, buscando um nível de mínima energia. A maneira pela qual a temperatura irá decrescer é extremamente importante. Em uma estrutura cristalina, por exemplo, se a temperatura for reduzida muito rapidamente, o cristal conterá inúmeras imperfeições, ou seja, não atingirá uma configuração de energia mínima.

Kirkpatrick (KIRKPATRICK; GELATT; VECCHI, 1983) propôs que a simulação desse processo termodinâmico poderia ser utilizada para buscar soluções factíveis em um problema de otimização objetivando, obviamente, encontrar a solução ótima. No Algoritmo 4.1 é apresentado um pseudo-código de um SA típico. O SA pode ser classificado como um tipo de busca local, onde uma configuração de energia (S) é uma solução para o problema a ser otimizado. A configuração de mínima energia é a solução ótima $\left(\mathrm{S}^{*}\right)$ do problema e a saída produzida pela função-objetivo é o nível de energia (energia $(\cdot))$. A temperatura inicial $\left(T_{0}\right)$, a proporção de decréscimo da temperatura $\left(\alpha_{r}\right)$ e a temperatura final $\left(T_{f}\right)$ são parâmetros de controle do algoritmo.

O parâmetro $G_{e}$ define o número de iterações para atingir o equilíbrio em uma dada temperatura. O procedimento GeraSoluçãoVizinha(S) retorna uma nova configuração de energia com alguma perturbação de S, sendo o responsável pela exploração local do espaço de busca. O termo $\mathrm{U}[0,1]<\exp \left(-\frac{\triangle_{\text {energia }}}{t}\right)$ estabelece uma condição probabilística dependente da temperatura para aceitação de uma solução ruim. Em outras palavras, o SA permite que configurações de mais alta energia sejam aceitas em temperaturas mais altas a fim de possibilitar a exploração de outras regiões do

\footnotetext{
${ }^{1}$ Simulated Annealing.
} 


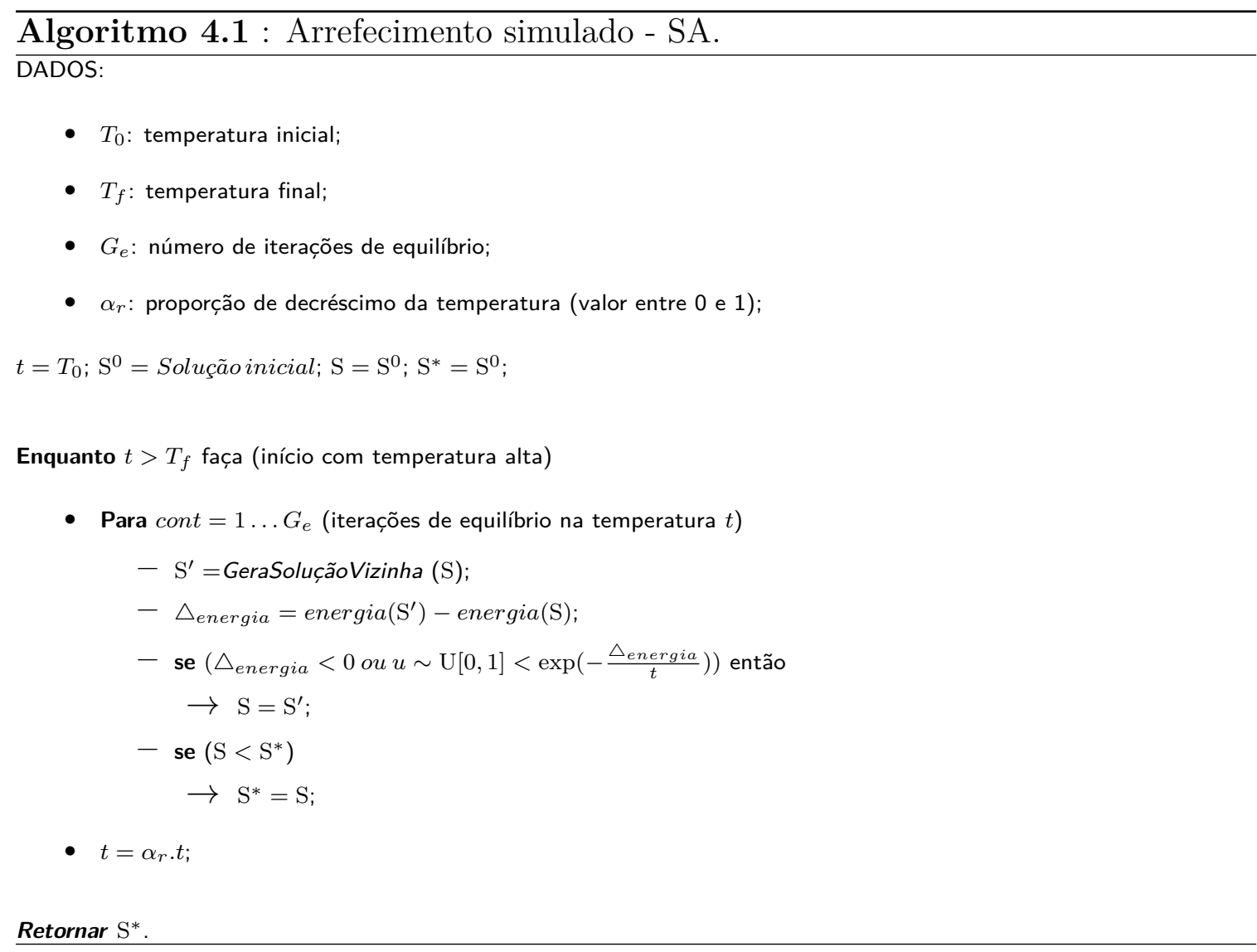

espaço de busca. À medida que a temperatura diminui, $\exp \left(-\frac{\triangle_{\text {energia }}}{t}\right)$ reduz substancialmente a probabilidade de exploração de outras regiões do espaço, limitando o algoritmo a uma busca localizada no final do processo de otimização.

Alguns aspectos sobre os parâmetros do SA são notáveis e intuitivos: quanto maior $T_{0}, G_{e}, \alpha_{r}$ e menor $T_{f}$, maior a probabilidade de encontrar o ótimo. Por outro lado, isso implica em testar um número exponencialmente grande de configurações de energia, o que resulta em tempos de processamento elevados.

\subsubsection{Arrefecimento simulado com vizinhança dinâmica}

A definição da vizinhança, necessária no procedimento GeraSoluçãoVizinha(S), não é simples para o problema de otimização da roto-projeção. Uma perturbação angular muito pequena pode fazer o algoritmo ficar estacionado em um subótimo ou sequer sair da condição inicial. Por outro lado, considerar uma perturbação angular muito grande pode tornar o algoritmo essecialmente estocástico como na otimização por Monte Carlo (DICKMAN; GILMAN, 1989). Assim, o procedimento GeraSoluçãoVizinha pode impactar negativamente na eficiência do SA na construção da transformação de roto-projeção. Para minimizar esse impacto, adotou-se um procedimento de perturbação dinâmica. Esse procedimento considera as perturbações angulares 
e do subespaço de projeção como uma função da temperatura. Quanto menor a temperatura, menor a perturbação provocada para geração da solução vizinha. Essa abordagem que utiliza uma vizinhança que decresce com a temperatura faz com que o SA explore, por meio de ângulos de rotação maiores (ou saltos maiores entre subespaços), diversas regiões do espaço de busca nas temperaturas mais altas e refine a busca local nas temperaturas mais baixas por meio de perturbações angulares menores (ou saltos menores entre subespaços). Na prática, o procedimento GeraSoluçãoVizinha $(\mathrm{S}, t)$ para roto-projeção foi implementado com base no pseudo-código apresentado no Algoritmo 4.2.

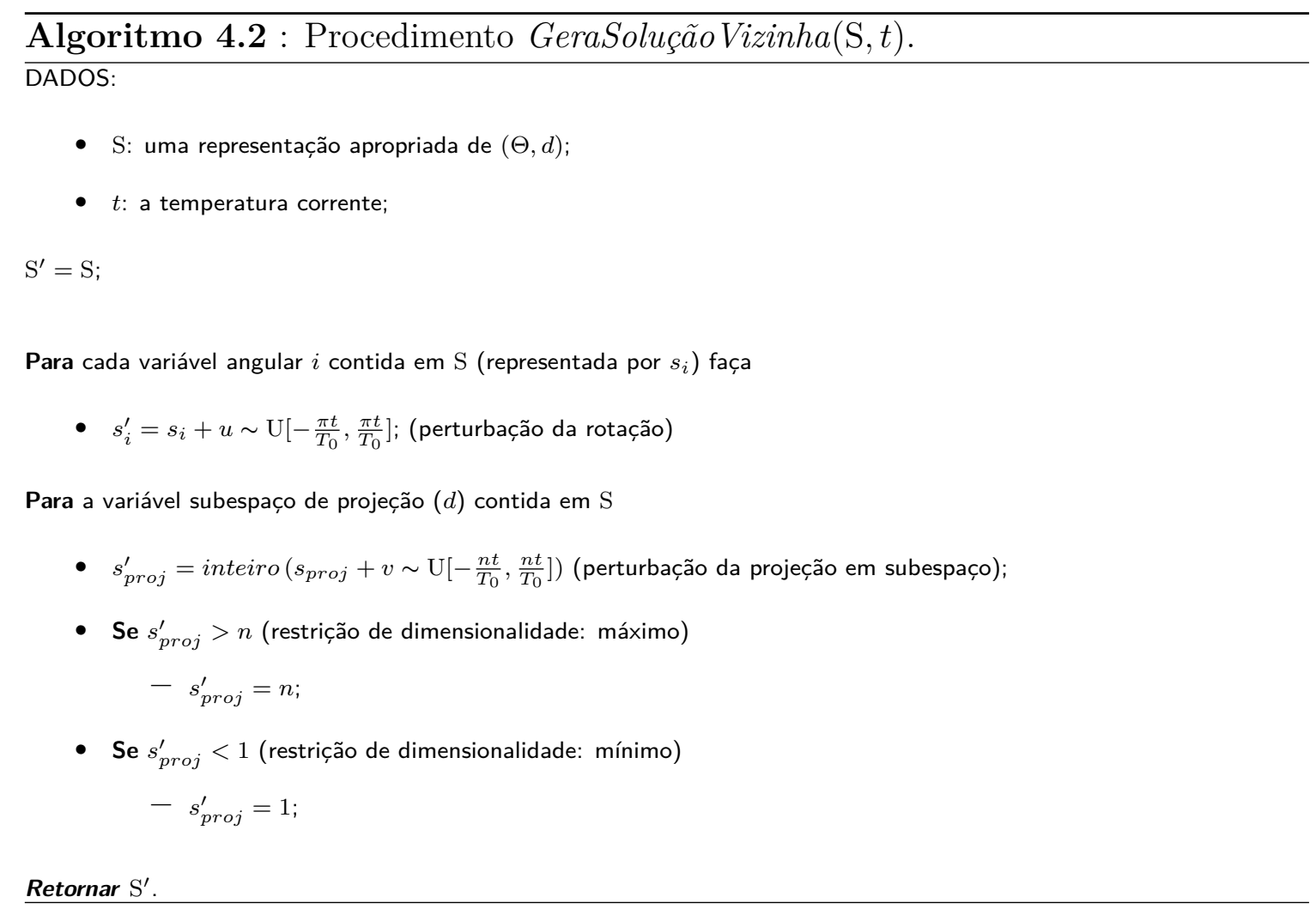

Note que o procedimento estabelece uma relação entre a temperatura, que é uma grandeza adimensional para o algoritmo, e o ângulo de rotação, que é definido em radianos (ou graus). Por isso, os parâmetros de temperatura para a versão do SA com vizinhança dinâmica foram uniformizados para serem especificados em termos de ângulos. Logo, convencionou-se denominar os parâmetros de temperatura envolvidos no SA como parâmetros de temperatura angular. A temperatura inicial define o ângulo máximo e a temperatura final o ângulo mínimo de perturbação sobre S. O subespaço de projeção é uma excessão à terminologia da temperatura angular, mas é similarmente obtido, respeitando apenas as restrições de dimensionalidade conforme pode ser observado no Algoritmo 4.2. Finalmente, a função energia $(\cdot)$ é a própria função-objetivo da roto-projeção, ou seja, energia $(\mathrm{S})=\phi^{\mathscr{A}}(X, Y \mid(\Theta, d))$ e a configuração de energia ou solução, S, é uma representação computacional mais apropriada de $(\Theta, d)$. 


\subsection{Metodologia de implementação e validação}

A técnica ORPT e o método ORPE foram completamente desenvolvidos em Java utilizando a coleção de pacotes de algoritmos e o framework do projeto Weka (HALL et al., 2009), na versão 3.6.4. As implementações resultantes foram agregadas ao Weka para análise do desempenho e comparações com outros métodos da literatura disponíveis na ferramenta. A ferramenta Experimenter do Weka foi utilizada para análise geral de desempenho e comparações pareadas. Para estimativa da qualidade da solução no processo de otimização pelo SA foi utilizada a REQM calculada da saída produzida pelo modelo induzido pela técnica diretora para o conjunto de treinamento. Em problemas de classificação a REQM foi obtida da função de perda 0-1.

A validação cruzada extratificada em 10 partições (10-fold stratified cross validation) foi utilizada para prover uma estimativa da medida de desempenho e para comparações pareadas dos EMs e das SLTs avaliadas. Nesse estimador estatístico, as instâncias do conjunto de dados são divididas aleatoriamente em 10 partes mutuamente exclusivas (folds) com tamanhos e, no caso de classificação, distribuições de classes aproximadamente iguais. Uma partição é separada para validação e as 9 partições restantes são consideradas como um único conjunto de treinamento para indução do modelo. Cada par (partição de teste, partição de treinamento) constitui uma iteração para a validação do algoritmo, totalizando 10 iterações. Após o treinamento utilizando a partição de treinamento, a partição de validação é apresentada ao modelo construído e uma estimativa do desempenho é calculada. Esse processo é repetido para as 9 partições restantes para obtenção de uma estimativa média. A medida de desempenho de predição utilizada foi a acurácia para problemas de classificação ou a REQM para regressão. Foram utilizadas 10 execuções do 10-fold stratified cross validation (totalizando 100 folds) para uma estimativa mais fiel da acurácia/REQM e do respectivo desvio padrão.

Nas comparações pareadas foi utilizado o teste de hipóteses para comparação de médias proposto por Nadeau e Bengio (NADEAU; BENGIO, 2003), denominado teste $t$ pareado corrigido, com nível de confiança de $95 \%$ ( $\alpha=0,05)$, conforme implementado no Weka. Esse teste utiliza uma estimativa corrigida do desvio padrão como forma de responder à crítica de que os testes estatísticos de comparação utilizados recentemente são desnecessariamente "liberais", ou seja, mostram diferenças significativas, embora elas não existam. Isso categoriza o teste $t$ pareado corrigido como um teste mais conservador.

A validação cruzada e o teste estatístico de comparação pareada constituem um padrão convencional amplamente aceito pela comunidade de ML para analisar e validar um novo EM ou uma nova SLT. A inferência geral sobre a eficiência da nova SLT 
ou novo EM decorre da análise e interpretação das diferenças estatisticamente significativas utilizando um conjunto relativamente grande de bases de dados de benchmark. Por isso, ORPT e ORPE foram analisados utilizando 57 bases de dados, divididas em bases públicas e bases privadas disponibilizadas pela Embrapa, detalhadas a seguir.

\subsubsection{Bases de dados públicas}

A análise comparativa de desempenho foi realizada com 52 bases de dados de domínio público de problemas de classificação e regressão obtidas do repositório eletrônico da Universidade da Califórnia em Irvine (UCI) (FRANK; ASUNCION, 2010), do repositório da Universidade de Waikato do projeto Weka ${ }^{2}$ e do repositório da Universidade de Carnegie Mellon em Pittsburgh (VLACHOS, 1999). As características dessas bases para a tarefa de classificação são apresentadas na Tabela 4.1. Das 37 bases de classificação da UCI utilizadas, 26 delas também foram utilizadas por Rodríguez e colaboradores em (RODRIGUEZ; KUnCHEVA; ALONSO, 2006). Para a tarefa de regressão foram selecionadas 15 bases de dados com diferentes características, incluindo algumas com atributos nominais. Na Tabela 4.2 são apresentadas as características das bases utilizadas em regressão.

\subsubsection{Bases de dados da Embrapa}

Algumas aplicações específicas da pesquisa agropecuária e agroindustrial nacional, especialmente ligadas ao desenvolvimento de metodologias, equipamentos e sensores, têm apresentado resultados insatisfatórios no que tange à precisão e acurácia dos modelos de predição. Por isso, a EIA tem buscado soluções nas áreas de ML, especialmente com ensemble de modelos, e obtido sucesso em algumas aplicações (FERREIRA et al., 2007; FERREIRA et al., 2011; CARDINALI et al., 2012). O desafio imposto por dados experimentais de pesquisa e a possibilidade de prover alguma solução eficaz motivaram a validação de ORPT e ORPE também nas bases da EIA. Uma descrição sintética ${ }^{3}$ dos problemas de pesquisa em desenvolvimento na EIA, bem como os detalhes das características das bases disponibilizadas para validação da proposta, são apresentados a seguir.

\footnotetext{
${ }^{2}$ http://www.cs.waikato.ac.nz/ml/weka/index_datasets.html

${ }^{3}$ A EIA possui uma política de confidencialidade em relação aos dados de pesquisa, por isso foram fornecidas apenas informações sobre os problemas e características das bases geradas. Maiores detalhes sobre a metodologia utilizada para geração e pré-processamento dos dados serão adequadamente efetuadas nas prováveis publicações ou patentes advindas direta ou indiretamente deste trabalho. As informações sobre as características das bases foram suficientes para o propósito de validação.
} 
Tabela 4.1: Características das bases públicas de classificação.

\begin{tabular}{|c|c|c|c|c|}
\hline Base de dados & no. Instâncias & no. Classes & no. Atrib. numéricos & no. Atrib. nominais \\
\hline audiology & 226 & 24 & 0 & 69 \\
\hline autos & 205 & 7 & 15 & 10 \\
\hline balance-scale & 625 & 3 & 4 & 0 \\
\hline breast-cancer & 286 & 2 & 0 & 9 \\
\hline breast-cancer-wisc & 699 & 2 & 9 & 0 \\
\hline breast-tissue & 106 & 6 & 9 & 0 \\
\hline car & 1728 & 4 & 0 & 6 \\
\hline cleveland-14-heart & 303 & 5 & 6 & 7 \\
\hline credit-rating & 690 & 2 & 6 & 9 \\
\hline ecoli & 336 & 8 & 7 & 0 \\
\hline glass & 214 & 7 & 9 & 0 \\
\hline haberman & 306 & 2 & 2 & 1 \\
\hline heart-statlog & 270 & 2 & 13 & 0 \\
\hline hepatitis & 155 & 2 & 6 & 13 \\
\hline horse-colic & 368 & 2 & 7 & 15 \\
\hline hungarian-heart & 294 & 5 & 6 & 7 \\
\hline ionosphere & 351 & 2 & 34 & 0 \\
\hline iris & 150 & 3 & 4 & 0 \\
\hline labor & 57 & 2 & 8 & 8 \\
\hline lung-cancer & 32 & 3 & 0 & 56 \\
\hline lymphography & 148 & 4 & 3 & 15 \\
\hline mfeat-morpho & 2000 & 10 & 6 & 0 \\
\hline parkinsons & 195 & 2 & 22 & 0 \\
\hline pima-diabetes & 768 & 2 & 8 & 0 \\
\hline primary-tumor & 339 & 22 & 0 & 17 \\
\hline segment & 2310 & 7 & 19 & 0 \\
\hline sonar & 208 & 2 & 60 & 0 \\
\hline soybean & 683 & 19 & 0 & 35 \\
\hline transfusion & 748 & 2 & 4 & 0 \\
\hline vehicle & 846 & 4 & 18 & 0 \\
\hline vote & 435 & 2 & 0 & 16 \\
\hline vowel-c & 990 & 11 & 10 & 2 \\
\hline vowel- $n$ & 990 & 11 & 10 & 0 \\
\hline waveform & 5000 & 3 & 40 & 0 \\
\hline wine & 178 & 3 & 13 & 0 \\
\hline$z o o$ & 101 & 7 & 1 & 15 \\
\hline
\end{tabular}

\section{Estimativa de carbono em solos}

A estimativa da quantidade de matéria orgânica de solos é uma medida importante na agricultura por estar diretamente correlacionada com a fertilidade. Essa matéria orgânica é composta por um conjunto de substâncias heterogêneas que inclui numerosos compostos de carbono. O elemento carbono é, portanto, o principal constituinte dessa matéria orgânica do solo. Assim, uma medida da quantidade de carbono é importante para prover, indiretamente, uma estimativa da matéria orgânica do solo. Para uma medida rápida e de baixo custo a EIA tem explorado a potencialidade da técnica LIBS. Contudo, o maior desafio desse tipo de técnica espectroscópica em solos tem sido correlacionar os espectros com a quantidade de carbono determinada por uma técnica convencional. Configura-se, nessa pesquisa, um problema típico de regressão para o qual as regressões lineares convencionais não têm apresentado resultados satisfatórios.

A EIA forneceu duas bases de dados para predição da quantidade de carbono como forma de explorar outros modelos de regressão e de contribuir para análise e validação de ORPT e ORPE. A primeira base com 60 instâncias representando solos de diferentes regiões do Brasil (base de dados denominada: snv-carb-areia) e 13 
Tabela 4.2: Características das bases públicas de regressão.

\begin{tabular}{cccc}
\hline Base de dados & No. Instâncias & No. Atrib. numéricos & No. Atrib. nominais \\
\hline auto-price & 159 & 14 & 1 \\
auto-mpg & 398 & 7 & 0 \\
bodyfat & 252 & 14 & 0 \\
bolts & 40 & 7 & 0 \\
cloud & 108 & 4 & 2 \\
concrete & 1030 & 8 & 0 \\
cpu & 209 & 6 & 0 \\
fishcatch & 158 & 5 & 1 \\
housing & 506 & 13 & 0 \\
pollution & 60 & 15 & 0 \\
pyrim & 74 & 27 & 0 \\
servo & 167 & 0 & 4 \\
triazines & 186 & 60 & 0 \\
winequality-red & 1599 & 11 & 0 \\
wisconsin & 194 & 32 & \\
\hline
\end{tabular}

atributos numéricos, sendo 12 relativos aos comprimentos de onda característicos de emissão de carbono e 1 da concentração de areia no solo. A segunda base de dados foi derivada da primeira, com 21 atributos numéricos relacionados à textura (argila, silte e areia), aos comprimentos de onda do carbono e a um conjunto de características relativas à cor do solo (base de dados denominada: carbono-cor).

\section{Qualidade de cafés}

A Associação Brasileira das Indústrias de Café lançou em 2004 um programa para estimular a produção e o consumo de cafés de alta qualidade. A qualidade global (QG) do café é um escore real, escalar entre 0 e 10, que representa a composição de diversos escores avaliados por vários degustadores especialistas em quesitos organolépticos intrinsicamente relacionados à qualidade da bebida. A QG tem sido utilizada para classificar cafés segundo quatro classes distintas: Inferior, para QG abaixo de 4,5; Tradicional, para QG entre 4,5 e 5,9; Superior, para QG entre 6,0 e 7,3; e Gourmet para QG acima de 7,3. Essa metodologia de obtenção da QG tem custo elevado, pois envolve o treinamento e a manutenção de uma equipe de especialistas (degustadores). Além disso, a estimativa de QG pode sofrer variações se o conjunto de especialistas for significativamente reduzido, além da susceptibilidade a problemas emocionais e/ou físicos, que pode agregar subjetividade à análise.

Para essa vertente da demanda agroindustrial, a EIA tem analisado diversas técnicas espectroscópicas. Em 2007 foi proposto o uso de uma língua eletrônica associada a um ensemble construído pelo RSM-PCS (FERREIRA et al., 2007). Os resultados foram promissores e de alta correlação com a QG atribuída por especialistas. Contudo, o método não se mostrou prático para aplicações industriais em larga escala.

Em 2011 pesquisadores da EIA e colaboradores propuseram o uso de LIBS como um método robusto, prático, de reduzido custo e apropriado para aplicações em larga escala. O problema foi configurado como uma tarefa de classificação e foram utiliza- 
dos os EMs RB e RSM-IPCS para construção dos modelos acoplados de classificação (FERREIRA et al., 2011). O estudo foi realizado em diversas regiões do espectro típicas de emissão do elemento hidrogênio. Os resultados foram surpreendentes, apresentando acurácia relativamente alta e erros em classes adjascentes, algo condizente com a prática observada na avaliação por degustadores. Como seqüência desse estudo, a EIA realizou uma extração de características baseada em centróides por extratos de regiões típicas do hidrogênio e compôs uma nova base de dados, denominada cafescentroids, com 62 atributos numéricos e 41 instâncias distribuídas em 4 classes de QG. Essa base também foi utilizada para compor o rol de bases privadas para análise e validação de ORPT e ORPE.

\section{Diagnóstico do Greening}

O Brasil responde por aproximadamente $50 \%$ da produção mundial de suco de laranja, exportando $98 \%$ do suco produzido (NEVES et al., 2010). A citricultura nacional gera cerca de 230 mil empregos diretos e indiretos sendo uma atividade importante para o agronegócio e economia do país (NEVES et al., 2010). Algumas doenças de citros têm provocado prejuízos econômicos importantes para os produtores de laranja e, conseqüentemente, para a citricultura no Brasil e no mundo. Dentre essas doenças, o Huanglongbing ou Greening é a mais temida pela capacidade de disseminação, carência de tratamentos eficazes e dificuldade de controle.

A maneira mais eficiente de atuar no controle do Greening é por meio de um diagnóstico precoce e, posteriormente, erradicação da planta doente. Um diagnóstico relativamente preciso é obtido por meio da técnica de reação em cadeia da polimerase em tempo real (KUBISTA et al., 2006), mas é uma metodologia de laboratório de alto custo e inviável para aplicações em larga escala. Nessa linha de instrumentação para um diagnóstico precoce e preciso do Greening a EIA tem investido em algumas técnicas espectroscópicas, além de investigar o processamento e reconhecimento de padrões de imagens de fluorescência induzida por laser $\left(\mathrm{LIFI}^{4}\right)$ das folhas. Resultados precisos e acurados utilizando espectroscopia de infravermelho foram publicados recentemente pela equipe de pesquisadores da EIA (CARDINALI et al., 2012), indicando que a solução tecnológica para o diagnóstico está prestes a ser consolidada.

$\mathrm{Na}$ vertente de LIFI das folhas dos citros a pesquisa ainda é incipiente, mas com potencial considerável e altamente motivadora em função da possibilidade de utilização de um aparato tecnológico de baixo custo. Nesse sentido, a EIA preparou e disponibilizou duas bases com 150 imagens de fluorescência (instâncias) divididas em 3 classes: sintomática, saudável e assintomática (planta doente, mas sem sintoma visivelmente detectável). A primeira base de dados é descrita por 41 atributos nu-

\footnotetext{
${ }^{4}$ Laser Induced Fluorescence Image.
} 
méricos de características extraídas dos modelos de cores (base de dados nomeada como greening) e a segunda com os mesmos atributos pré-processados por um tipo de normalização das componentes de cores (denominada greening $N$ ).

\subsubsection{Pré-processamento}

Um requisito imprescindível para aplicar a roto-projeção, assim como a PCA e as projeções aleatórias (FRADKIN; MADIGAN, 2003), é que as instâncias do conjunto de dados sejam representadas por atributos exclusivamente numéricos. Assim, as bases com atributos nominais necessitam de uma conversão para uma representação numérica antes de serem submetidas a ORPT, ORPE, RB (RODRIGUEZ; KUNCHEVA; ALONSO, 2006), RPEM (SCHCLAR; ROKACH, 2009) e RSM-IPCS (FERREIRA et al., 2009). Para lidar com isso, o método RB implementado na ferramenta Weka utiliza uma dicotomização para cada valor distinto assumido pelo atributo nominal. Isso significa que um novo atributo binário é criado para cada valor nominal do atributo original. Embora seja um procedimento relativamente eficiente, ele aumenta consideravelmente a dimensão do problema, minimiza a eficiência de indução e pode provocar esparcidade das informações no novo conjunto criado. Por isso, optou-se por uma conversão nominal-numérica mais simples, tal como a alternativa disponível na ferramenta RapidMiner (MIERSWA et al., 2006). Nessa representação alternativa, os valores nominais de um atributo são considerados igualmente ranqueáveis. Assim, cada valor nominal é simplesmente representado por um valor real (ou inteiro) igualmente equidistante dos eleitos adjascentes. Essa forma de representação não altera a dimensionalidade do problema. Dessa forma, todas as bases com atributos nominais foram convertidas para uma representação numérica utilizando esse procedimento disponível na ferramenta RapidMiner.

Os valores faltantes de algumas bases de dados foram previamente inseridos utilizando um procedimento de pré-processamento específico, baseado na substituição pela moda dos valores no caso de atributos nominais ou pela média no caso de numéricos. Esse procedimento, disponível na ferramenta Weka, é ampla e internamente utilizado pelas SLTs que não dispõem de mecanismos específicos para lidar com valores faltantes.

Os atributos nominais com valores únicos para cada instância das bases de dados foram previamente removidos por serem de notável irrelevância preditiva. Esses atributos foram encontrados nas bases auto-mpg (atributo: modelo do carro), parkinsons (atributo: nome), yeast (atributo: nome da seqüência) e zoo (atributo: nome dos animais). Para a base fishcatch foi removido o atributo sexo, pois mais de $50 \%$ dos valores eram faltantes. As bases vowel-c e vowel-n foram idênticas às versões 
utilizadas por Rodríguez e colaboradores (RODRIGUEZ; KUNCHEVA; ALONSO, 2006).

Finalmente, o método RB implementado no Weka adota, internamente, um procedimento de normalização [0-1] dos atributos aplicado antes da transformação da PCA. O mesmo tipo de normalização foi utilizada em ORPT e ORPE para garantir condições de igualdade nas comparações.

\subsubsection{Experimentos e configurações}

A abordagem metodológica para análise e validação foi apoiada em dois experimentos principais e um complementar. O primeiro experimento, denominado rotoprojeção, foi delineado para comprovar a primeira asserção desta tese (vide Seção 1.2). Similarmente, o segundo experimento, denominado ensembles, visou a comprovação da segunda asserção (vide Seção 1.2). Finalmente, o experimento complementar foi realizado apenas para estabelecer uma análise comparativa adicional entre os métodos ORPE e RB utilizando outra SLT sensível à rotação e de sucesso com esse último EM.

\section{Experimento roto-projeção}

O experimento roto-projeção teve por objetivo evidenciar ou prover indícios sobre o aumento de desempenho de predição e/ou redução de complexidade do modelo ou mesmo dos dados. Assim, a ORPT foi analisada no desempenho, na complexidade (do modelo e/ou dos dados) e no impacto de redução de dimensionalidade em comparação com a mesma SLT aplicada diretamente nos dados originais. Foram selecionadas 4 SLTs de estabilidades variadas para serem utilizadas nos experimentos referidos anteriormente. Foram elas:

1. C4.5 (J48): indução de modelos de árvores de decisão para a tarefa de classificação. Foi utilizada a implementação do Weka, denominada J48, com a configuração padrão dos parâmetros. O C4.5 é uma SLT instável e sensível à rotação. Para menor complexidade da técnica diretora em ORPT foi utilizado o fator de confiança mínimo permitido para a poda, ou seja, $10^{-7}$. Esse fator tende a provocar maior poda da árvore induzida e, conseqüentemente, menor complexidade da árvore final;

2. Naive Bayes (NB): indução de classificadores Bayesianos ingênuos para a tarefa de classificação. Foi utilizada a configuração padrão do Weka que assume que os atributos numéricos são gerados por uma distribuição normal simples, de acordo com as classes, e as probabilidades condicionais estimadas em termos dos parâmetros dessa distribuição. Embora classificadores NB tenham como 
suposição/pré-requisito a independência condicional dos atributos, muitas vezes violada em problemas do mundo real, ainda assim o desempenho desses é surpreendentemente acurado para muitas tarefas em comparação com outros classificadores mais complexos (DOMINGOS; PAZZANI, 1997; YANG; WEBB, 2001). O NB é considerado uma SLT relativamente estável. A configuração padrão do NB também foi utilizada para a técnica diretora;

3. Radial Basis Function (RBF): indução de modelos para a tarefa de regressão. Foi utilizada a implementação disponível no Weka com sua configuração padrão de parâmetros. No Weka essa SLT foi denominada rede $R B F$, embora a implementação não seja consistente com o conceito de ANNs dotadas de funções de base radiais (HAYKIN, 1999; BUHMANN; BUHMANN, 2003). Essa SLT utiliza o algoritmo de agrupamento k-médias (MACQUEEN, 1967) e uma regressão logística (AGRESTI, 2007) para problemas de classificação ou uma regressão linear múltipla (LEVINE et al., 2007) para problemas de regressão. Por depender do k-médias, torna-se uma SLT instável tanto para regressão como para classificação. A configuração padrão também foi utilizada para a técnica diretora, uma vez que os parâmetros disponíveis que interferem na complexidade do modelo final são de impactos incertos;

4. $k N N$ : modelagem utilizada apenas para a tarefa de regressão. Foi utilizado $k$ igual a 3 e o esquema de ponderação de um menos a distância Euclidiana, disponível na implementação da SLT. O kNN é uma SLT estável e insensível também à rotação das instâncias no espaço. Para menor complexidade da técnica diretora foi utilizado um valor de $k$ duas vezes maior $(k=6)$.

Desse modo, uma SLT instável (J48) e uma relativamente estável (NB) para classificação e uma instável (RBF) e outra estável $(\mathrm{kNN})$ para regressão foram pareadas na comparação de desempenho com seus acoplamentos ao ORPT. Para facilitar a distinção do acoplamento, a SLT utilizada com ORPT foi denotada entre parênteses tal como, por exemplo, ORPT(RBF) referindo à uma ORP para uma RBF.

As configurações dos parâmetros do SA para a ORPT foram as seguintes:

- Temperatura angular inicial $\left(T_{0}\right): \pi$;

- Temperatura angular final $\left(T_{f}\right): 10^{-3}$;

- Proporção de decréscimo da temperatura $\left(\alpha_{r}\right)$ : 0,95.

O número de iterações de equilíbrio $\left(G_{e}\right)$ foi definido por uma função dependente do número de instâncias $(M)$, de classes $(c)$ e de atributos $(n)$ da base de dados, tal como: $G_{e}=10+2 \log _{2} M+c+n$. Essa forma automática de definir o parâmetro é dependente das características da base de dados e garante que o número de instâncias 
impacte apenas logaritimicamente em $G_{e}$. Por outro lado, o aumento no número de classes e de atributos têm impacto linear no número de iterações de equilíbrio.

Como forma de prover indícios da redução da complexidade do modelo e/ou dos dados, decorrentes da transformação resultante da ORP, foram utilizadas algumas médias de medidas anteriormente mencionadas. Para comparação pareada das complexidades de árvores de decisão foi adotada a média do tamanho das árvores $(\overline{\mathrm{TA}})$ induzidas nas diferentes iterações (folds) da validação cruzada. Como indício indireto da redução de complexidade do modelo e direto da redução da complexidade dos dados proporcionada pela ORP para as demais SLTs foi utilizada a média de T2 (vide Seção 3.5.4) relativo, nesta denominada: taxa média de den-

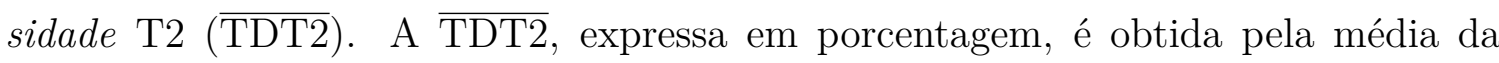
proporção do aumento da densidade dos dados transformados em relação à densidade dos dados originais nas diferentes iterações da validação cruzada, tal como: $\overline{\mathrm{TDT} 2}=\frac{1}{n o . \text { folds }} \sum \frac{T 2_{\text {dadostransformados }}-T 2_{\text {dados originais }}}{T 2_{\text {dados originais }}}$. A TDT2 está correlacionada com a complexidade do modelo, pois quanto menor a esparcidade das instâncias no espaço de projeção $d$-dimensional, maior a chance de obtenção de um modelo mais simples. Complementarmente, a taxa média de redução de dimensionalidade (TRD) também foi calculada, tal como $\overline{\mathrm{TRD}}=\frac{1}{n o . \text { folds }} \sum \frac{n-d}{n}$, para auxiliar na interpretação dos resultados.

\section{Experimento ensembles}

O experimento ensembles teve por objetivo a análise de desempenho e comparações pareadas do ORPE com outros EMs da literatura, incluindo o método referência: RB. Essa comparação foi efetuada utilizando 4 EMs apresentados no Capítulo 2: RPEM (SCHCLAR; ROKACH, 2009), RSM (HO, 1998), RSM-IPCS (FERREIRA et al., 2009) e RB (RODRIGUEZ; KUNCHEVA; ALONSO, 2006).

Da mesma forma que ORPT (experimento roto-projeção), a SLT utilizada em cada EM foi explicitada entre parênteses para facilitar o entendimento. O tamanho do ensemble foi fixado em $10 \mathrm{MCs}(L=10)$ para todos os métodos, tal como utilizado na validação do método RB (RODRIGUEZ; KUNCHEVA; ALONSO, 2006; RODRÍGUEZ; MAUDES; ALONSO, 2006). Para os EMs baseados em projeção em subespaço fixo (RPEM, RSM e RSM-IPCS) foi utilizado um subespaço de $50 \%$ da dimensão do espaço original $(d=n / 2)$. Para o RPEM foi utilizada a matriz de projeção aleatória construída tal como apresentado na Equação 2.6. A função de integração utilizada em todos os EMs foi a média das probabilidades de saída com pesos iguais, ou seja, votação majoritária para classificação e média aritmética para regressão, tal como apresentado na Equação 2.3.

No método RB foi utilizada a configuração padrão dos parâmetros do método 
disponível no Weka, tal como implementação e ajustes realizados pelo próprio autor (Juan J. Rodríguez). Essa configuração padrão é decorrente do desempenho relevante obtido para uma quantidade relativamente grande de bases de dados, assim como de outros estudos experimentais realizados e publicados por seus autores (RODRíGUEZ; ALONSO, 2004; RODRÍGUEZ; ALONSO; PRIETO, 2005; RODRIGUEZ; KUNCHEVA; ALONSO, 2006; KUNCHEVA; RODRÍGUEZ, 2007).

A proporção de decréscimo da temperatura utilizada para o ORPE foi de 0,85 $\left(\alpha_{r}=0,85\right)$ e os demais parâmetros do SA foram idênticos aos utilizados para a ORPT no experimento roto-projeção. Os parâmetros das técnicas diretoras também foram os mesmos utilizados no experimento roto-projeção.

\section{Experimento complementar}

O experimento complementar teve por objetivo a análise do desempenho de ORPE utilizando a SLT RBF em problemas de classificação. Uma característica interessante da implementação da RBF no Weka é a produção de uma estimativa da distribuição de probabilidade das classes, tal como um modelo ordinal, algo importante para maior precisão da transformação de ORP. Além disso, trata-se de uma comparação desafiadora com uma SLT para a qual o método RB já demonstrou sucesso frente a EMs clássicos como: Bagging, AdaBoost e RSM (RODRÍGUEZ; MAUDES; ALONSO, 2006). Esses aspectos motivaram essa análise de desempenho adicional. Para esse experimento foram selecionadas 29 bases de dados do conjunto de classificação utilizado nos experimentos anteriores. As configurações dos parâmetros dos métodos foram idênticas às definidas no experimento ensembles.

\subsection{Considerações finais}

Neste capítulo foram apresentadas a metaheurística utilizada para obtenção da ORP e a metodologia de desenvolvimento, análise comparativa e validação de ORPT e ORPE. A abordagem de análise e validação foi baseada em dois experimentos principais, relacionados com as asserções desta tese, e um experimento complementar com uma SLT com a qual o método RB também apresentou ótimo desempenho. Esses experimentos foram executados utilizando um conjunto de bases de dados de domínio público e privado em tarefas de regressão e classificação. Também foram definidas SLTs instáveis e estáveis para ambas as tarefas de predição visando evidenciar a menor restrição quanto à estabilidade da SLT (segunda asserção). No próximo capítulo são apresentados os resultados obtidos e as discussões para cada um dos referidos experimentos. 

CAPÍTULO 5

\section{Resultados e discussões}

Conforme mencionado no capítulo anterior, a abordagem metodológica para análise e validação de ORPT e ORPE foi apoiada em dois experimentos principais e um complementar. Nas duas subseções seguintes são apresentados os resultados obtidos, na forma de gráficos e/ou tabelas, em cada um dos experimentos principais. Os resultados das comparações pareadas para as bases de regressão introduzem as discussões nos experimentos principais. O impacto da transformação de ORP sobre os dados é avaliado na seqüência, por meio do desempenho de ORPT e das medidas de complexidade dos dados e da redução de dimensionalidade. Posteriormente, a mesma análise de resultados é realizada para as bases de classificação. No experimento ensembles são apresentadas as tabelas com os resultados obtidos e comparativas de desempenho pareadas com ORPE. Finalmente, as interpretações e discussões sobre os resultados obtidos no experimento complementar concluem a análise.

Como forma de apresentar as diferenças estatisticamente significativas (ao nível de confiança de 95\%) resultantes do teste $t$-pareado corrigido (NADEAU; BENGIO, 2003) foram inseridos círculos com ou sem preenchimento próximos às médias nas tabelas que ilustram os desempenhos das SLTs/EMs. O círculo preenchido em preto (•) indica que a SLT/EM apresenta uma média da REQM/acurácia significativamente menor do que aquela apresentada pela SLT/EM da primeira coluna de técnicas, para a respectiva base de dados disposta na linha. Para problemas de regressão isso 
significa que a SLT/EM da respectiva coluna marcada com o círculo em preto supera ${ }^{1}$ estatisticamente a SLT/EM da primeira coluna na respectiva base. Por outro lado, em classificação a interpretação é inversa, ou seja, a SLT/EM da respectiva coluna é superada pela SLT/EM da primeira coluna. O círculo sem preenchimento (o) indica que a média da REQM ou da acurácia é significativamente maior do que aquela obtida com a SLT/EM da primeira coluna. Novamente, em regressão significa que a SLT/EM é estatisticamente inferior e em classificação é superior à SLT/EM da primeira coluna de técnicas da tabela para a respectiva base de dados.

Ressalta-se que, a comparação foi sempre pareada entre cada SLT/EM com a SLT/EM da primeira coluna de técnicas da tabela. Por isso, ORPT ou ORPE foram sempre dispostos na primeira coluna de técnicas da tabela, em seus respectivos experimentos, para ter seus desempenhos comparados com todas as outras SLTs/EMs considerados neste trabalho.

\subsection{Experimento roto-projeção}

O experimento roto-projeção foi subdividido em 4 análises comparativas de acordo com as tarefas de modelagem e SLTs utilizadas. As duas primeiras tratam da regressão utilizando uma SLT estável e outra instável. Da mesma forma, as duas últimas análises tratam do desempenho em classificação utilizando uma SLT instável e outra relativamente estável.

\subsubsection{Análise do desempenho de ORPT(kNN) em regressão}

As médias e os desvios padrão da REQM calculados para todas as bases de regressão utilizando ORPT $(\mathrm{kNN})$ e kNN são apresentados na Tabela 5.1. Para as bases bodyfat, bolts, concrete e housing as médias de REQM obtidas com ORPT $(\mathrm{kNN})$ foram significativamente inferiores àquelas obtidas com o kNN. Para as demais bases não houve diferença mínima significativa entre as SLTs.

As comparações das médias de REQM obtidas com ORPT (kNN) e kNN em todas as bases consideradas mostram que o desempenho do kNN após a transformação da ORP para regressão tende a melhorar ou, no máximo, se manter igual ao desempenho do $\mathrm{kNN}$ aplicado diretamente nos dados originais.

A redução da complexidade dos dados obtida após a ORP em ORPT $(\mathrm{kNN})$,

\footnotetext{
${ }^{1} \mathrm{O}$ verbo superar também foi utilizado para diferenças significativas em regressão. Logo, uma SLT $\mathcal{A}$ supera $\mathcal{B}$ se apresentar uma média da REQM significativamente menor ao nível de confiança de $95 \%$.
} 
Tabela 5.1: REQM em regressão - ORPT $(\mathrm{kNN})$.

\begin{tabular}{lrrrr}
\hline Base de dados & \multicolumn{2}{c}{ ORPT(kNN) } & \multicolumn{2}{c}{$\mathrm{kNN}$} \\
\hline auto-price & $2568,74 \pm 1164,87$ & $2622,29 \pm 1123,92$ \\
auto-mpg & $2,80 \pm$ & 0,55 & $2,88 \pm$ & 0,54 \\
bodyfat & $2,26 \pm$ & 0,64 & $2,97 \pm$ & $0,54 \circ$ \\
bolts & $7,37 \pm$ & 8,85 & $14,71 \pm$ & $9,68 \circ$ \\
carbono-cor & $0,46 \pm$ & 0,30 & $0,42 \pm$ & 0,32 \\
cloud & $0,50 \pm$ & 0,20 & $0,62 \pm$ & 0,28 \\
concrete & $7,13 \pm$ & 0,79 & $8,88 \pm$ & 0,78 \\
cpu & $57,88 \pm$ & 34,07 & $61,00 \pm$ & 41,22 \\
fishcatch & $56,15 \pm$ & 21,95 & $69,75 \pm$ & 31,26 \\
housing & $3,56 \pm$ & 0,66 & $4,38 \pm$ & $1,06 \circ$ \\
pollution & $46,87 \pm$ & 14,08 & $45,66 \pm$ & 14,09 \\
pyrim & $0,08 \pm$ & 0,06 & $0,08 \pm$ & 0,06 \\
servo & $0,79 \pm$ & 0,40 & $0,77 \pm$ & 0,29 \\
snv-carb-areia & $0,46 \pm$ & 0,31 & $0,46 \pm$ & 0,30 \\
triazines & $0,14 \pm$ & 0,04 & $0,14 \pm$ & 0,04 \\
winequality-red & $0,69 \pm$ & 0,05 & $0,69 \pm$ & 0,04 \\
wisconsin & $37,05 \pm$ & 5,12 & $36,00 \pm$ & 5,34 \\
\hline Média & 164,29 & \multicolumn{3}{c}{168,92} \\
\hline
\end{tabular}

medida por meio da $\overline{\mathrm{TDT}} 2$, é apresentada na Figura 5.1. Para todas as bases houve aumento da densidade de pontos por dimensão expresso por uma TDT2 maior que zero. Maiores taxas médias são observadas nas bases auto-price e bolts com 613,01\% e $524,06 \%$, respectivamente. As barras de desvios (desvio padrão) mostram que nas bases auto-price, cloud e pyrim a variabilidade de T2 é relativamente grande, um indício de que soluções adequadas são encontradas em densidades variadas. Por outro lado, em auto-mpg e bodyfat o desvio padrão é visivelmente menor, indicando que as soluções ótimas/subótimas de roto-projeção estão um pouco mais restritas às condições de densidades próximas.

A TDT2 fornece indícios sobre o impacto causado pela ORP sobre a redução da REQM e, especialmente, da dimensionalidade do problema. Na Figura 5.2 é apresentada a TRD para todas as bases. Observa-se que o perfil da taxa média de redução de dimensionalidade guarda alguma similaridade com o perfil de $\overline{\text { TDT2}}$. Contudo, a maior taxa média de redução é observada na base bolts, com 79\%, seguida pela autoprice com aproximadamente $77 \%$ de redução. O alto desvio padrão observado na base cloud associado ao desempenho de ORPT(kNN) apresentado na Tabela 5.1 são indicativos da multiplicidade de soluções ótimas/subótimas disponíveis em subespaços de projeção de dimensões variadas, ou seja, uma característica de multimodalidade relacionada à dimensão.

A $\overline{\text { TRD }}$ evidencia o amplo uso do artifício da projeção em subespaço na otimização para melhoria no desempenho com kNN. Em 10 das 17 bases de regressão a TRD foi superior a 40\%. Essa redução como um processo precedente à indução tende a diminuir a esparcidade da informação no novo espaço, possibilitando a construção de modelos mais simples. Modelos mais simples são mais robustos em conjunto de dados de dimensões reduzidas e apresentam menor variância, isso é, são menos sensíveis 
às particularidades de uma amostra, incluindo ruídos, outliers e outros (ALPAYDIN, 2010).

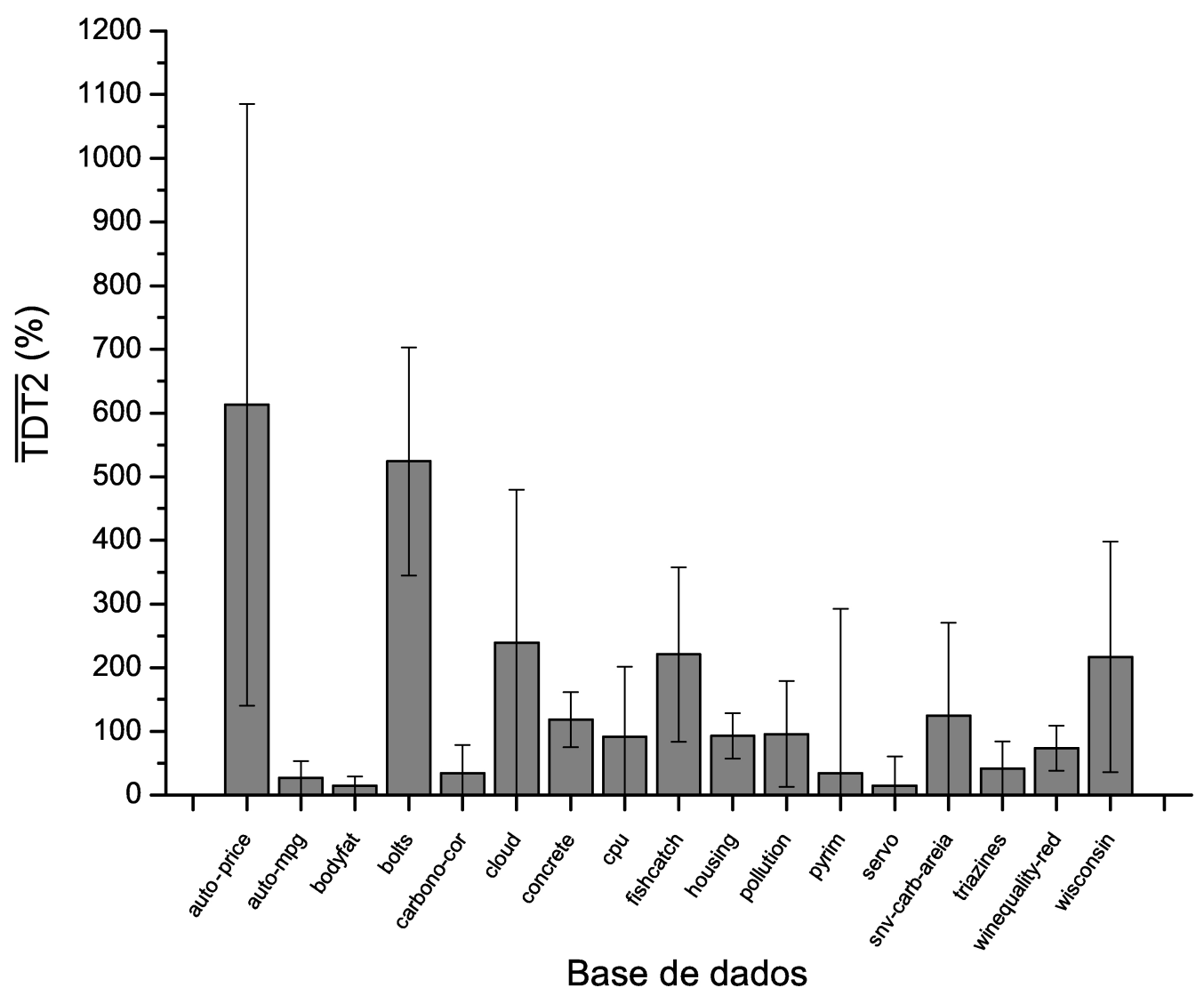

Figura 5.1: Taxa de densidade média T2 - ORPT $(\mathrm{kNN})$.

Em suma, as REQMs apresentadas na Tabela 5.1 conjuntamente com TDT2 e $\overline{\text { TRD }}$ permitem concluir que a transformação de ORP para regressão com kNN proporciona aumento da densidade das instâncias por dimensão, redução considerável da dimensionalidade e aumento do desempenho do kNN quando associado à referida transformação. Mais enfaticamente, as superações significativas com ORPT $(\mathrm{kNN})$ mostram que a transformação de ORP satisfaz a expectativa de adaptabilidade quando do uso de SLTs insensíveis à rotação (vide Seção 3.4).

\subsubsection{Análise do desempenho de ORPT(RBF) em regressão}

Na Tabela 5.2 são apresentadas as médias e os respectivos desvios padrão da REQM calculados para todas as bases de regressão utilizando ORPT(RBF) e RBF. Em 11 bases as médias de REQM obtidas com ORPT(RBF) foram significativamente inferiores àquelas obtidas com a RBF. Para as demais bases as diferenças não foram estatisticamente significativas. Os resultados de ORPT(RBF) foram muito promissores e excederam a expectativa para uma associação com uma SLT instável em problemas de regressão. 


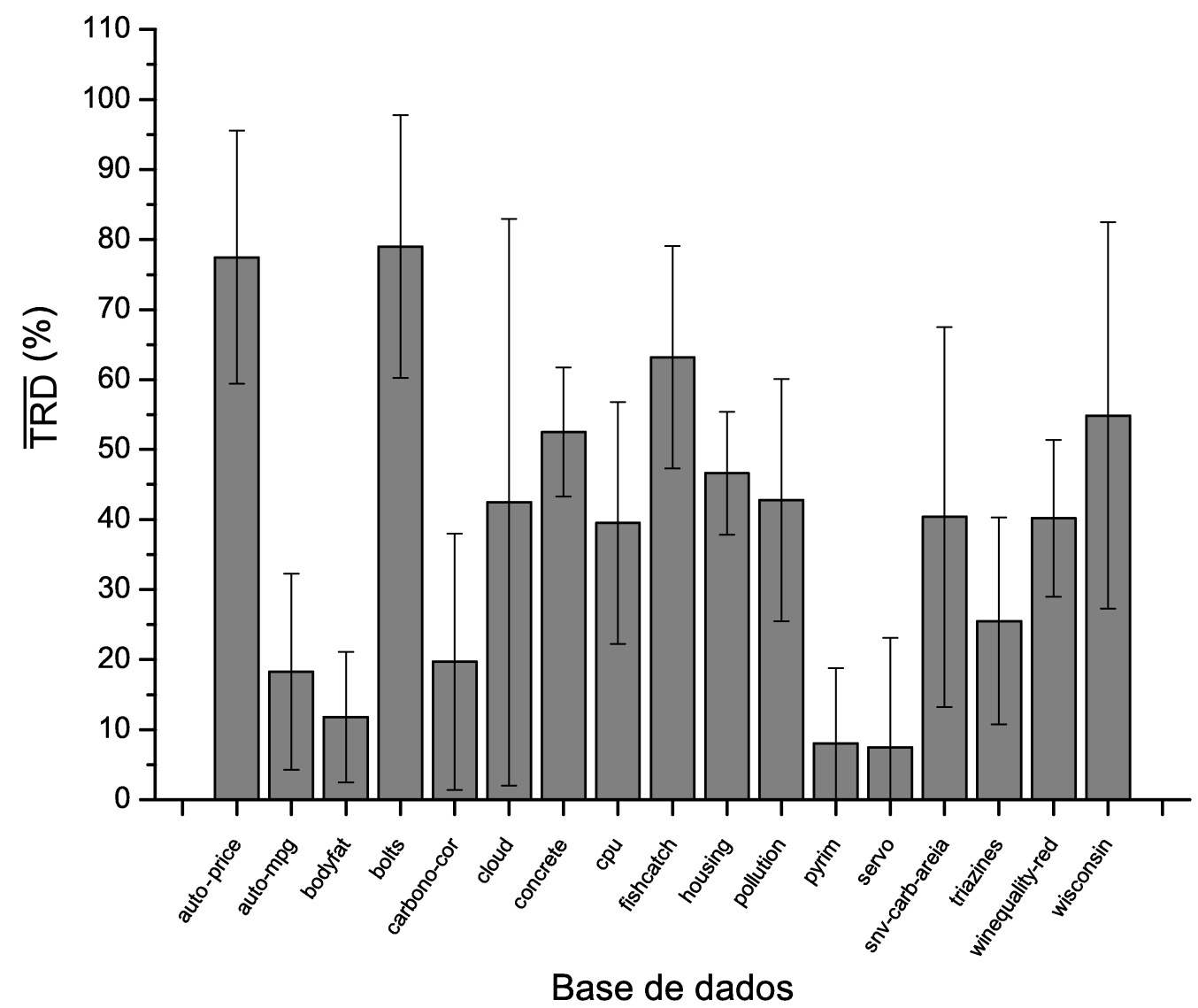

Figura 5.2: Taxa de redução de dimensionalidade - ORPT(kNN).

Tabela 5.2: REQM em regressão - ORPT(RBF).

\begin{tabular}{lrrrr}
\hline Base de dados & \multicolumn{1}{c}{ ORPT(RBF $)$} & \multicolumn{2}{c}{$\mathrm{RBF}$} \\
\hline auto-price & $3151,94 \pm 1109,59$ & $3888,52 \pm 1462,78 \circ$ \\
auto-mpg & $3,90 \pm$ & 0,53 & $5,05 \pm$ & $0,59 \circ$ \\
bodyfat & $3,70 \pm$ & 0,86 & $6,88 \pm$ & $0,81 \circ$ \\
bolts & $10,99 \pm$ & 8,17 & $19,86 \pm$ & $9,57 \circ$ \\
carbono-cor & $0,78 \pm$ & 0,38 & $0,97 \pm$ & 0,49 \\
cloud & $0,62 \pm$ & 0,19 & $1,00 \pm$ & $0,36 \circ$ \\
concrete & $11,22 \pm$ & 0,83 & $16,59 \pm$ & $0,98 \circ$ \\
cpu & $93,04 \pm$ & 48,45 & $109,02 \pm$ & 61,67 \\
fishcatch & $139,21 \pm$ & 55,53 & $356,47 \pm$ & $68,19 \circ$ \\
housing & $5,61 \pm$ & 0,92 & $8,15 \pm$ & $1,36 \circ$ \\
pollution & $45,55 \pm$ & 15,06 & $57,56 \pm$ & $16,95 \circ$ \\
pyrim & $0,10 \pm$ & 0,06 & $0,12 \pm$ & 0,05 \\
servo & $1,04 \pm$ & 0,28 & $1,44 \pm$ & $0,34 \circ$ \\
snv-carb-areia & $0,83 \pm$ & 0,29 & $0,94 \pm$ & 0,46 \\
triazines & $0,15 \pm$ & 0,04 & $0,15 \pm$ & 0,04 \\
winequality-red & $0,66 \pm$ & 0,04 & $0,78 \pm$ & $0,05 \circ$ \\
wisconsin & $33,22 \pm$ & 4,50 & $33,54 \pm$ & 4,05 \\
\hline Média & 206,03 & \multicolumn{4}{c}{265,12} \\
\hline
\end{tabular}

O excelente desempenho de ORPT(RBF) pode ser correlacionado com os resultados de $\overline{\text { TDT2 }}$ ou de TRD. Na Figura 5.3 é apresentado o gráfico do impacto causado pela ORP na redução da complexidade dos dados medida por TDT2. Em geral, a TDT2 foi consideravelmente maior do que a observada com ORPT(kNN). O aumento da média de densidade relativa foi superior a 200\% para 15 das 17 bases e 
superior a $2000 \%$ para a base pyrim. Reflexo visivelmente correlacionado é observado também nas taxas de redução de dimensionalidade apresentadas na Figura 5.4.

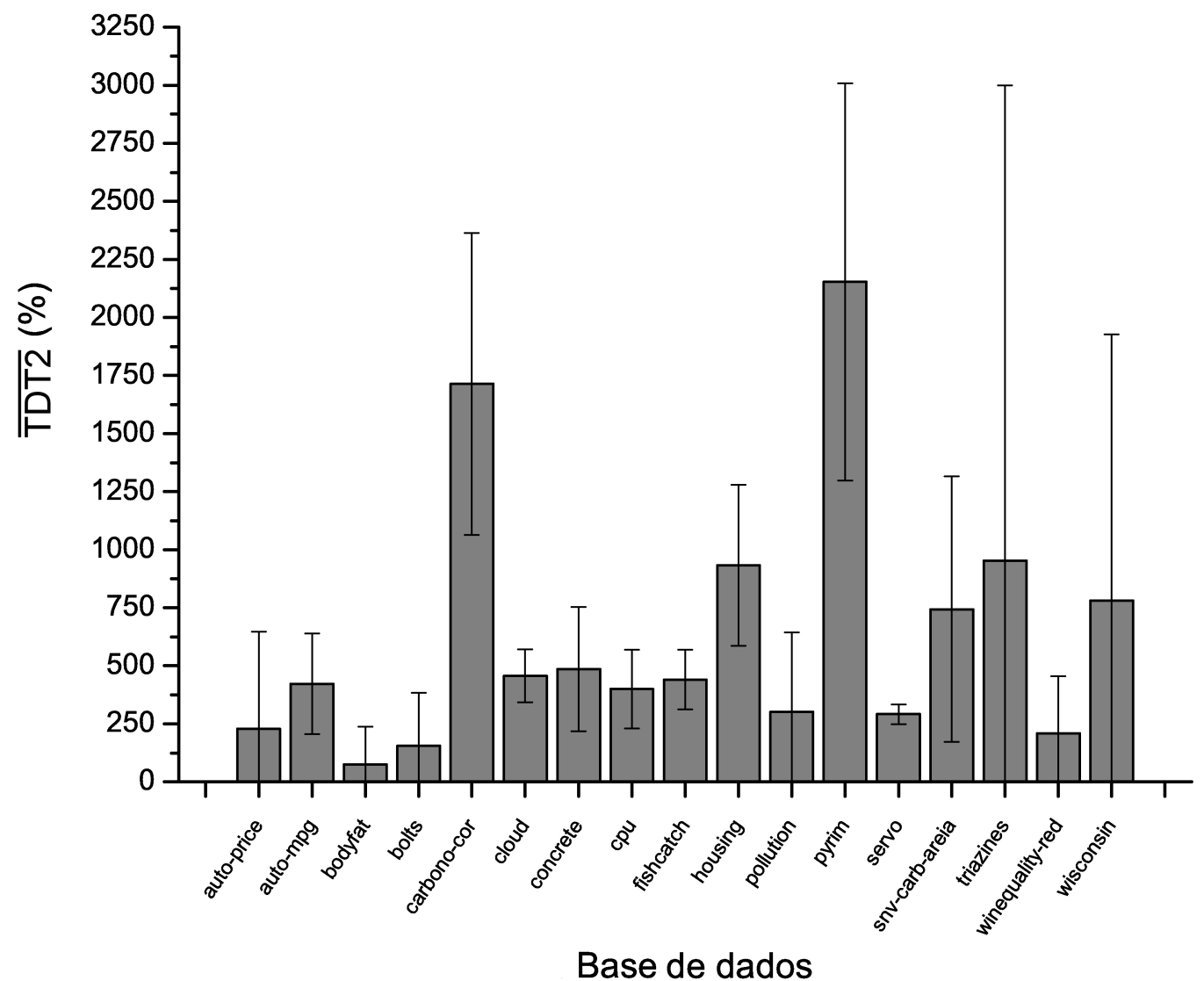

Figura 5.3: Taxa de densidade média T2 - ORPT(RBF).

Similarmente ao observado com ORPT $(\mathrm{kNN})$, o gráfico da TRD (Figura 5.4) torna evidente que foi freqüente e diversificado o uso do artifício da projeção em subespaço para obtenção de soluções em prol do desempenho da RBF. Para todas as bases a TRD foi superior a 25\%. Em 13 das 17 bases essa taxa foi superior a $40 \%$ e para as bases carbono-cor, cloud, housing e pyrim a TRD foi ainda mais drástica, apresentando média superior a $80 \%$ de redução. Essa redução considerável na dimensionalidade do problema e o correlacionado aumento da densidade ( $\overline{\mathrm{TDT} 2}$ ) auxiliam na compreensão do desempenho superior de ORPT(RBF) em relação a RBF.

A ORP para regressão proporcionou forte impacto na redução da complexidade e da dimensionalidade do problema tanto para uma SLT estável e robusta à rotação como o kNN, quanto para uma SLT instável e insensível à rotação como a RBF. Modelos induzidos de dados de reduzida dimensionalidade e complexidade tendem a ser menos complexos, mais robustos e acurados. Os erros e comparações apresentados na Tabela 5.1 e na Tabela 5.2 corroboram essa tendência e mostram que não houve nenhuma degradação estatisticamente importante no desempenho com ORPT. Ao contrário, a transformação de ORP tende a melhorar significativamente o desempenho 


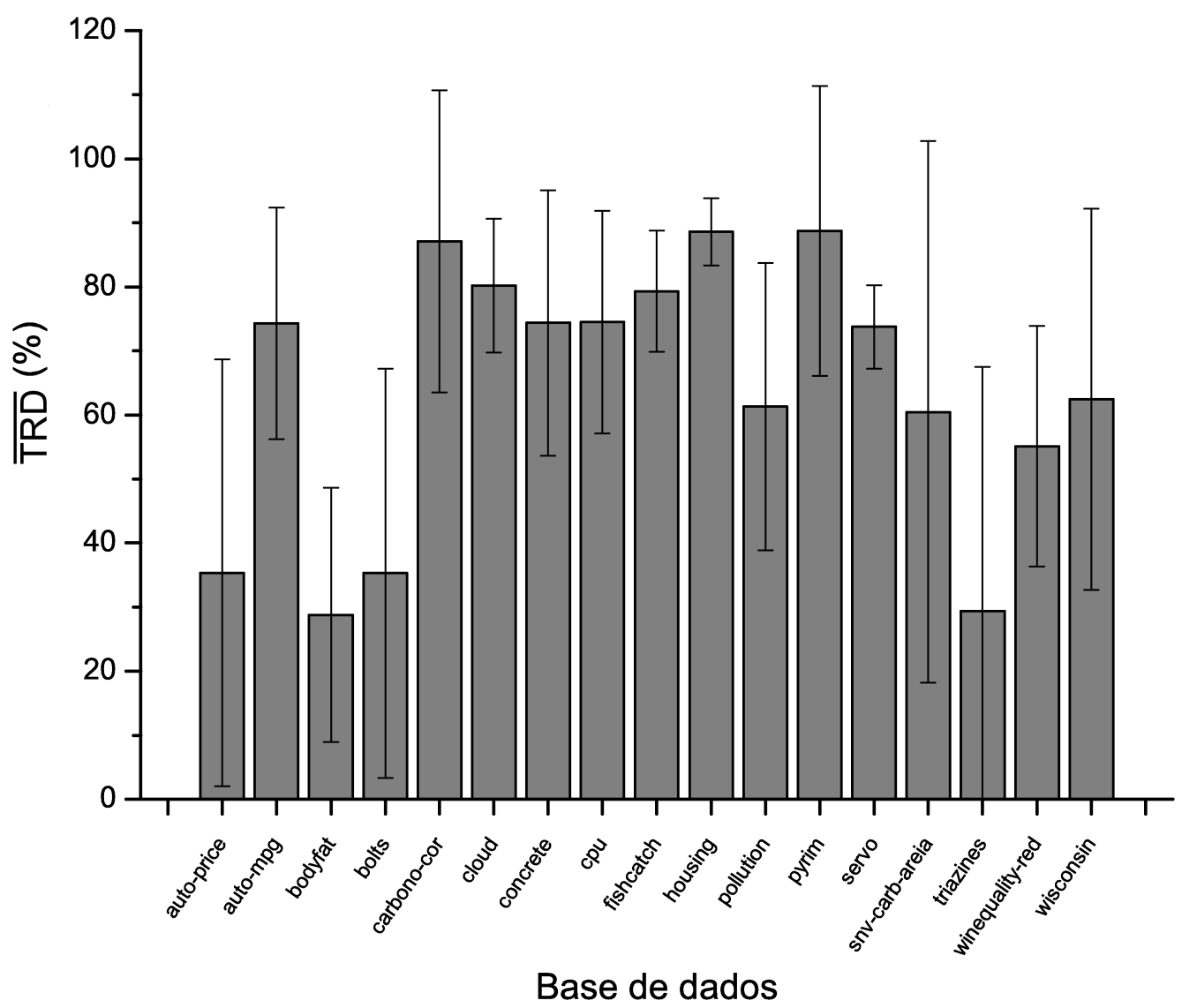

Figura 5.4: Taxa de redução de dimensionalidade - ORPT(RBF).

da SLT adotada para indução do modelo de regressão.

A natureza mandatoriamente ordinal de um modelo de regressão agrega precisão à medida do erro residual. É provável que o relativo sucesso de ORPT em regressão decorra, principalmente, da capacidade que a REQM possui para estimar, com maior precisão, a direção e o subespaço de projeção no processo de otimização.

\subsubsection{Análise do desempenho de ORPT(J48) em classificação}

Um total de 40 bases de classificação, entre públicas e privadas, foram utilizadas para análise e comparação do desempenho de ORPT(J48) e J48. Na Tabela 5.3 são apresentadas as médias de acurácia (\% de acerto) e os respectivos desvios padrão para todas as bases do estudo. Em 31 bases não houve diferença mínima significativa entre ORPT(J48) e J48. Contudo, ORPT(J48) superou significativamente J48 em balancescale, car e waveform e foi superado em 6 bases: autos, primary-tumor, segment, soybean, vote e yeast.

Esse resultado aparentemente adverso era esperado para ORPT(J48) uma vez que o J48 produz modelos não-ordinais incapazes de prover estimativas precisas da 
Tabela 5.3: Acurácia em classificação - ORPT(J48).

\begin{tabular}{|c|c|c|}
\hline Base de dados & ORPT(J48) & $\mathrm{J} 48$ \\
\hline audiology & $71,72 \pm 8,89$ & $76,96 \pm 7,65$ \\
\hline autos & $65,57 \pm 9,58$ & $77,04 \pm 8,76 \circ$ \\
\hline balance-scale & $91,70 \pm 4,45$ & $77,82 \pm 3,42 \bullet$ \\
\hline breast-cancer & $72,25 \pm 6,21$ & $70,29 \pm 6,87$ \\
\hline breast-cancer-wisc & $95,52 \pm 2,62$ & $94,89 \pm 2,49$ \\
\hline breast-tissue & $64,58 \pm 13,65$ & $65,41 \pm 12,83$ \\
\hline cafes-centroids & $65,10 \pm 20,65$ & $78,15 \pm 20,79$ \\
\hline car & $98,61 \pm 1,27$ & $97,34 \pm 1,26 \bullet$ \\
\hline cleveland-14-heart & $76,58 \pm 7,35$ & $77,99 \pm 6,53$ \\
\hline credit-rating & $83,91 \pm 4,27$ & $84,84 \pm 3,91$ \\
\hline ecoli & $81,10 \pm 5,82$ & $82,83 \pm 5,73$ \\
\hline glass & $65,64 \pm 10,29$ & $67,63 \pm 9,31$ \\
\hline greening & $67,53 \pm 10,28$ & $67,93 \pm 10,75$ \\
\hline greening $N$ & $69,93 \pm 12,52$ & $69,07 \pm 11,35$ \\
\hline haberman & $71,72 \pm 4,70$ & $70,75 \pm 4,93$ \\
\hline heart-statlog & $76,70 \pm 7,52$ & $78,15 \pm 7,42$ \\
\hline hepatitis & $79,57 \pm 10,24$ & $77,41 \pm 9,85$ \\
\hline horse-colic & $78,21 \pm 6,98$ & $83,01 \pm 5,73$ \\
\hline hungarian-heart & $77,98 \pm 7,35$ & $78,83 \pm 7,10$ \\
\hline ionosphere & $88,89 \pm 5,11$ & $89,74 \pm 4,38$ \\
\hline iris & $94,93 \pm 5,69$ & $94,73 \pm 5,30$ \\
\hline labor & $84,03 \pm 14,99$ & $85,27 \pm 13,69$ \\
\hline lung-cancer & $42,42 \pm 24,36$ & $40,33 \pm 25,89$ \\
\hline lymphography & $72,04 \pm 12,12$ & $80,11 \pm 9,20$ \\
\hline mfeat-morpho & $72,56 \pm 2,59$ & $72,02 \pm 2,44$ \\
\hline parkinsons & $88,18 \pm 7,34$ & $84,74 \pm 8,01$ \\
\hline pima-diabetes & $73,67 \pm 4,85$ & $74,49 \pm 5,27$ \\
\hline primary-tumor & $35,17 \pm 6,90$ & $41,45 \pm 6,70 \circ$ \\
\hline segment & $95,46 \pm 1,38$ & $96,79 \pm 1,29 \circ$ \\
\hline sonar & $73,70 \pm 8,11$ & $73,61 \pm 9,34$ \\
\hline soybean & $86,66 \pm 4,50$ & $92,38 \pm 2,86$ ○ \\
\hline transfusion & $78,53 \pm 3,56$ & $78,20 \pm 3,71$ \\
\hline vehicle & $69,25 \pm 5,39$ & $72,28 \pm 4,32$ \\
\hline vote & $92,41 \pm 3,89$ & $96,27 \pm 2,79 \circ$ \\
\hline vowel-c & $80,07 \pm 4,34$ & $80,34 \pm 4,75$ \\
\hline vowel- $n$ & $79,90 \pm 4,93$ & $79,34 \pm 4,66$ \\
\hline waveform & $78,58 \pm 2,20$ & $75,25 \pm 1,90 \bullet$ \\
\hline wine & $92,01 \pm 6,96$ & $93,20 \pm 5,90$ \\
\hline yeast & $53,03 \pm 3,79$ & $56,42 \pm 3,57 \circ$ \\
\hline$z o o$ & $90,10 \pm 8,71$ & $92,61 \pm 7,33$ \\
\hline Média & 76,89 & 78,15 \\
\hline
\end{tabular}

REQM para as soluções produzidas durante o processo de otimização (vide Seção 3.6). Ainda assim, é possível extrair algumas informações correlacionadas com esse desempenho por meio da análise de $\overline{\mathrm{TDT} 2}, \overline{\mathrm{TRD}}$ e, principalmente, de $\overline{\mathrm{TA}}$. Na Figura 5.5 é apresentado o gráfico de barras de $\overline{\text { TDT2 }}$ para todas as bases. Em geral, os percentuais de aumento da densidade foram consideravelmente inferiores aos observados nas bases de regressão. Em 32 das 40 bases a TDT2 foi inferior a $15 \%$ e a máxima taxa obtida foi de 27,08\% para a base cafes-centroids da Embrapa.

O fator responsável pela TDT2 relativamente baixa está diretamente relacionado com a redução de dimensionalidade do problema. Diferentemente das SLTs utilizadas nos problemas de regressão anteriores, que utilizam todos os atributos no modelo final induzido, o J48 realiza uma seleção embutida dos atributos utilizados na construção da árvore de classificação. Essa seleção faz com que o desempenho da técnica diretora retrate apenas o subconjunto selecionado e não o subespaço de projeção como um 


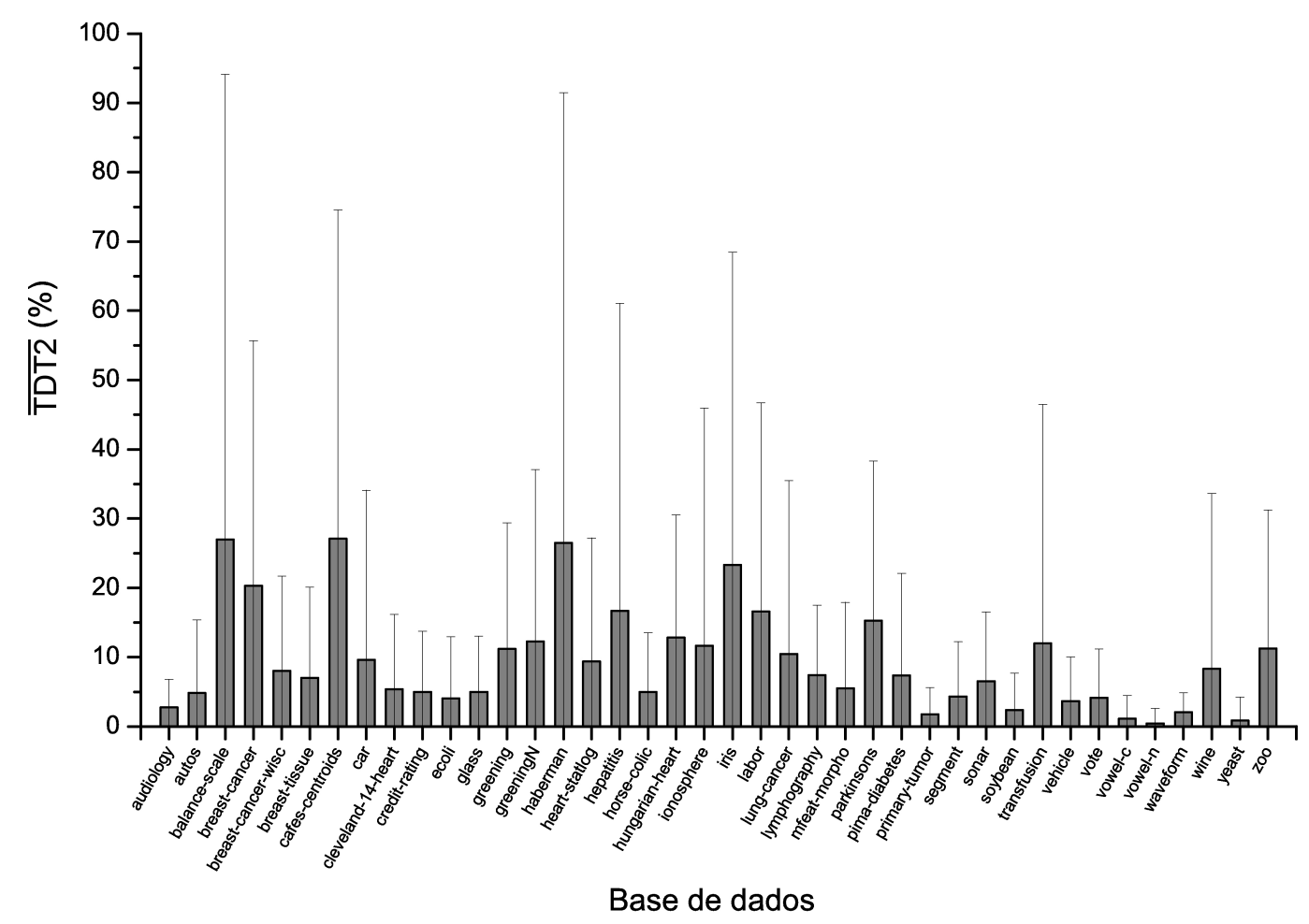

Figura 5.5: Taxa de densidade média T2 - ORPT(J48).

todo. Isso contribui para a imprecisão da otimização do tamanho do subespaço de projeção. Em outras palavras, trata-se de uma multimodalidade da função-objetivo relacionada com a dimensão do subespaço. Assim, é esperado que as taxas de redução de dimensionalidade obtidas nas diferentes iterações de validação apresentem desvios padrão relativamente altos como reflexo principal da imprecisão característica da dimensão do subespaço de projeção. Na Figura 5.6 são apresentadas as TRD's com os respectivos desvios padrão para todas as bases consideradas no estudo.

Observa-se, nas $\overline{\mathrm{TRD}}$ 's de ORPT(J48) (Figura 5.6), que as médias percentuais obtidas foram relativamente baixas e desvios visivelmente exacerbados. Em 34 bases a $\overline{\text { TRD }}$ foi inferior a $10 \%$ e a máxima obtida, base cafe-centroids, não superou $15 \%$ de redução. Embora as bases em que $\operatorname{ORPT}(\mathrm{J} 48)$ apresentou acurácia estatisticamente inferior ao J48 tenham sido impactada por taxas muito baixas, inferiores a $4 \%$, apenas a TRD não é suficiente para prover indícios do desempenho inadequado de ORPT(J48) em uma base de dados. Nesse caso, a análise da complexidade da árvore induzida pode auxiliar na compreensão dos resultados e no desenvolvimento de trabalhos futuros.

Na Tabela 5.4 são apresentadas as médias e os desvios padrão do tamanho das árvores induzidas $(\overline{\mathrm{TA}})$ nas diferentes iterações da validação cruzada para cada uma das bases de dados. Em 20 bases o $\overline{\mathrm{TA}}$ obtido após a ORP foi significativamente menor do que o $\overline{\mathrm{TA}}$ com J48 diretamente nos dados originais. Para 14 bases não 


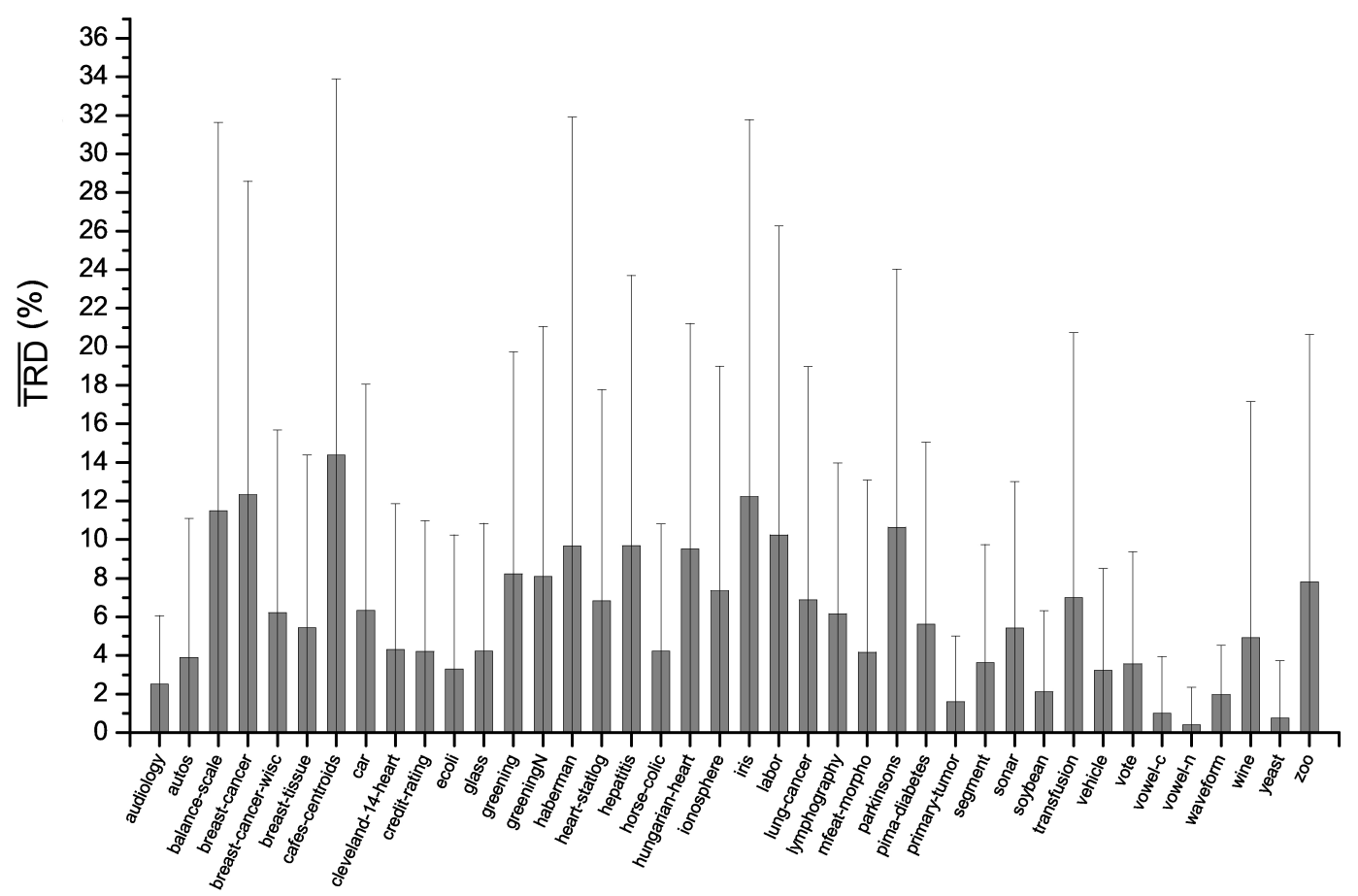

Base de dados

Figura 5.6: Taxa de redução de dimensionalidade - ORPT(J48).

houve diferença significativa e em apenas 6 bases houve um aumento significativo de $\overline{\mathrm{TA}}$. Nas bases em que ORPT(J48) superou J48 em acurácia também houve redução do $\overline{\mathrm{TA}}$ e em 4 das 6 bases em que ORPT(J48) foi superado na acurácia por J48 houve um aumento significativo de $\overline{\mathrm{TA}}$. Na base yeast o J48 superou ORPT(J48), porém não foi constatada diferença significativa entre as TAs. Somente para a base autos ocorreu uma inversão, ou seja, tanto a complexidade medida por $\overline{\mathrm{TA}}$ como acurácia média foram significativamente reduzidas. Uma causa possível para esse efeito é a poda exagerada provocada pela definição do fator de confiança mínimo do J48 para a técnica diretora.

A ORP com uma técnica diretora de menor complexidade realmente tende a reduzir a complexidade do modelo final. Porém, a definição do fator de confiança da poda para a técnica diretora não pareceu ser um parâmetro de controle de complexidade trivial e efetivo para ORPT(J48), pois em 6 bases foi observado um aumento significativo do tamanho médio das árvores. Adicionalmente, o ajuste adequado é complexo uma vez que a poda resultante pode ser exagerada ou insuficiente em alguns problemas de classificação. No entanto, a opção pelo mínimo surtiu efeito na redução da complexidade em metade das bases utilizadas e, mesmo não tendo sido adequada para ORPT(J48), é útil como heurística para ser utilizada em ORPE(J48). Isso permite inferir que ORPE(J48) deve apresentar como característica a tendência de construir MCs de menores complexidades e, conseqüentemente, ensembles menos complexos. 
Tabela 5.4: Média dos tamanhos das árvores induzidas - ORPT(J48).

\begin{tabular}{|c|c|c|}
\hline Base de dados & ORPT(J48) & $\mathrm{J} 48$ \\
\hline audiology & $51,16 \pm 3,12$ & $46,56 \pm 2,82 \bullet$ \\
\hline autos & $47,42 \pm 3,54$ & $51,40 \pm 3,60 \circ$ \\
\hline balance-scale & $34,54 \pm 13,24$ & $82,20 \pm 9,93 \circ$ \\
\hline breast-cancer & $14,50 \pm 4,12$ & $25,82 \pm 8,33 \circ$ \\
\hline breast-cancer-wisc & $14,78 \pm 2,98$ & $24,56 \pm 5,60 \circ$ \\
\hline breast-tissue & $22,40 \pm 2,67$ & $25,54 \pm 3,34 \circ$ \\
\hline cafes-centroids & $7,18 \pm 0,58$ & $8,68 \pm 0,97 \circ$ \\
\hline car & $51,04 \pm 12,80$ & $108,64 \pm 5,32 \circ$ \\
\hline cleveland-14-heart & $28,66 \pm 6,34$ & $42,60 \pm 6,60 \circ$ \\
\hline credit-rating & $33,90 \pm 8,64$ & $50,08 \pm 10,98 \circ$ \\
\hline ecoli & $28,80 \pm 3,61$ & $36,18 \pm 5,62 \circ$ \\
\hline glass & $43,62 \pm 5,08$ & $46,16 \pm 4,58$ \\
\hline greening & $23,76 \pm 3,05$ & $27,78 \pm 6,22$ \\
\hline greening $N$ & $23,92 \pm 3,01$ & $22,50 \pm 7,58$ \\
\hline haberman & $4,60 \pm 3,20$ & $6,60 \pm 4,30$ \\
\hline heart-statlog & $24,14 \pm 5,77$ & $34,64 \pm 5,72 \circ$ \\
\hline hepatitis & $16,92 \pm 2,63$ & $20,40 \pm 4,50$ \\
\hline horse-colic & $31,96 \pm 8,52$ & $33,14 \pm 7,57$ \\
\hline hungarian-heart & $21,94 \pm 5,40$ & $23,38 \pm 7,35$ \\
\hline ionosphere & $21,18 \pm 5,01$ & $26,74 \pm 3,89 \circ$ \\
\hline iris & $7,66 \pm 1,39$ & $8,28 \pm 1,19$ \\
\hline labor & $5,94 \pm 1,43$ & $8,96 \pm 1,63 \circ$ \\
\hline lung-cancer & $8,30 \pm 1,00$ & $12,92 \pm 2,39 \circ$ \\
\hline lymphography & $21,64 \pm 2,93$ & $29,10 \pm 4,35 \circ$ \\
\hline mfeat-morpho & $158,42 \pm 17,21$ & $163,26 \pm 17,38$ \\
\hline parkinsons & $15,50 \pm 1,87$ & $19,48 \pm 2,58$ ○ \\
\hline pima-diabetes & $30,28 \pm 10,64$ & $43,40 \pm 13,10 \circ$ \\
\hline primary-tumor & $104,46 \pm 6,43$ & $82,56 \pm 9,87 \bullet$ \\
\hline segment & $90,48 \pm 10,18$ & $81,42 \pm 6,10 \bullet$ \\
\hline sonar & $26,84 \pm 2,72$ & $27,90 \pm 3,50$ \\
\hline soybean & $80,12 \pm 5,37$ & $72,66 \pm 8,99 \bullet$ \\
\hline transfusion & $7,28 \pm 3,47$ & $12,00 \pm 4,18 \circ$ \\
\hline vehicle & $123,36 \pm 15,38$ & $138,00 \pm 20,57$ \\
\hline vote & $19,54 \pm 4,24$ & $10,54 \pm 1,20 \bullet$ \\
\hline vowel-c & $184,84 \pm 12,34$ & $185,26 \pm 9,01$ \\
\hline vowel- $n$ & $177,98 \pm 11,24$ & $187,10 \pm 8,33$ \\
\hline waveform & $469,56 \pm 51,38$ & $591,94 \pm 24,31 \circ$ \\
\hline wine & $11,26 \pm 1,52$ & $9,60 \pm 1,26 \bullet$ \\
\hline yeast & $318,44 \pm 27,49$ & $323,94 \pm 25,45$ \\
\hline$z o o$ & $13,12 \pm 0,56$ & $15,70 \pm 1,64 \circ$ \\
\hline Média & 60,54 & 69,19 \\
\hline
\end{tabular}

\subsubsection{Análise do desempenho de ORPT(NB) em classificação}

As acurácias médias obtidas com ORPT(NB) e NB e os respectivos desvios padrão para todas as bases de classificação são apresentados na Tabela 5.5. Em 16 bases a ORPT(NB) superou o NB com diferença significativa; e para 23 as diferenças não foram estatisticamente importantes. O NB superou significativamente ORPT(NB) apenas na base zoo. Assim, é possível extrair desses resultados que, em geral, a transformação dos dados pela ORP tende fortemente a beneficiar o desempenho do NB.

O aumento da taxa de densidade média, medido por TDT2, ocorreu em alguma proporção para a maioria das bases, mas de forma bastante particular como mostrado na Figura 5.7. Para as bases breast-cancer-wisc, hepatitis e parkinsons a TDT2 foi superior a 200\%. Por outro lado, para as bases balance-scale, car, vowel-c, vowel-n 
Tabela 5.5: Acurácia em classificação - ORPT(NB).

\begin{tabular}{lll}
\hline Base de dados & ORPT(NB) & NB \\
\hline audiology & $75,85 \pm 7,26$ & $79,05 \pm 7,69$ \\
autos & $69,52 \pm 7,96$ & $50,45 \pm 9,56 \bullet$ \\
balance-scale & $91,47 \pm 3,20$ & $90,53 \pm 1,67$ \\
breast-cancer & $73,58 \pm 7,07$ & $71,70 \pm 7,27$ \\
breast-cancer-wisc & $95,95 \pm 2,40$ & $96,12 \pm 2,16$ \\
breast-tissue & $69,84 \pm 13,07$ & $67,75 \pm 13,69$ \\
cafes-centroids & $73,50 \pm 20,11$ & $71,75 \pm 21,17$ \\
car & $90,62 \pm 2,02$ & $82,34 \pm 2,52 \bullet$ \\
cleveland-14-heart & $80,47 \pm 6,48$ & $82,02 \pm 7,93$ \\
credit-rating & $85,14 \pm 4,12$ & $75,52 \pm 4,22 \bullet$ \\
ecoli & $86,22 \pm 5,39$ & $85,50 \pm 5,46$ \\
glass & $64,97 \pm 9,12$ & $49,45 \pm 9,50 \bullet$ \\
greening & $74,00 \pm 10,91$ & $74,80 \pm 9,69$ \\
greeningN & $76,67 \pm 10,36$ & $77,53 \pm 10,37$ \\
haberman & $72,78 \pm 3,99$ & $74,83 \pm 5,31$ \\
heart-statlog & $81,44 \pm 6,67$ & $83,59 \pm 5,98$ \\
hepatitis & $81,79 \pm 9,80$ & $84,00 \pm 9,81$ \\
horse-colic & $82,12 \pm 6,02$ & $75,23 \pm 6,99 \bullet$ \\
hungarian-heart & $83,71 \pm 6,49$ & $83,20 \pm 6,36$ \\
ionosphere & $94,20 \pm 3,85$ & $82,17 \pm 6,14 \bullet$ \\
iris & $96,40 \pm 4,59$ & $95,53 \pm 5,02$ \\
labor & $93,40 \pm 10,03$ & $95,30 \pm 8,81$ \\
lung-cancer & $45,83 \pm 24,69$ & $56,58 \pm 25,33$ \\
lymphography & $84,26 \pm 8,39$ & $80,78 \pm 10,32$ \\
mfeat-morpho & $74,19 \pm 2,54$ & $69,49 \pm 2,74 \bullet$ \\
parkinsons & $85,55 \pm 7,78$ & $70,14 \pm 9,30 \bullet$ \\
pima-diabetes & $76,61 \pm 4,64$ & $75,75 \pm 5,32$ \\
primary-tumor & $41,96 \pm 6,37$ & $42,96 \pm 6,24$ \\
segment & $94,94 \pm 1,26$ & $80,17 \pm 2,12 \bullet$ \\
sonar & $86,17 \pm 7,04$ & $67,71 \pm 8,66 \bullet$ \\
soybean & $90,55 \pm 3,03$ & $91,99 \pm 3,00$ \\
transfusion & $78,64 \pm 2,70$ & $75,28 \pm 3,47 \bullet$ \\
vehicle & $76,79 \pm 4,34$ & $44,68 \pm 4,59 \bullet$ \\
vote & $95,38 \pm 2,80$ & $91,38 \pm 3,78 \bullet$ \\
vowel-c & $82,75 \pm 4,16$ & $66,32 \pm 4,46 \bullet$ \\
vowel- & $79,26 \pm 4,50$ & $67,03 \pm 4,50 \bullet$ \\
waveform & $85,15 \pm 1,61$ & $80,01 \pm 1,45 \bullet$ \\
wine & $98,70 \pm 2,89$ & $97,46 \pm 3,70$ \\
yeast & $58,28 \pm 3,69$ & $57,99 \pm 3,33$ \\
zoo & $89,89 \pm 8,00$ & $96,95 \pm 4,75 \circ$ \\
\hline Média & & 76,03 \\
& &
\end{tabular}

e zoo as taxas foram inferiores a $2 \%$. Apenas para a base car não houve mudança na densidade, o que indica que o artifício da projeção não foi utilizado na transformação de ORP (somente rotação das instâncias). A base hepatitis apresentou um alto desvio padrão da densidade, que pode ser explicado por soluções encontradas (ótimos/subótimos) em subespaços de dimensões bastante variadas (novamente, uma provável característica de multimodalidade relacionada com a dimensão do espaço de projeção).

Complementando a análise de TDT2, na Figura 5.8 são apresentadas as $\overline{\text { TRD }}$ 's. A maior taxa de redução de dimensionalidade produzida pela ORP ocorreu na base parkinsons com 79,23\%. O desvio padrão em ORPT(NB) para a referida base foi relativamente pequeno indicando que as soluções de ORP encontradas são mais homogêneas em termos da dimensão do subespaço de projeção. Os coeficientes de variação (desvios padrão relativos) da $\overline{\mathrm{TRD}}$ com ORPT(NB) se apresentaram menores do que 


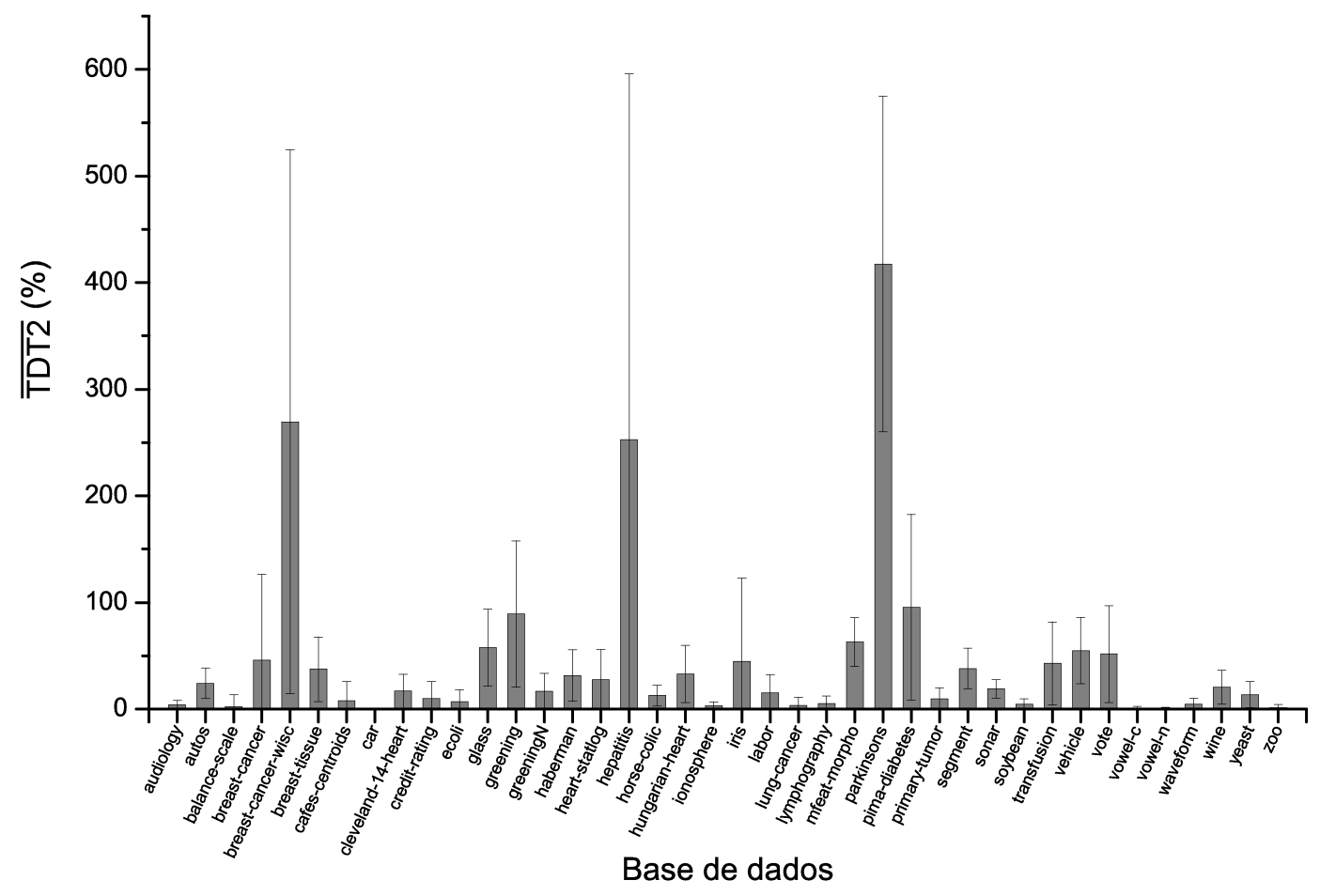

Figura 5.7: Taxa de densidade média T2 - ORPT(NB).

aqueles obtidos com ORPT(J48) para 34 bases de dados.

Não foi encontrada nenhuma relação direta entre a redução da complexidade ou da dimensionalidade dos dados com o desempenho apresentado por ORPT(NB) (Tabela 5.5). A hipótese para o ótimo desempenho observado com ORPT(NB) baseia-se na capacidade do NB produzir algum tipo de ordinalidade na saída do modelo. Embora a estimativa de probabilidade de classes produzida pelo NB seja considerada pobre (DOMINGOS; PAZZANI, 1996; ZHANG; SU, 2004), ainda assim ela é mais precisa do que aquela produzida por modelos não-ordinais que limitam-se a produzir saídas binárias. Uma estimativa um pouco mais realista das probabilidades de classes repercurte positivamente na fidelidade da REQM no processo de otimização e, conseqüentemente, na qualidade e precisão da transformação de roto-projeção.

\subsection{Experimento ensembles}

Similarmente ao experimento anterior, este também foi subdividido em 4 análises de acordo com as tarefas de modelagem e SLTs adotadas. As duas primeiras subseções apresentam as análises dos resultados obtidos com ORPE(kNN) e ORPE(RBF) para regressão. Nas duas subseções seguintes são apresentados os desempenhos e comparações de classificação com ORPE(J48) e ORPE(NB). Os desempenhos já apresentados no experimento roto-projeção foram incluídos nessas análises para verificar se ORPE 


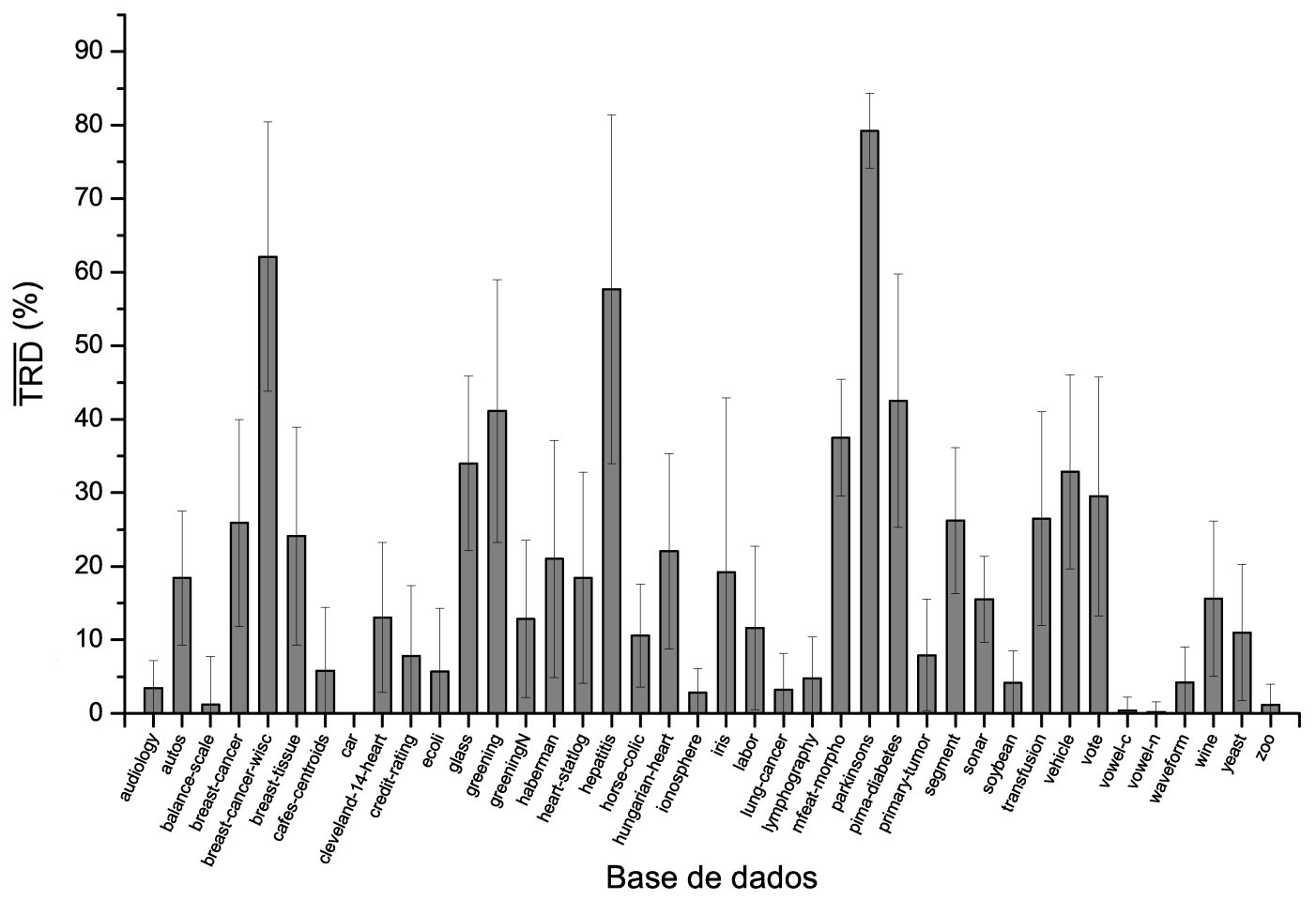

Figura 5.8: Taxa de redução de dimensionalidade - ORPT(NB).

produziu aumento ou degradação do desempenho em relação à SLT utilizada de forma singular com e sem a ORP.

No final de cada análise foi incluído um quadro de ranqueamento de dominância dos EMs e SLTs tal como realizado por Kuncheva e Rodríguez (KUNCHEVA; RODRÍGUEZ, 2007). Para esse ranqueamento, cada método foi comparado com todos os outros, par-a-par, e os ganhos e perdas significativas foram contabilizados para determinação da dominância. A dominância de um método é o resultado da diferença entre o número de ganhos e o número de perdas estatisticamente significativas em todas as bases do estudo. Assim, quanto maior a dominância de um método, melhor será seu posicionamento no ranqueamento em relação aos demais.

\subsubsection{Análise do desempenho de $\operatorname{ORPE}(k N N)$ em regressão}

Na Tabela 5.6 são apresentadas as médias da REQM e os respectivos desvios padrão obtidos com ORPE(kNN), kNN, RPEM(kNN), RSM(kNN), RSM-IPCS(kNN), $\mathrm{RB}(\mathrm{kNN})$ e ORPT $(\mathrm{kNN})$. O método $\mathrm{ORPE}(\mathrm{kNN})$ não foi superado estatisticamente por nenhum dos EMs ou SLTs em todas as bases de regressão. As médias da REQM obtidas com ORPE $(\mathrm{kNN})$ foram significativamente menores do que as médias de RPEM(kNN) em 7 bases; de RSM(kNN) em 8 bases; de RSM-IPCS em 11 bases; e de $\mathrm{RB}(\mathrm{kNN})$ em 9 bases de dados. Adicionalmente, $\mathrm{ORPE}(\mathrm{kNN})$ apresentou médias significativamente menores às obtidas com kNN para 10 bases e superou o próprio 
ORPT $(\mathrm{kNN})$ em 5 bases, tendo reduzido de modo significativo ainda mais a média da REQM nas bases bodyfat e fishcatch.

Na Tabela 5.7 é apresentado o ranqueamento de dominância para todos EMs e SLTs analisadas na regressão utilizando o kNN. O método ORPE $(\mathrm{kNN})$ foi o primeiro no ranqueamento com uma vantagem considerável para o segundo colocado. $\mathrm{O}$ ORPT $(\mathrm{kNN})$ foi o segundo no ranqueamento de dominância também com considerável vantagem sobre o terceiro. O método $\mathrm{RB}(\mathrm{kNN})$ assumiu apenas o quarto lugar no raqueamento dos métodos com uma dominância consideravelmente menor do que $\operatorname{ORPE}(\mathrm{kNN})$ e ORPT $(\mathrm{kNN})$.

Em síntese, os resultados apresentados na Tabela 5.6 e do ranqueamento de dominância (Tabela 5.7) mostram que ORPE foi significativamente superior aos outros EMs e SLTs e, enfaticamente, superior ao método RB para regressão com kNN. É possível extrair dessa análise que ORPE tende fortemente a melhorar o desempenho de um ensemble de regressão com o kNN sem degradá-lo quando nenhuma melhoria é possível.

\subsubsection{Análise do desempenho de ORPE(RBF) em regressão}

Na Tabela 5.8 são apresentadas as médias de REQM e os respectivos desvios obtidos com ORPE(RBF), RBF, RPEM(RBF), RSM(RBF), RSM-IPCS(RBF), RB(RBF) e ORPT(RBF). Os resultados tornam evidente a superioridade de ORPE(RBF) em relação aos EMs e SLTs considerados na análise comparativa. O método ORPE(RBF) apresentou as menores médias de REQM e não foi superado estatisticamente por nenhum dos EMs/SLTs para todas as bases de regressão do estudo. Ao contrário, na comparação pareada com outros EMs, ORPE(RBF) superou significativamente RPEM(RBF) em 15 bases; RSM(RBF) em 14 bases; RSM-IPCS(RBF) em 16 bases; e $\mathrm{RB}(\mathrm{RBF})$ em 16 bases de dados. Note-se que, o desempenho de ORPE(RBF) foi muito superior ao método RB com uma SLT instável e apropriada para utilização com esse último EM (RODRÍGUEZ; MAUDES; ALONSO, 2006).

O método ORPE(RBF) superou a RBF em 16 bases e apresentou ainda redução estatisticamente significativa das médias de REQM em bodyfat, concrete, triazines e wisconsin quando comparado com sua SLT cerne: ORPT(RBF). Nas bases bodyfat e concrete, nas quais ORPT(RBF) já havia apresentado desempenho estatisticamente superior à RBF, ORPE(RBF) construiu ensembles ainda superiores. Apenas para a base snv-carb-areia da Embrapa não houve diferença mínima significativa, mas, ainda assim, a média de REQM com ORPE(RBF) foi a menor dentre as obtidas por todos os EMs e SLTs considerados no experimento. 


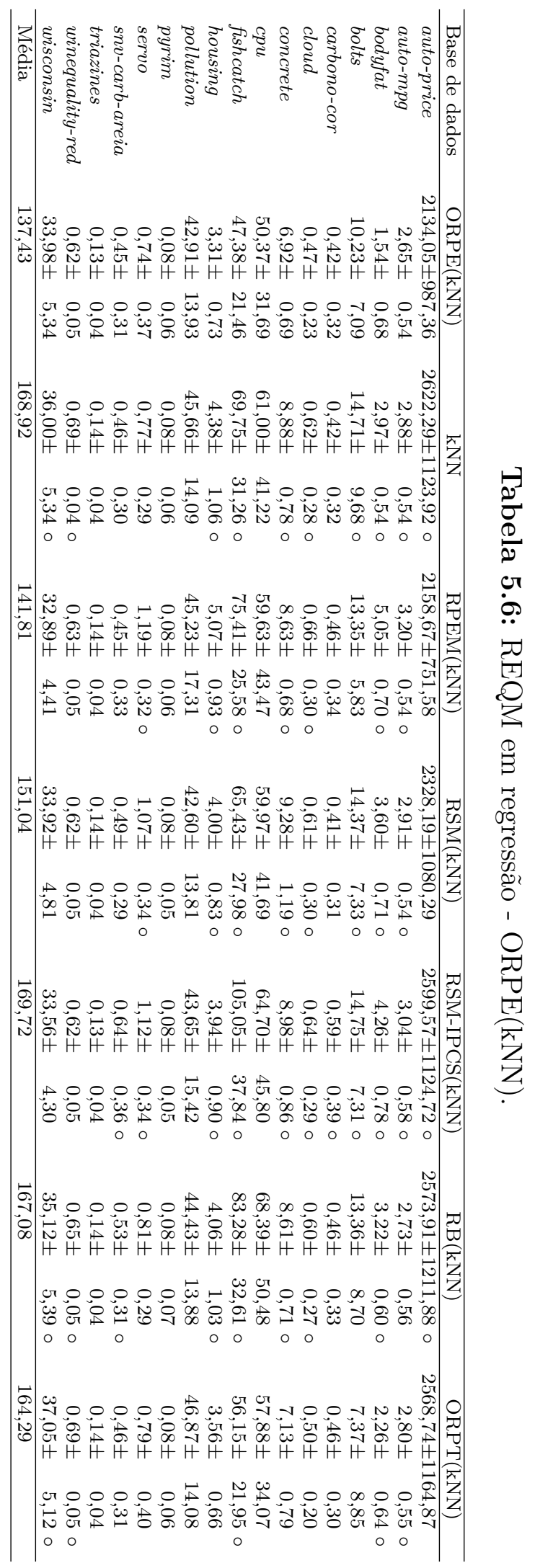


Tabela 5.7: Ranqueamento de dominância - ORPE(kNN).

\begin{tabular}{cccc}
\hline SLT $/$ EM & Ganha & Perde & Dominância \\
\hline ORPE(kNN) & 50 & 0 & 50 \\
ORPT(kNN) & 28 & 12 & 16 \\
RSM(kNN) & 16 & 15 & 1 \\
RB $(\mathrm{kNN})$ & 15 & 19 & -4 \\
kNN & 12 & 26 & -14 \\
RPEM $(k N N)$ & 9 & 29 & -20 \\
RSM-IPCS(kNN) & 8 & 37 & -29 \\
\hline
\end{tabular}

ORPE(RBF) foi mais efetivo na construção de ensembles em mais de $80 \%$ das bases de diversos domínios em comparação com diversos EMs eficientes da literatura, incluindo o $\mathrm{RB}(\mathrm{RBF})$. A quantidade de superações estatisticamente significativas e a ausência de deteriorações do desempenho permitem inferir que ORPE tende a construir, com alta probabilidade, um ensemble de reduzido erro de generalização para uma tarefa de regressão qualquer utilizando uma RBF.

Na Tabela 5.9 é apresentado o ranqueamento de dominância de todas as SLTs e EMs considerados no experimento com RBF para regressão. O método ORPE(RBF) e ORPT(RBF) assumiram a primeira e segunda posição no ranqueamento, respectivamente, com dominâncias muito superiores aos demais métodos. O RB(RBF) assumiu apenas a quinta posição no ranqueamento de dominância ficando, novamente, muito distante de ORPE(RBF).

Em linhas gerais, ORPE apresentou excelente desempenho em regressão tanto para uma SLT estável (kNN) como para uma instável (RBF). Esse desempenho corrobora parte da segunda asserção desta tese. Nas seções seguintes são apresentadas as análises dos resultados de ORPE nas tarefas de classificação utilizando J48 e NB.

\subsubsection{Análise do desempenho de $\operatorname{ORPE}(\mathrm{J} 48)$ em classificação}

As acurácias médias e os respectivos desvios padrão obtidos com ORPE(J48), J48, RPEM(J48), RSM(J48), RSM-IPCS(J48), RB(J48) e ORPT(J48) para todas as bases de classificação são apresentados na Tabela 5.10. Conforme esperado, o método ORPE(J48) superou ORPT(J48) em 22 bases e não apresentou diferença mínima significativa nas demais. Esses resultados constituem os indícios mais contundentes para corroborar o pressuposto de que a componente de imprecisão da direção de rotação e/ou do subespaço de projeção no processo de otimização (vide Seção 3.6) é um artifício importante para construção de ensembles.

Na comparação pareada com outros EMs, ORPE(J48) superou significativamente RPEM(J48) em 12 bases; RSM(J48) em 10 bases; RSM-IPCS(J48) em 9 bases; e $\mathrm{RB}(\mathrm{J} 48)$ em 2 bases de dados. Note-se que o método ORPE(J48) não foi superado pelo $\mathrm{RB}(\mathrm{J} 48)$ em nenhuma das bases de classificação e apresentou, ainda, média 


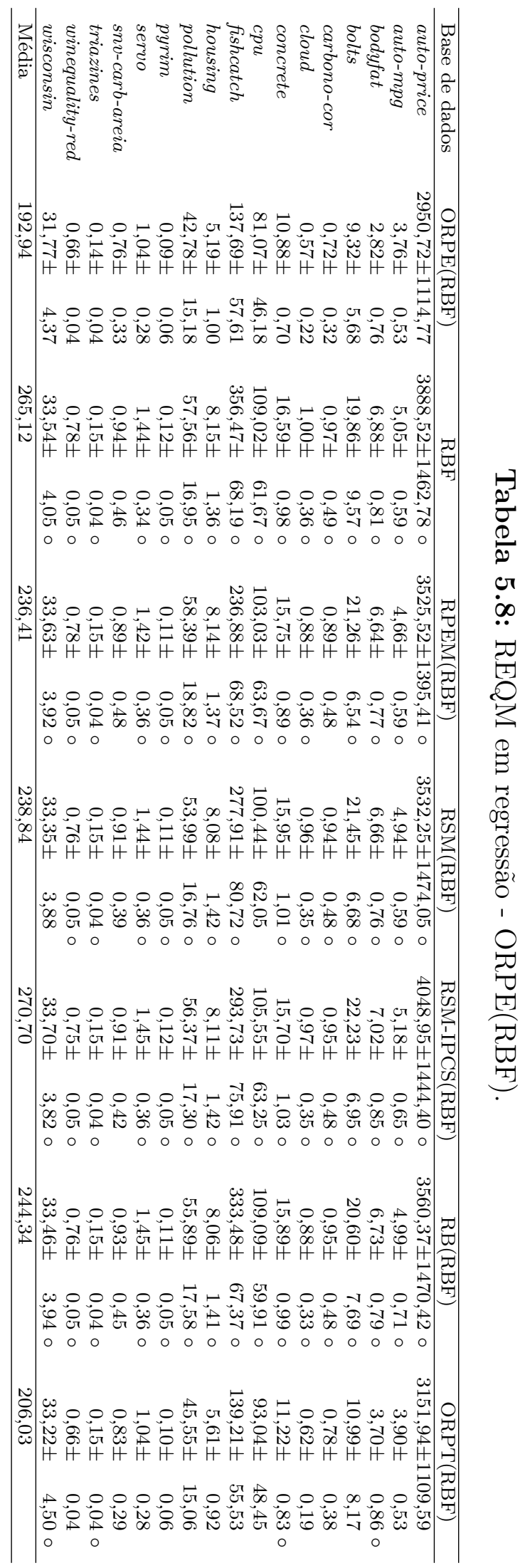


Tabela 5.9: Ranqueamento de dominância - ORPE(RBF).

\begin{tabular}{cccc}
\hline SLT/EM & Ganha & Perde & Dominância \\
\hline ORPE(RBF) & 81 & 0 & 81 \\
ORPT(RBF) & 51 & 4 & 47 \\
RPEM(RBF) & 14 & 29 & -15 \\
RSM(RBF) & 9 & 27 & -18 \\
RB(RBF) & 8 & 30 & -22 \\
RSM-IPCS(RBF) & 7 & 36 & -29 \\
RBF & 0 & 44 & -44 \\
\hline
\end{tabular}

de acurácia significativamente superior nas bases balance-scale e car. Curiosamente, balance-scale foi uma base particularmente destacada por Rodríguez e colaboradores (RODRIGUEZ; KUNCHEVA; ALONSO, 2006) como um extremo representante do excelente desempenho com $\mathrm{RB}(\mathrm{J} 48)$.

O método ORPE(J48) apresentou ainda acurácias médias significativamente maiores que as de J48 em 14 bases de dados. Dentre todas as SLTs, EMs e bases, ORPE(J48) foi superado apenas nas bases autos e soybean pelo RSM(J48).

Na Tabela 5.11 é apresentado o ranqueamento de dominância de todas as SLTs e EMs considerados no experimento com J48. Novamente, o ORPE(J48) assumiu a primeira posição no ranqueamento apresentando dominância ligeiramente superior à obtida para método RB(J48). Por outro lado, ORPT(J48) apresentou a pior dominância, tendo sido superado inclusive pelo próprio J48. Desse modo, a ORP para o J48 com as configurações utilizadas para a técnica diretora é particularmente interessante se utilizada para construção de ensembles.

\subsubsection{Análise do desempenho de $\operatorname{ORPE}(\mathrm{NB})$ em classificação}

As médias de acurácia e os respectivos desvios padrão obtidos com modelos de ORPE(NB), NB, RPEM(NB), RSM(NB), RSM-IPCS(NB), RB(NB) e ORPT(NB) para todas as bases de classificação são apresentados na Tabela 5.12. Repetindo o desempenho observado nas análises anteriores, ORPE(NB) construiu ensembles significativamente mais acurados para boa parcela das bases consideradas no estudo. Na comparação pareada com outros EMs, ORPE(NB) superou o RPEM(NB) em 26 bases; RSM(NB) em 19 bases; RSM-IPCS(NB) em 19 bases; e RB(NB) em 18 bases de dados. Dentre todas as comparativas com os demais EMs e SLTs, ORPE(NB) foi superado apenas na base zoo pelo NB, mas superou-o em 16 bases de dados.

O método ORPE(NB) obteve ainda médias de acurácias significativamente maiores que aquelas obtidas com ORPT(NB) nas bases credit-rating, vowel-c e vowel- $n$. Note-se que, para as referidas bases, somente ORPT(NB) já havia proporcionado aumento de acurácia significativo em relação ao NB, e ORPE(NB) possibilitou um aumento adicional estatisticamente relevante. Logo, ORPE(NB) tende a melhorar o 


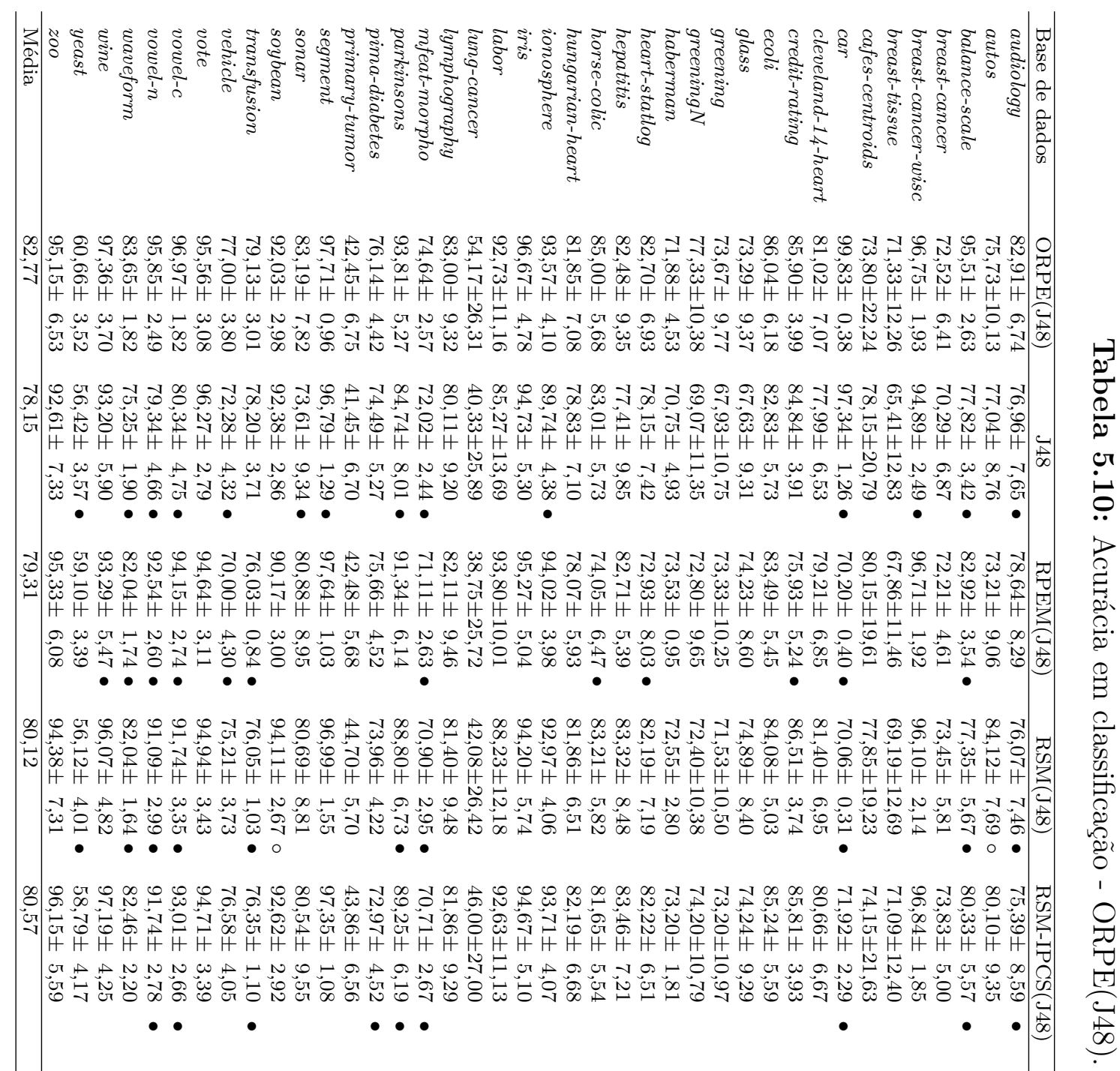

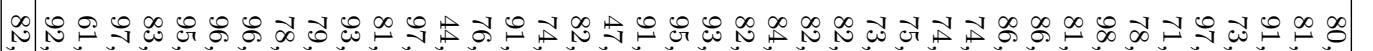

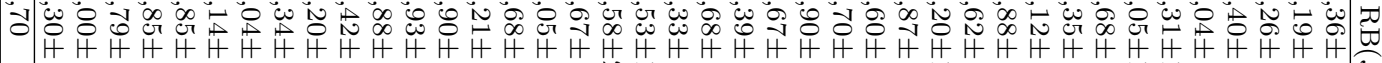
N w w ن

హె

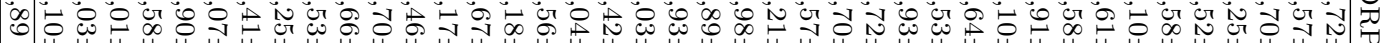

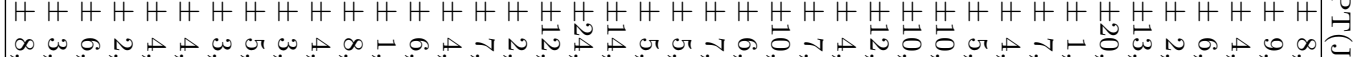

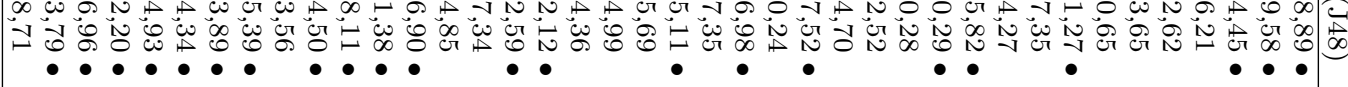


Tabela 5.11: Ranqueamento de dominância - ORPE(J48).

\begin{tabular}{cccc}
\hline SLT/EM & Ganha & Perde & Dominância \\
\hline ORPE(J48) & 69 & 2 & 67 \\
RB(J48) & 66 & 2 & 64 \\
RSM-IPCS(J48) & 32 & 18 & 14 \\
RSM(J48) & 25 & 26 & -1 \\
RPEM(J48) & 23 & 48 & -25 \\
J48 & 12 & 57 & -45 \\
ORPT(J48) & 12 & 86 & -74 \\
\hline
\end{tabular}

bom desempenho observado com ORPT(NB).

Na Tabela 5.13 é apresentado o ranqueamento de dominância de todas as SLTs e EMs considerados na análise de desempenho com NB. Novamente, ORPE(NB) dominou as demais SLTs e EMs com uma vantagem relativamente grande. ORPT(NB) foi o segundo no ranqueamento com dominância substancialmente maior que o terceiro dominante, o método $\mathrm{RB}(\mathrm{NB})$. O sumário de resultados apresentado na tabela de dominância (Tabela 5.13) torna explícita a impressionante superioridade de ORPE na construção de ensembles acurados com uma SLT relativamente estável como o NB.

\subsection{Experimento complementar}

Em regressão, ORPE(RBF) mostrou-se absoluto, em termos estatísticos, na construção de ensembles com reduzido erro de generalização, superando todas as SLTs e EMs na maioria das bases sem degradação significativa do desempenho. Esse absolutismo foi análogo para ORPE(RBF) nos problemas de classificação, como pode ser observado na Tabela 5.14. O método ORPE(RBF) não foi superado por nenhuma das SLTs e EMs nas 29 bases de dados consideradas no experimento. O método $\mathrm{ORPE}(\mathrm{RBF})$ construiu ensembles significativamente mais acurados que RBF em 8 bases; que RPEM(RBF) em 11 bases; que RSM(RBF) em 7 bases; que RSM-IPCS(RBF) em 5 bases; e que RB(RBF) em 5 bases de dados. O método ORPE(RBF) foi ainda superior ao ORPT(RBF) nas bases autos e car.

Na Tabela 5.15 é apresentado o ranqueamento de dominância de todas as SLTs e EMs considerados na análise de desempenho de classificação com RBF. Analogamente ao ocorrido no experimento ensembles com NB (Subseção 5.2.4), ORPE(RBF) assumiu a primeira posição no ranqueamento com dominância 2,375 vezes maior que o RB(RBF). Surpreendentemente, ORPT(RBF) assumiu a segunda posição no ranqueamento, com dominância ligeiramente superior ao RB(RBF). Essa descoberta, aliada aos resultados observados com ORPT(NB) (vide Subseção 5.1.4), reforçam a hipótese de que as direções de rotação e os subespaços de projeção são mais precisa e adequadamente otimizados quando a distribuição de probabilidade de classes reflete, 


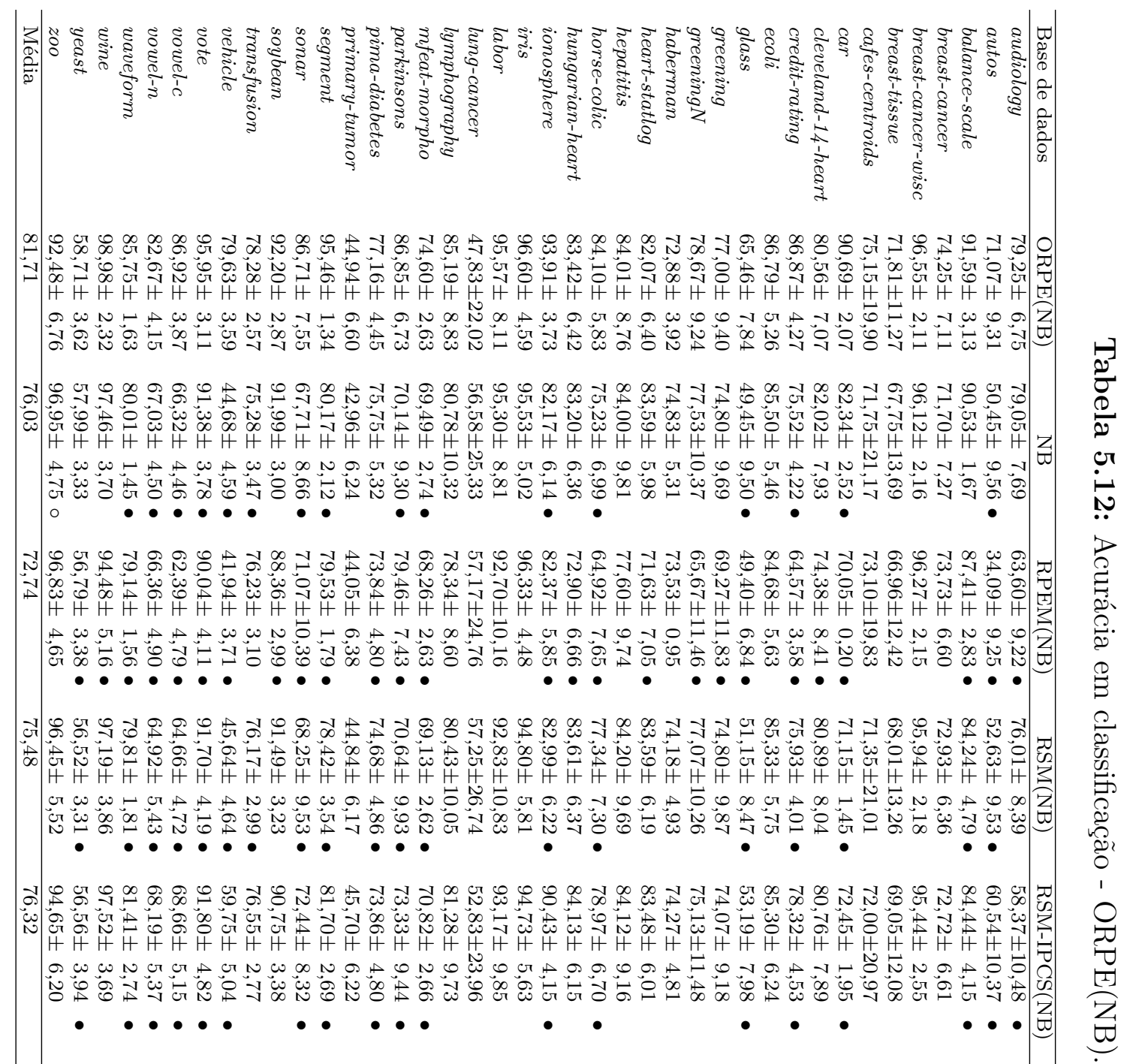

ᄀ

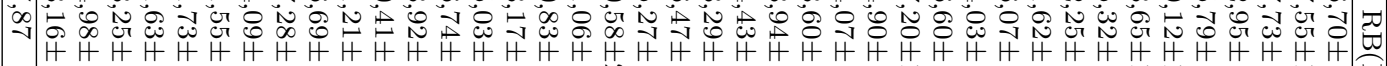

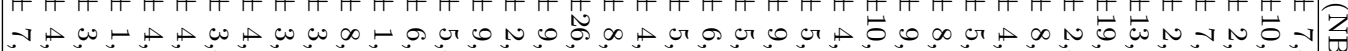

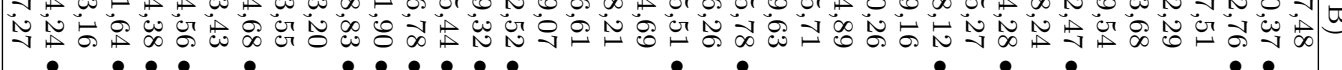

\& 官

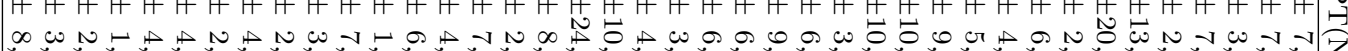

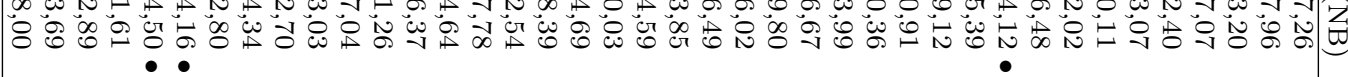


Tabela 5.13: Ranqueamento de dominância - ORPE(NB).

\begin{tabular}{cccc}
\hline SLT/EM & Ganha & Perde & Dominância \\
\hline ORPE(NB) & 101 & 1 & 100 \\
ORPT(NB) & 90 & 6 & 84 \\
RB(NB) & 49 & 40 & 9 \\
RSM-IPCS(NB) & 27 & 46 & -19 \\
NB & 26 & 60 & -34 \\
RSM(NB) & 14 & 56 & -42 \\
RPEM(NB) & 4 & 112 & -108 \\
\hline
\end{tabular}

de forma mais contínua, na estimativa da REQM durante o processo de otimização. Genericamente, um modelo ordinal tende a produzir uma ORP mais precisa e, provavelmente, mais adequada para posterior indução de um modelo de classificação.

\subsection{Considerações finais}

Os resultados obtidos com ORPT e ORPE com SLTs robustas ou não à rotação, estáveis e instáveis, em tarefas de classificação e regressão são bastante animadores. A técnica de extração de características baseada em ORP apresentou como tendência principal a redução da complexidade dos dados e da dimensionalidade do problema. Os resultados obtidos com ORPT apresentaram indícios de que modelos que produzem algum tipo de ordinalidade das instâncias na saída tendem a produzir transformações de roto-projeção um pouco mais precisas e que repercutem diretamente em desempenhos de generalização superiores até mesmo a outros EMs da literatura. Por outro lado, ORPT não mostrou desempenho satisfatório com J48. No entanto, a composição de um ensemble por meio de ORPE superou tal problema sendo irrestrita à característica de ordinalidade dos modelos ou mesmo à instabilidade da SLT. O método ORPE não foi superado, em termos de dominância, por nenhuma das SLTs e EMs considerados neste trabalho. ORPE se mostrou superior ou mesmo superior em ordens de grandeza ao método RB em diversos domínios, tarefas de modelagem e estabilidade da SLT escolhida. Finalmente, os resultados de ORPT e ORPE apresentados neste capítulo corroboram, respectivamente, a primeira e a segunda asserção desta tese. 


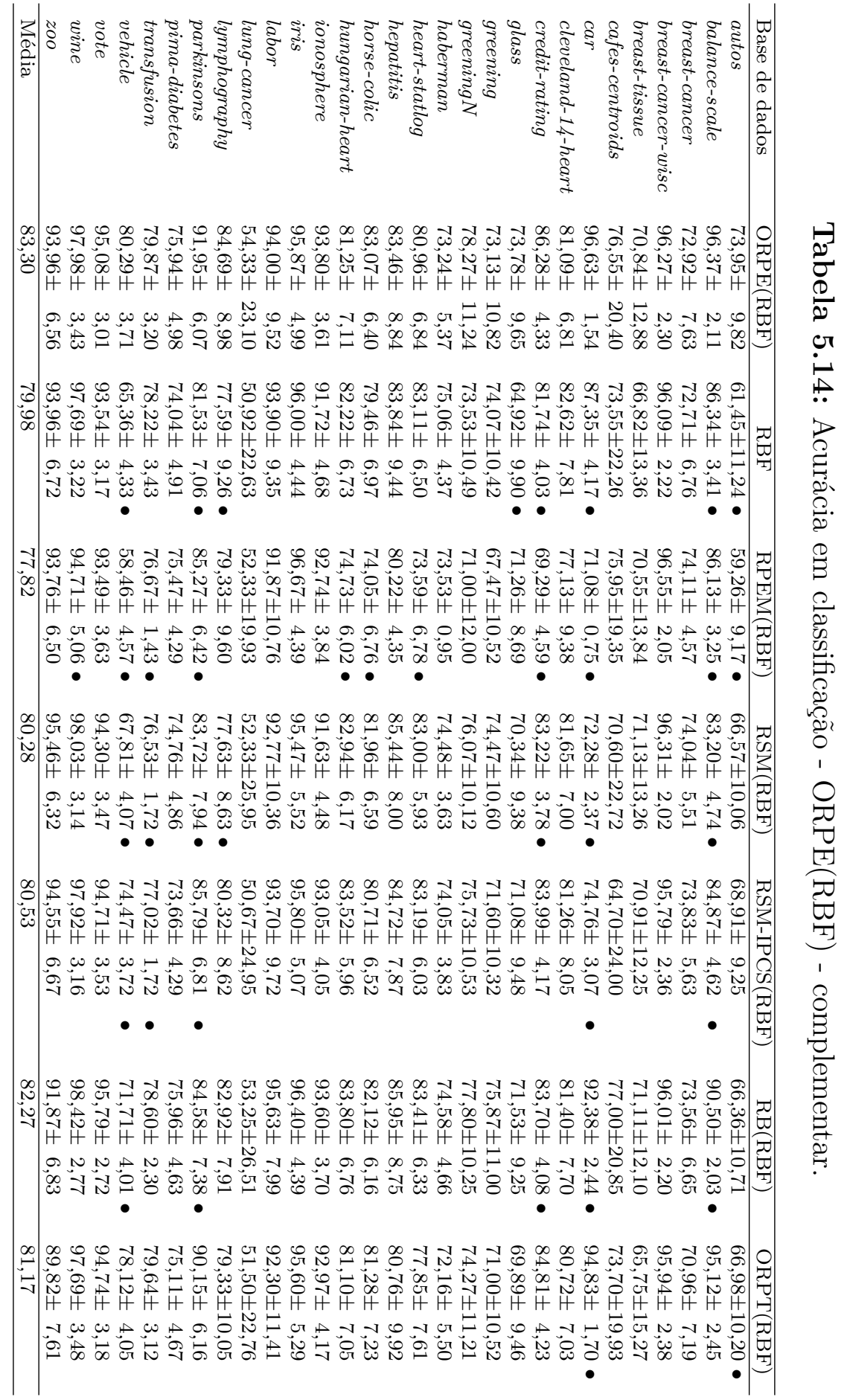


Tabela 5.15: Ranqueamento de dominância - ORPE(RBF) - complementar.

\begin{tabular}{cccc}
\hline SLT/EM & Ganha & Perde & Dominância \\
\hline ORPE(RBF) & 38 & 0 & 38 \\
ORPT(RBF) & 25 & 7 & 18 \\
RB(RBF) & 26 & 10 & 16 \\
RSM-IPCS(RBF) & 12 & 14 & -2 \\
RSM(RBF) & 11 & 18 & -7 \\
RBF & 9 & 22 & -13 \\
RPEM(RBF) & 0 & 50 & -50 \\
\hline
\end{tabular}



CAPÍTULO 6

\section{Conclusões e trabalhos futuros}

O desenvolvimento de novas técnicas de aprendizado supervisionado focadas no aumento do desempenho é uma constante na literatura de ML. Em particular, ensembles de modelos merecem destaque por sua capacidade teórica e empírica de redução do erro de generalização. A literatura de aprendizado de ensemble dispõe de um considerável número de métodos para a construção de ensembles acurados. Um dos métodos com desempenho consideravelmente superior a outros clássicos da literatura é o baseado em rotação ou método RB. Esse método pauta-se no princípio da rotação dos eixos por meio da técnica de extração de característica da PCA. Embora a estratégia de rotação seja um artifício interessante à construção de ensembles, o uso da PCA associada a outras heurísticas do método não fornecem garantias de que as direções obtidas contribuirão para a SLT escolhida para indução de cada MC. Além disso, o RB não é adequado para SLTs robustas à rotação das instâncias no espaço e não foi amplamente testado e validado com SLTs estáveis.

Nesta tese foi introduzida uma nova abordagem de extração de características supervisionada, baseada na otimização da transformação geométrica concatenada de rotação e projeção em subespaço, para aumento do desempenho da SLT escolhida. Essa transformação geométrica, denominada roto-projeção otimizada (ORP), associada a uma SLT (ORPT) foi analisada para corroborar a asserção embasadora desta tese. Posteriormente, a ORP foi integrada à proposta de um novo EM, denominado ORPE, para consolidar a segunda asserção apresentada no Capítulo 1.

A expectativa genérica sobre a ORP está em seu potencial de promover algum 
tipo de rearranjo das instâncias no espaço ou no subespaço por meio da otimização da direção de rotação e do subespaço de projeção em prol do desempenho da SLT utilizada posteriormente. Para isso, introduziu-se o conceito de técnica diretora do processo de otimização da roto-projeção, uma analogia à abordagem de seleção de atributos wrapper (KOHAVI; JOHN, 1997). Fundamentalmente, o propósito da técnica diretora é guiar o processo de otimização provendo uma estimativa da qualidade da roto-projeção para obtenção de uma transformação que simplifique os dados e possibilite a redução da complexidade e/ou o aumento do desempenho de generalização do modelo induzido posteriormente.

A metaheurística escolhida para otimização da roto-projeção foi o arrefecimento simulado (SA), com uma ligeira modificação do procedimento de geração das soluções candidatas vizinhas. Contudo, outras metaheurísticas podem ser utilizadas ou adaptadas para melhor desempenho ou eficiência na obtenção da transformação.

O método ORPE e seu componente base, ORPT, foram comparados com outras SLTs e EMs da literatura utilizando bases de domínio público e privado relativas a problemas de classificação e regressão utilizando SLTs instáveis e estáveis. Para regressão, foi utilizado o kNN e a RBF; e para a tarefa de classificação o J48 (implementação do C4.5) e o NB. Um experimento complementar também foi delineado para avaliar o desempenho utilizando a RBF para classificação.

Os resultados obtidos são animadores e superaram as expectativas tanto para ORPT como para ORPE. O método ORPT tendeu a reduzir a dimensionalidade e a complexidade do problema na maioria das bases. Além disso, observou-se uma redução significativa da complexidade das árvores de decisão para metade das bases de dados de classificação. Nos modelos que produzem algum tipo de ordinalidade na saída (NB e RBF) e nos problemas de regressão ORPT apresentou capacidade de generalização relativamente alta, assumindo a segunda posição no ranqueamento de dominância dentre todas as SLTs e EMs avaliados. ORPT não apresentou resultados satisfatórios somente para o J48, provavelmente pela falta de ordinalidade da saída produzida por árvores de decisão.

Resultados ainda mais entusiasmantes foram obtidos com ORPE. Nas análises comparativas realizadas utilizando todas as bases, SLTs e tarefas de predição, ORPE assumiu sempre a primeira posição no ranqueamento de dominância. O método ORPE não apresentou desempenho satisfatório em apenas 3 bases de dados: zoo superado pelo NB; e autos e soybean superado pelo RSM(J48). O método consolidador da segunda asserção desta tese foi superior ou muito superior em ordem de grandeza (segundo o critério de ranqueamento) ao método RB, até mesmo com as SLTs J48 e RBF. Deve-se observar que, com ambas as SLTs, o RB já havia sido validado na literatura com resultados positivos frente a outros EMs clássicos, como Bagging, Ada- 
Boost, Random Forest e RSM. Finalmente, ORPE superou os demais nas bases de regressão com uma dominância substancialmente maior, tanto com uma SLT estável e insensível à rotação $(\mathrm{kNN})$ como uma instável (RBF).

Os resultados obtidos mostram que a ORP na construção de ensembles é consistente e consideravelmente melhor do que uma abordagem que visa somente a diversificação das direções de rotação. A natureza dos dados, da otimização e da SLT escolhida contribuem para a diversidade no ensemble. A imprecisão da solução da roto-projeção decorrente de subótimos, da multimodalidade e/ou da presença de múltiplas e extensas regiões de platôs contribuem para a diversidade na construção de ensembles acurados. Esse aspecto foi corroborado pelos resultados do experimento de ORPE com J48. Embora ORPT não tenha apresentado resultados adequados, a composição de um ensemble por meio de ORPE superou tal dificuldade com êxito, sendo igual ou melhor que o método RB. Além disso, ORPE foi, em geral, significativamente superior a ORPT, mesmo nas SLTs estáveis e/ou com algum tipo de ordinalidade da saída.

O experimento com ORPT(J48) mostrou que a ORP reduziu significativamente o tamanho das árvores de decisão induzidas posteriormente em metade das bases de classificação do estudo. Esse é um indicativo relevante de que os ensembles construídos por ORPE tendem também a serem mais simples, ou seja, dotados de MCs de menores complexidades.

Em linhas gerais, pode-se concluir que o método ORPE apresenta-se como uma nova solução genérica, eficaz e menos restrita em relação à SLT, domínio do problema e tarefa de modelagem, visando a construção de ensembles de alto desempenho para classificação e regressão.

\subsection{Propostas de melhorias computacionais}

Em termos de desempenho computacional, a otimização da roto-projeção está em função da eficiência na construção da matriz de rotação, da transformação do conjunto de dados de treinamento e da demanda computacional para indução do modelo. Assim, como era esperado, o método ORPE não apresentou um desempenho computacional satisfatório na construção dos ensembles. Por isso, a paralelização do código de ORPE é uma ação necessária. Ressalta-se que a paralelização deve ser projetada e implementada para melhorar a eficiência de construção da matriz de rotação e de transformação dos dados.

A paralelização da construção dos MCs do ensemble é outro aspecto importante em um EM. O método ORPE permite a paralelização da construção de seus MCs. É 
provável que essa paralelização também reduza, consideravelmente, o impacto causado pelo tempo computacional demandado na construção do ensemble.

Um outro aspecto a ser investigado para melhoria do desempenho computacional diz respeito à metaheurística de arrefecimento simulado (SA). Esse algoritmo apresentou alto custo computacional na otimização da roto-projeção. A primeira proposta de melhoria é considerar um critério de parada adicional. Observou-se, em uma parcela considerável das bases, que uma solução adequada (ótima/subótima) é quase sempre encontrada muito antes do algoritmo finalizar sua execução. Logo, a idéia é monitorar a evolução da solução e interromper a otimização se não for observada melhoria por um número determinado de iterações. A segunda proposta de melhoria é avaliar e implementar outras metaheurísticas que realizam menor número de chamadas de avaliação da função-objetivo para obtenção de uma solução adequada.

É importante também o estudo do impacto da definição dos parâmetros da metaheurística do SA no desempenho do ensemble construído. Uma análise exploratória realizada utilizando $\operatorname{ORPE}(\mathrm{NB})$, ORPE $(\mathrm{J} 48)$ e $\mathrm{ORPE}(\mathrm{kNN})$, com as bases balancescale, glass, greeningN, labor, ecoli, wine, zoo, servo, fischcatch e snv-carb-areia, sugeriu que resultados satisfatórios podem ser obtidos com um número de iterações de equilíbrio $\left(G_{e}\right)$ consideravelmente menor do que aquele utilizado nos experimentos desta tese $\left(G_{e}=10+2 \log _{2} M+c+n\right)$. Por exemplo, com apenas 20 iterações de equilíbrio foram obtidos resultados muito similares aos apresentados nesta tese para as referidas bases (apenas com ORPE). Uma escolha mais ponderada desse parâmetro deve contribuir para o aumento da eficiência computacional.

É também foco de pesquisas futuras a implementação de uma metaheurística multiobjetivo para minimização simultânea do erro (REQM) e de uma medida de complexidade do modelo induzido pela técnica diretora. A dificuldade em definir parâmetros adequados em algumas SLTs, visando a redução da complexidade do modelo induzido pela técnica diretora, motiva uma otimização que considere esse aspecto de dualidade na indução do modelo.

\subsection{Outros aspectos para análises futuras}

Como fruto da parceria com a Embrapa e das discussões técnicas, emergiu a possibilidade de utilizar regressões lineares simples ou múltiplas para a solução de alguns problemas específicos, para os quais é esperado alguma linearidade do fenômeno. Esses experimentos estão sendo planejados em conjunto com a Embrapa e devem viabilizar publicações ou patentes de aplicações diretas.

É relevante também analisar e comparar o desempenho de ORPE com outros 
EMs utilizando outras SLTs estáveis disponíveis na literatura como, por exemplo, SVMs; outrossim avaliar o desempenho na construção de ensembles de tamanhos variados. Além disso, deve ser foco um estudo detalhado sobre o efeito da diversidade em ORPE.

Outro estudo a ser focado é a utilização de uma técnica diretora de outra natureza de concepção em prol da melhoria da transformação para uma SLT não-ordinal. Em especial, pretende-se utilizar o kNN como técnica diretora para uma transformação de ORP a ser utilizada em prol do C4.5 (J48). A expectativa é ampliar a margem de separação e minimizar o erro de generalização da árvore final induzida.

Finalmente, o fato das SLTs que produzem algum tipo de ordinalidade na saída terem apresentado melhores resultados com ORPT encoraja o uso de algumas estratégias de ranking para aumento da precisão da transformação de roto-projeção com C4.5 (J48). Nesse sentido, deve-se também analisar o desempenho utilizando outras medidas relacionadas à qualidade da roto-projeção como, por exemplo, a área da curva ROC ${ }^{1}$ (FAWCETT, 2006).

${ }^{1}$ Receiver Operating Characteristic. 



\section{Referências Bibliográficas}

ACHLIOPTAS, D. Database-friendly random projections: Johnson-lindenstrauss with binary coins. J. Comput. Syst. Sci., v. 66, n. 4, p. 671-687, 2003.

AGRESTI, A. An introduction to categorical data analysis. [S.l.]: Wiley-Blackwell, 2007.

AHA, D. W.; KIBLER, D. F.; ALBERT, M. K. Instance-based learning algorithms. Machine Learning, v. 6, p. 37-66, 1991.

ALPAYDIN, E. Introduction to Machine Learning. 2nd. ed. [S.1.]: The MIT Press, 2010. ISBN 026201243X, 9780262012430.

ANDERSSON, A.; DAVIDSSON, P.; LINDéN, J. Model selection using measure functions. In: Proc. of the ECML'98 Workshop on Upgrading Learning to the Meta-Level: Model Selection and Data Transformation. [S.l.: s.n.], 1998. p. 54-65.

ANGEL, E. Interactive Computer Graphics: A Top-Down Approach Using OpenGL. 5th. ed. USA: Addison-Wesley Publishing Company, 2008. ISBN 0321535863, 9780321535863 .

BACK, T.; SCHWEFEL, H.-P. An overview of evolutionary algorithms for parameter optimization. Evol. Comput., MIT Press, Cambridge, MA, USA, v. 1, p. 1-23, March 1993. ISSN 1063-6560. Disponível em: <http://dx.doi.org/10.1162/evco.1993.1.1.1>.

BAUER, E.; KOHAVI, R. An empirical comparison of voting classification algorithms: Bagging, boosting, and variants. Mach. Learn., Kluwer Academic Publishers, Hingham, MA, USA, v. 36, p. 105-139, July 1999. ISSN 0885-6125. Disponível em: <http://dl.acm.org/citation.cfm?id=599591.599607>. 
BERnARDINI, F. C.; MONARD, M. C.; PRATI, R. C. Constructing ensembles of symbolic classifiers. Int. J. Hybrid Intell. Syst., IOS Press, Amsterdam, The Netherlands, The Netherlands, v. 3, n. 3, p. 159-167, ago. 2006. ISSN 1448-5869. Disponível em: <http://dl.acm.org/citation.cfm?id=1366989.1366992>.

BLUM, A.; LANGLEY, P. Selection of relevant features and examples in machine learning. Artificial Intelligence, v. 97, n. 1-2, p. 245-271, 1997. Disponível em: $<$ citeseer.ist.psu.edu/blum97selection.html $>$.

BREIMAN, L. Bagging predictors. Mach. Learn., Kluwer Academic Publishers, Hingham, MA, USA, v. 24, p. 123-140, August 1996. ISSN 0885-6125. Disponível em: <http://dl.acm.org/citation.cfm?id=231986.231989>.

BREIMAN, L. Arcing Classifiers. The Annals of Statistics, Institute of Mathematical Statistics, v. 26, n. 3, p. 801-824, 1998. ISSN 00905364. Disponível em: <http://dx.doi.org/10.2307/120055>.

BREIMAN, L. Randomizing outputs to increase prediction accuracy. Machine Learning, v. 40, n. 3, p. 229-242, 2000.

BREIMAN, L. Random forests. Mach. Learn., Kluwer Academic Publishers, Hingham, MA, USA, v. 45, p. 5-32, October 2001. ISSN 0885-6125. Disponível em: $<$ http://dl.acm.org/citation.cfm?id=570181.570182>.

BROWN, G. et al. Diversity creation methods: A survey and categorisation. Journal of Information Fusion, v. 6, n. 1, p. 5-20, March 2005.

BUHMANN, M. D.; BUHMANN, M. D. Radial Basis Functions. New York, NY, USA: Cambridge University Press, 2003. ISBN 0521633389.

CARDINALI, M. C. do B. et al. Infrared spectroscopy: A potential tool in huanglongbing and citrus variegated chlorosis diagnosis. Talanta, v. 91, n. 0, p. 1 6, 2012. ISSN 0039-9140. Disponível em: <http://www.sciencedirect.com/science/article/pii/S0039914012000148>.

CASTRO, P. A. D. de; VON-ZUBEN, F. J. Learning ensembles of neural networks by means of a bayesian artificial immune system. IEEE Transactions on Neural Networks, v. 22, n. 2, p. 304-316, 2011.

CHERKASSKY, V.; MA, Y.; TANG, J. Model selection for k-nearest neighbors regression using vc bounds. In: Neural Networks, 2003. Proceedings of the International Joint Conference on. [S.l.: s.n.], 2003. v. 2, p. $1143-1148$ vol.2. ISSN 1098-7576.

CUNNINGHAM, P.; CARNEY, J. Diversity versus quality in classification ensembles based on feature selection. In: In 11th European Conference on Machine 
Learning. [S.1.]: Springer, 2000. p. 109-116.

DIAMANTARAS, K. I.; KUNG, S. Y. Principal component neural networks: theory and applications. New York, NY, USA: John Wiley \& Sons, Inc., 1996. ISBN 0-471-05436-4

DICKMAN, B. H.; GILMAN, M. J. Monte carlo optimization. Journal of Optimization Theory and Applications, Springer Netherlands, v. 60, p. 149-157, 1989. ISSN 0022-3239. Disponível em: <http://dx.doi.org/10.1007/BF00938806>.

DIETTERICH, T. G. Ensemble methods in machine learning. In: Proceedings of the First International Workshop on Multiple Classifier Systems. London, UK: Springer-Verlag, 2000. (MCS '00), p. 1-15. ISBN 3-540-67704-6. Disponível em: $<$ http://portal.acm.org/citation.cfm?id=648054.743935>.

DIETTERICH, T. G.; BAKIRI, G. Solving multiclass learning problems via error-correcting output codes. J. Artif. Int. Res., AI Access Foundation, , USA, v. 2, p. 263-286, January 1995. ISSN 1076-9757. Disponível em: <http://dl.acm.org/citation.cfm?id=1622826.1622834>.

DOMINGOS, P. The role of occam's razor in knowledge discovery. Data Min. Knowl. Discov., Kluwer Academic Publishers, Hingham, MA, USA, v. 3, p. 409-425, December 1999. ISSN 1384-5810. Disponível em: <http://dl.acm.org/citation.cfm?id=593425.593490>.

DOMINGOS, P.; PAZZANI, M. On the optimality of the simple bayesian classifier under zero-one loss. Machine Learning, Kluwer Academic Publishers, Hingham, MA, USA, v. 29, p. 103-130, November 1997. ISSN 0885-6125. Disponível em: $<$ http://dl.acm.org/citation.cfm?id=274158.274160>.

DOMINGOS, P.; PAZZANI, M. J. Beyond independence: Conditions for the optimality of the simple bayesian classifier. In: International Conference on Machine Learning. [s.n.], 1996. p. 105-112. Disponível em: <citeseer.ist.psu.edu/domingos96beyond.html>.

DORIGO, M.; BIRATTARI, M.; STüTZLE, T. Ant Colony Optimization: Artificial ants as a computational intelligence technique. IEEE Computational Intelligence Magazine, v. 1, n. 4, p. 28-39, 2006.

DOUGHERTY, J.; KOHAVI, R.; SAHAMI, M. Supervised and unsupervised discretization of continuous features. In: ICML-95. [S.l.: s.n.], 1995.

DUDA, R. O.; HART, P. E.; STORK, D. G. Pattern classification and scene analysis. [S.l.]: Wiley New York, 1973.

DUFFIN, K. L.; BARRETT, W. A. Spiders: a new user interface for rotation 
and visualization of $\mathrm{n}$-dimensional point sets. In: Proceedings of the conference on Visualization '94. Los Alamitos, CA, USA: IEEE Computer Society Press, 1994. (VIS '94), p. 205-211. ISBN 0-7803-2521-4. Disponível em: <http://dl.acm.org/citation.cfm?id=951087.951126>.

FAWCETT, T. An introduction to roc analysis. Pattern Recogn. Lett., Elsevier Science Inc., New York, NY, USA, v. 27, n. 8, p. 861-874, jun. 2006. ISSN 0167-8655. Disponível em: <http://dx.doi.org/10.1016/j.patrec.2005.10.010>.

FERREIRA, E. J. et al. Random subspaces of the instance and principal component spaces for ensembles. In: Proceedings of the 2009 international joint conference on Neural Networks. Piscataway, NJ, USA: IEEE Press, 2009. (IJCNN'09), p. 923-926. ISBN 978-1-4244-3549-4. Disponível em: < http://portal.acm.org/citation$. c f m ? \mathrm{id}=1704175.1704310>$.

FERREIRA, E. J. et al. Ensemble of predictors and laser induced breakdown spectroscopy for certifying coffee. Electronics Letters, IEE, v. 47, n. 17, p. 967-969, 2011. Disponível em: <http://link.aip.org/link/?ELL/47/967/1>.

FERREIRA, E. J. et al. Random subspace method for analysing coffee with electronic tongue. Electronics Letters, v. 43, n. 21, p. 1138 -1139, 11 2007. ISSN 0013-5194.

FOLEY, J. D. et al. Computer graphics: principles and practice (2nd ed.). Boston, MA, USA: Addison-Wesley Longman Publishing Co., Inc., 1990. ISBN 0-201-12110-7.

FRADKIN, D.; MADIGAN, D. Experiments with random projections for machine learning. In: KDD '03: Proceedings of the ninth ACM SIGKDD international conference on Knowledge discovery and data mining. [S.1.]: ACM Press, 2003. p. 517-522. ISBN 1-58113-737-0.

FRANK, A.; ASUNCION, A. UCI Machine Learning Repository. 2010. Disponível em: <http://archive.ics.uci.edu/ml>.

FREUND, Y.; SCHAPIRE, R. E. Experiments with a new boosting algorithm. p. 148-156, 1996. Disponível em: <citeseer.ist.psu.edu/article/freund96experiments.html>.

FUKUNAGA, K.; MANTOCK, J. M. Nonparametric discriminant analysis. IEEE Trans. Pattern Anal. Mach. Intell., IEEE Computer Society, Washington, DC, USA, v. 5, n. 6, p. 671-678, jun. 1983. ISSN 0162-8828. Disponível em: $<$ http://dl.acm.org/citation.cfm?id=2052536.2052590>.

GOLDBERG, D. E. Genetic Algorithms in Search, Optimization and Machine 
Learning. 1st. ed. Boston, MA, USA: Addison-Wesley Longman Publishing Co., Inc., 1989. ISBN 0201157675.

HALL, M. et al. The weka data mining software: an update. SIGKDD Explor. Newsl., ACM, New York, NY, USA, v. 11, p. 10-18, November 2009. ISSN 1931-0145. Disponível em: <http://doi.acm.org/10.1145/1656274.1656278>.

HANSEN, L. K.; SALAMON, P. Neural network ensembles. IEEE Trans. Pattern Anal. Mach. Intell., IEEE Computer Society, Washington, DC, USA, v. 12, p. 993-1001, October 1990. ISSN 0162-8828. Disponível em: <http://dl.acm.org/ citation.cfm?id=628297.628429>.

HAYKIN, S. Neural Networks: A Comprehensive Foundation. Upper Saddle River, NJ: Prentice Hall, 1999. 2nd edition.

HO, T. K. The random subspace method for constructing decision forests. IEEE Trans. Pattern Anal. Mach. Intell., IEEE Computer Society, Washington, DC, USA, v. 20, p. 832-844, August 1998. ISSN 0162-8828. Disponível em: $<$ http://portal.acm.org/citation.cfm?id=284980.284986>.

HO, T. K.; BASU, M. Complexity measures of supervised classification problems. IEEE Trans. Pattern Anal. Mach. Intell., IEEE Computer Society, Washington, DC, USA, v. 24, p. 289-300, March 2002. ISSN 0162-8828. Disponível em: <http://dx.doi.org/10.1109/34.990132>.

JOHNSON, W.; LINDENSTRAUSS, J. Extensions of Lipschitz mappings into a Hilbert space. In: Conference in modern analysis and probability (New Haven, Conn., 1982). [S.1.]: American Mathematical Society, 1984, (Contemporary Mathematics, v. 26). p. 189-206.

KENNEDY, J.; EBERHART, R. C. Swarm Intelligence. [S.1.]: Morgan Kaufmann Publishers, 2001.

KIRKPATRICK, S.; GELATT, C. D.; VECCHI, M. P. Optimization by simulated annealing. Science, v. 220, n. 4598, p. 671-680, 1983. Disponível em: <http://www.sciencemag.org/content/220/4598/671.abstract>.

KOHAVI, R.; JOHN, G. H. Wrappers for feature subset selection. Artif. Intell., Elsevier Science Publishers Ltd., Essex, UK, v. 97, p. 273-324, December 1997. ISSN 0004-3702. Disponível em: <http://dl.acm.org/citation.cfm?id=270613.270627>.

KOTSIANTIS, S.; PINTELAS, P. Local rotation forest of decision stumps for regression problems. In: Computer Science and Information Technology, 2009. ICCSIT 2009. 2nd IEEE International Conference on. [S.l.: s.n.], 2009. p. $170-174$. KROGH, A.; VEDELSBY, J. Neural network ensembles, cross validation, and active 
learning. In: Advances in Neural Information Processing Systems. [S.l.]: MIT Press, 1995. p. 231-238.

KUBISTA, M. et al. The real-time polymerase chain reaction. Molecular Aspects of Medicine, v. 27, p. 95 - 125, 2006. ISSN 0098-2997. Real-time Polymerase Chain Reaction. Disponível em: <http://www.sciencedirect.com/science/article/pii/S0098299705000907>.

KUNCHEVA, L. I.; RODRÍGUEZ, J. J. An experimental study on rotation forest ensembles. In: Proceedings of the 7th international conference on Multiple classifier systems. Berlin, Heidelberg: Springer-Verlag, 2007. (MCS'07), p. 459-468. ISBN 978-3-540-72481-0. Disponível em: <http://dl.acm.org/citation.cfm?id=1761171$.1761226>$.

KUNCHEVA, L. I.; WHITAKER, C. J. Measures of diversity in classifier ensembles and their relationship with the ensemble accuracy. Mach. Learn., Kluwer Academic Publishers, Hingham, MA, USA, v. 51, p. 181-207, May 2003. ISSN 0885-6125.

Disponível em: <http://dl.acm.org/citation.cfm?id=640211.640232>.

LEVINE, D. M. et al. Statistics for Managers Using Microsoft Excel (5th Edition). Upper Saddle River, NJ, USA: Prentice-Hall, Inc., 2007. ISBN 0132295458.

LI, L. Data complexity in machine learning and novel classification algorithms. Tese (Doutorado), Pasadena, CA, USA, 2006. AAI3235581.

LI, L.; ABU-MOSTAFA, Y. S. Data Complexity in Machine Learning. [S.l.], maio 2006. Disponível em: <http://resolver.caltech.edu/CaltechCSTR:2006.004>.

LI, M.; VITNYI, P. M. An Introduction to Kolmogorov Complexity and Its Applications. 3. ed. [S.1.]: Springer Publishing Company, Incorporated, 2008. ISBN $0387339981,9780387339986$.

MACQUEEN, J. B. Some methods for classification and analysis of multivariate observations. In: CAM, L. M. L.; NEYMAN, J. (Ed.). Proc. of the fifth Berkeley Symposium on Mathematical Statistics and Probability. [S.l.]: University of California Press, 1967. v. 1, p. 281-297.

MELVILLE, P.; MOONEY, R. J. Creating diversity in ensembles using artificial data. Journal of Information Fusion: Special Issue on Diversity in Multi Classifier Systems, v. 6, n. 1, p. 99-111, 2004. Disponível em: <http://www.cs.utexas.edu/users/ai-lab/pub-view.php?PubID=51454>.

MICHALSKI, R.; TECUCI, G. Machine learning: A multistrategy approach. Cambridge, MA: The MIT Press, 1994.

MIERSWA, I. et al. Yale: Rapid prototyping for complex data mining tasks. 
In: UNGAR, L. et al. (Ed.). KDD '06: Proceedings of the 12th ACM SIGKDD international conference on Knowledge discovery and data mining. New York, NY, USA: ACM, 2006. p. 935-940. ISBN 1-59593-339-5. Disponível em: $<$ http://rapid-i.com>.

MOLLINEDA, R. A.; SáNCHEZ, J. S.; SOTOCA, J. M. Data characterization for effective prototype selection. In: MARQUES, J. S.; BLANCA, N. P. de la; PINA, P. (Ed.). Pattern Recognition and Image Analysis, Second Iberian Conference, IbPRIA 2005, Estoril, Portugal, June 7-9, 2005, Proceedings, Part II. [S.1.]: Springer, 2005. (Lecture Notes in Computer Science, v. 3523), p. 27-34. ISBN 3-540-26154-0.

MYUNG, I. J. The importance of complexity in model selection. J. Math. Psychol., Academic Press, Inc., Orlando, FL, USA, v. 44, n. 1, p. 190-204, mar. 2000. ISSN 0022-2496. Disponível em: <http://dx.doi.org/10.1006/jmps.1999.1283>.

NADEAU, C.; BENGIO, Y. Inference for the generalization error. Machine Learning, Kluwer Academic Publishers, Hingham, MA, USA, v. 52, p. 239-281, September 2003. ISSN 0885-6125. Disponível em: <http://dl.acm.org/citation.cfm?id=779909$.779927>$.

NEVES, M. F. et al. O retrato da citricultura brasileira. Outubro 2010. Disponível em: <http://www.citrusbr.com.br/citrusbr/assuntos/biblio.asp>.

NOLL, A. M. A computer technique for displaying n-dimensional hyperobjects. Commun. ACM, ACM, New York, NY, USA, v. 10, p. 469-473, August 1967. ISSN 0001-0782. Disponível em: <http://doi.acm.org/10.1145/363534.363544>.

OLIVEIRA, L. S.; MORITA, M.; SABOURIN, R. Feature selection for ensembles applied to handwriting recognition. Int. J. Doc. Anal. Recognit., Springer-Verlag, Berlin, Heidelberg, v. 8, n. 4, p. 262-279, ago. 2006. ISSN 1433-2833. Disponível em: $<$ http://dx.doi.org/10.1007/s10032-005-0013-6>.

OPITZ, D.; MACLIN, R. Popular ensemble methods: An empirical study. Journal of Artificial Intelligence Research, v. 11, p. 169-198, 1999.

OPITZ, D. W. Feature selection for ensembles. In: Proceedings of the sixteenth national conference on Artificial intelligence and the eleventh Innovative applications of artificial intelligence conference innovative applications of artificial intelligence. Menlo Park, CA, USA: American Association for Artificial Intelligence, 1999. (AAAI '99/IAAI '99), p. 379-384. ISBN 0-262-51106-1. Disponível em: $<$ http://dl.acm.org/citation.cfm?id=315149.315328>.

PASTI, R. et al. Neural network ensembles: immune-inspired approaches to the diversity of components. Natural Computing, Springer Netherlands, v. 9, p. 625-653, 2010. ISSN 1567-7818. 10.1007/s11047-009-9124-1. Disponível em: 
<http://dx.doi.org/10.1007/s11047-009-9124-1>.

QUINLAN, J. R. Induction of decision trees. Mach. Learn., Kluwer Academic Publishers, Hingham, MA, USA, v. 1, p. 81-106, March 1986. ISSN 0885-6125.

Disponível em: <http://dl.acm.org/citation.cfm?id=637962.637969>.

QUINLAN, J. R. C4.5: programs for machine learning. San Francisco, CA, USA: Morgan Kaufmann Publishers Inc., 1993. ISBN 1-55860-238-0.

REZENDE, S. O. Sistemas Inteligentes: Fundamentos e Aplicações. [S.l.: s.n.], 2003.

RODRíGUEZ, J. J.; ALONSO, C. J. Rotation-based ensembles. In: In Current Topics in Artificial Intelligence: 10th Conference of the Spanish Association for Artificial Intelligence. [S.1.]: Springer, 2004. p. 498-506.

RODRÍGUEZ, J. J.; ALONSO, C. J.; PRIETO, O. J. Bias and variance of rotation-based ensembles. In: IWANN. [S.l.: s.n.], 2005. p. 779-786.

RODRIGUEZ, J. J.; KUNCHEVA, L. I.; ALONSO, C. J. Rotation forest: A new classifier ensemble method. IEEE Trans. Pattern Anal. Mach. Intell., IEEE Computer Society, Washington, DC, USA, v. 28, p. 1619-1630, October 2006. ISSN 0162-8828. Disponível em: <http://dx.doi.org/10.1109/TPAMI.2006.211>.

RODRÍGUEZ, J. J.; MAUDES, J.; ALONSO, C. J. Rotation-based ensembles of rbf networks. In: ESANN. [S.l.: s.n.], 2006. p. 605-610.

ROKACH, L. PATTERN CLASSIFICATION USING ENSEMBLE METHODS. [S.l.]: World Scientific Pub Co Inc, 2010. ISBN 9814271063.

RUMELHART, D. E.; HINTON, G. E.; WILLIAMS, R. J. Learning representations by back-propagating errors. In: . Cambridge, MA, USA: MIT Press, 1988. p. 696-699. ISBN 0-262-01097-6. Disponível em: <http://dl.acm.org/citation$. c f m ? \mathrm{id}=65669.104451>$.

SALGADO, R. M. et al. A hybrid ensemble model applied to the short-term load forecasting problem. In: IJCNN. [S.l.: s.n.], 2006. p. 2627-2634.

SÁNCHEZ, J. S.; SOTOCA, J. M.; MOLlinEDA, R. A. A review of data complexity measures and their applicability to pattern classification problems. In: III Taller Nacional de Minería de Datos y Aprendizaje (TAMIDA 05). Granada: [s.n.], 2005. p. 77-83.

SCHAPIRE, R. E. The strength of weak learnability. Mach. Learn., Kluwer Academic Publishers, Hingham, MA, USA, v. 5, p. 197-227, July 1990. ISSN 0885-6125. Disponível em: <http://dl.acm.org/citation.cfm?id=83637.83645>. SCHAPIRE, R. E.; FREUND, Y. Boosting the margin: a new explanation for the 
effectiveness of voting methods. The Annals of Statistics, v. 26, p. 322-330, 1998.

SCHCLAR, A.; ROKACH, L. Random Projection Ensemble Classifiers. In:

Enterprise Information Systems 11th International Conference Proceedings. [s.n.], 2009. (Lecture Notes in Business Information Processing), p. 309-316. Disponível em: <http://dx.doi.org/10.1007/978-3-642-01347-8\_26>.

SOHN, S. Y. Meta analysis of classification algorithms for pattern recognition. IEEE Trans. Pattern Anal. Mach. Intell., IEEE Computer Society, Washington, DC, USA, v. 21, p. 1137-1144, November 1999. ISSN 0162-8828. Disponível em: <http://dx.doi.org/10.1109/34.809107>.

STEUER, R. E. Multiple Criteria Optimization: Theory, Computation and Application. [S.l.]: John Wiley, New York, 546 pp, 1986.

SUROWIECKI, J. The Wisdom of Crowds. [S.l.]: Anchor, 2005. ISBN 0385721706.

TAN, P.-N.; STEINBACH, M.; KUMAR, V. Introduction to Data Mining, (First Edition). Boston, MA, USA: Addison-Wesley Longman Publishing Co., Inc., 2005. ISBN 0321321367.

TANG, E. K.; SUGANTHAN, P. N.; YAO, X. An analysis of diversity measures. Mach. Learn., Kluwer Academic Publishers, Hingham, MA, USA, v. 65, p. 247-271, October 2006. ISSN 0885-6125. Disponível em: <http://dl.acm.org/citation.cfm?id $=1164582.1164584>$.

TEIXEIRA, R. de A. et al. Improving generalization of mlps with multi-objective optimization. Neurocomputing, v. 35, n. 1-4, p. 189-194, 2000. Disponível em: $<$ http://dblp.uni-trier.de/db/journals/ijon/ijon35.html>.

TING, K. M.; ZHENG, Z. Improving the performance of boosting for naive bayesian classification. In: In Proc. 3rd Pacific-Asia Conf. on Knowledge Discovery and Data Mining. [S.l.: s.n.], 1999. p. 296-305.

TSYMBAL, A.; PECHENIZKIY, M.; CUNNINGHAM, P. Diversity in random subspacing ensembles. In: KAMBAYASHI, Y.; MOHANIA, M. K.; Wöß, W. (Ed.). DaWaK. [S.l.]: Springer, 2004. (Lecture Notes in Computer Science, v. 3181), p. 309-319. ISBN 3-540-22937-X.

TSYMBAL, A.; PECHENIZKIY, M.; CUNNINGHAM, P. Diversity in search strategies for ensemble feature selection. Information Fusion, v. 6, n. 1, p. 83 - 98, 2005. ISSN 1566-2535. <ce:title>Diversity in Multiple Classifier Systems</ce:title $>$. Disponível em: <http://www.sciencedirect.com/science/article/pii/S1566253504000363>.

TSYMBAL, A.; PUURONEN, S.; PATTERSON, D. W. Ensemble feature selection 
with the simple bayesian classification. Information Fusion, v. 4, n. 2, p. 87 - 100, 2003. ISSN 1566-2535. Disponível em: <http://www.sciencedirect.com/science/article/pii/S1566253503000046>.

VLACHOS, P. StatLib. 1999.

VOß, S. Meta-heuristics: The state of the art. In: Proceedings of the Workshop on Local Search for Planning and Scheduling-Revised Papers. London, UK: Springer-Verlag, 2001. (ECAI '00), p. 1-23. ISBN 3-540-42898-4. Disponível em: <http://dl.acm.org/citation.cfm?id=646143.681106>.

YANG, Y.; WEBB, G. I. Proportional k-interval discretization for naive-bayes classifiers. In: Proceedings of the 12th European Conference on Machine Learning. London, UK: Springer-Verlag, 2001. (EMCL '01), p. 564-575. ISBN 3-540-42536-5. Disponível em: <http://dl.acm.org/citation.cfm?id=645328.757479>.

ZAHALKA, J.; ZELEZNY, F. An experimental test of occam's razor in classification. Mach. Learn., Kluwer Academic Publishers, Hingham, MA, USA, v. 82, p. 475-481, March 2011. ISSN 0885-6125. Disponível em: <http://dx.doi.org/10.1007/s10994$010-5227-2>$.

ZENOBI, G. A detailed derivation of the relationship between generalization error and ambiguity in regression ensembles. [S.1.], 1999.

ZENOBI, G.; CUNNINGHAM, P. Using diversity in preparing ensembles of classifiers based on different feature subsets to minimize generalization error. In: Proceedings of the 12th European Conference on Machine Learning. London, UK: Springer-Verlag, 2001. (EMCL '01), p. 576-587. ISBN 3-540-42536-5. Disponível em: <http://dl.acm.org/citation.cfm?id=645328.756425>.

ZHANG, C.; ZHANG, J.; WANG, G. An empirical study of using Rotation Forest to improve regressors. Applied Mathematics and Computation, v. 195, n. 2, p. 618-629, fev. 2008. ISSN 00963003. Disponível em: <http://dx.doi.org/10.1016/j.amc.2007$.05 .010>$.

ZHANG, H.; SU, J. Naive bayesian classifiers for ranking. In: Proceedings of the 15th European Conference on Machine Learning (ECML2004. [S.1.]: Springer, 2004. 